SERVIÇO DE PÓS-GRADUAÇÃO DO ICMC.USP

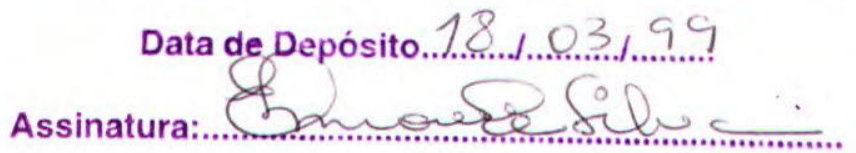

\title{
A Abordagem de Críticas \\ para a Construção de Sistemas \\ de Aprendizado da Escrita Técnica ${ }^{1}$
}

\author{
Maria Helena Barriviera e Silva
}

Orientação:

Prof ${ }^{\mathrm{a}}$. Dr ${ }^{\mathrm{a}}$. Sandra Maria Aluísio

Dissertação apresentada ao Instituto de Ciências Matemáticas e de Computação USP, como parte dos requisitos para a obtenção do título de Mestre em Ciências Área de Ciências de Computação e Matemática Computacional.

USP - São Carlos

Março de 1999

\footnotetext{
${ }^{1}$ Trabalho realizado com auxilio financeiro da CAPES
} 


\section{Dedicatória}

Aos meus pais, Silvério e Virginia, e ao meu esposo Jair. 


\section{Agradecimentos}

À Deus, por acompanhar-me em todos os momentos.

À Profa. Dra. Sandra Maria Aluísio, por sua compreensão e amizade, e pelo excelente trabalho de orientação.

À Prof. Dra. Solange Oliveira Rezende, por ter me recebido de modo acolhedor nesta universidade.

Ao Jorge, por muito contribuir na realização deste trabalho através de tantas sugestões importantes, e principalmente por sua amizade.

Ao Renato Barros e ao Luciano, pela amizade, companheirismo e espirito de equipe durante o desenvolvimento deste projeto.

À grande amiga Kalinka, por sua compreensão, carinho, sinceridade, e por tantas palavras de incentivo.

Aos amigos de curso, Renato Haber, Helder, Adriana, João Benedito e Fábio, pela verdadeira amizade.

Aos amigos Helder, Sérgio, Renata, Fernanda e Maria, pelos bons "papos" durante as incontáveis viagens.

À minha familia, pelo apoio, amor e compreensão pelo tempo que estive ausente, e em especial ao Jair, por estar comigo e participar de modo tão próximo desta etapa da minha vida.

À Patrícia Dátilo e Maurício Duarte, pelo incentivo e compreensão.

Às funcionárias da Pós-Graduação, Beth, Laura e Marilia, por serem sempre tão educadas e prestativas.

À CAPES pelo apoio financeiro.

Ȧqueles que, de um modo ou de outro, contribuiram para a realização deste trabalho. 


\section{Sumário}

INTRODUÇÄO...........................................................................................................................................................1

1.1 CONTEXTUALUZAÇÃO

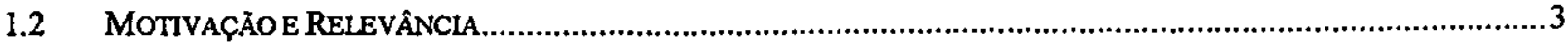

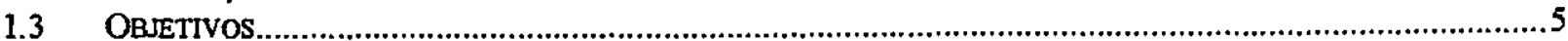

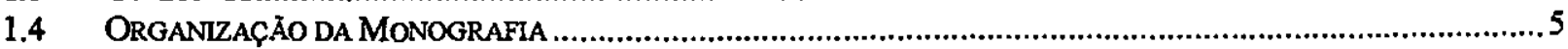

SISTEMAS TUTORES INTELIGENTES E AMBIENTES DE APRENDIZADO ........................................6

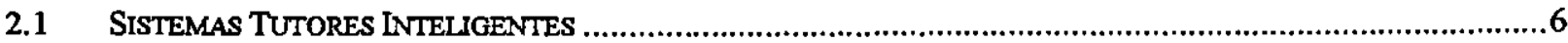

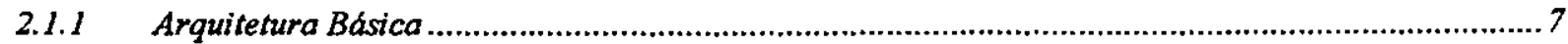

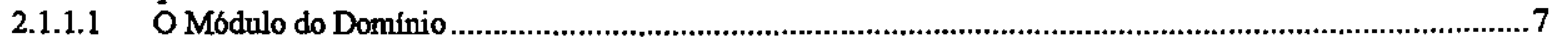

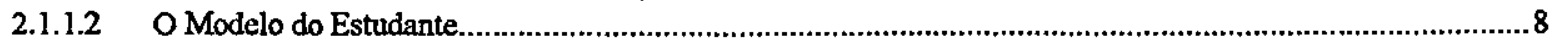

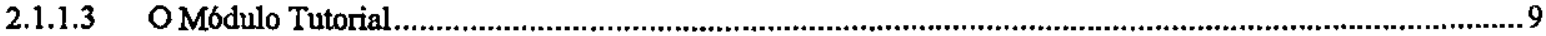

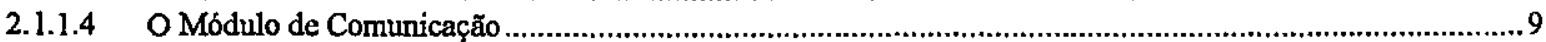

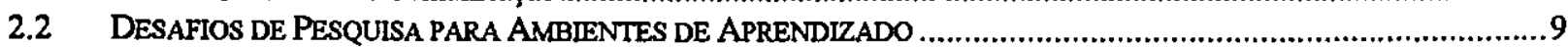

2.3 SISTEMAS TUTORES INTELIGENTES EM DOMINIOS NÃO PRESCRITIVOS .................................................. 11

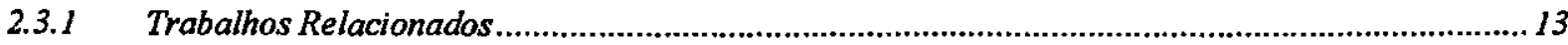

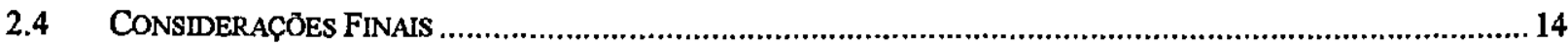

A ESCRTA TÉCNICA EM INGLÊS COMO LÍNGUA ESTRANGEIRA .................................................16

3.1 ALGUNS ERROS COMETIDOS POR ESTUDANTES BRASILEIROS NA ESCRITA EM INGLES................................17

3.2 AMBIENIES DE SOFTWARE E FERRAMENTAS PARA O AUXILIO E ENSINO Ȧ ESCRITA TECNICA …................... 18

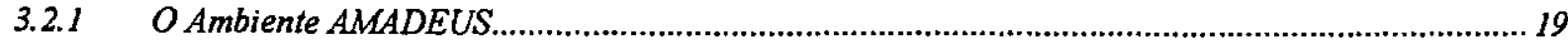

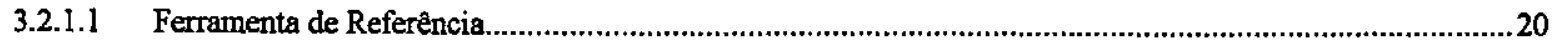

3.2.1.1.1 Arquitetura da Ferramenta de Referência.....................................................................................22

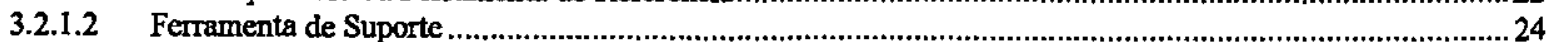

3.2.1.2.1 Arquitetura da Ferramenta de Suporte .....................................................................................24

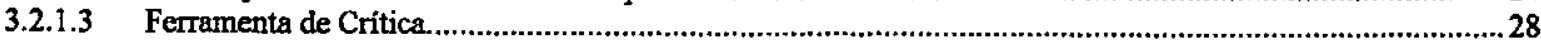

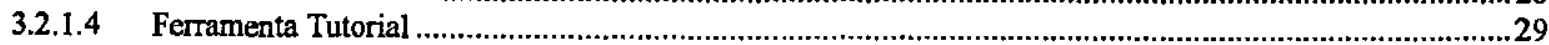

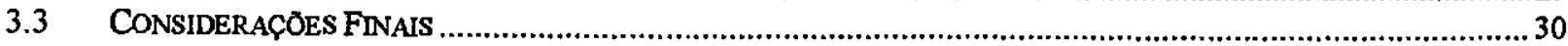

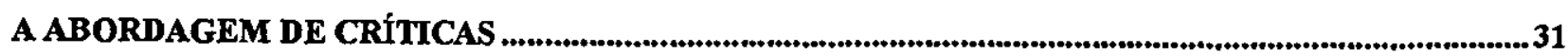

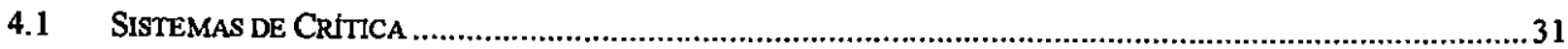

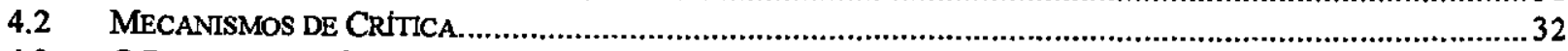

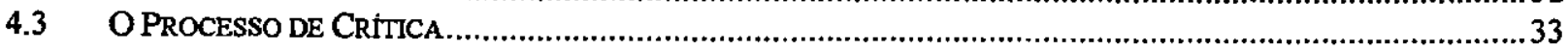

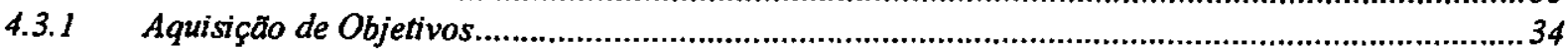

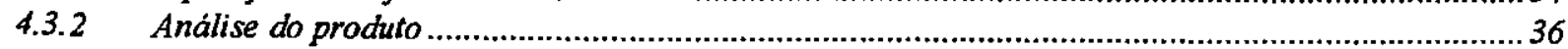

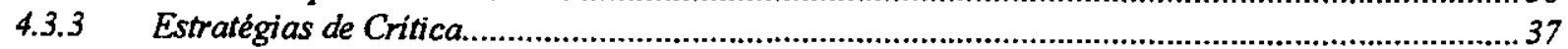

4.3.3.1 Como Intervir: as Várias Formas de Críticas..............................................................................................37

4.3.3.2 Quando Intervir: o Momento de Apresentação das Críticas ........................................................................40

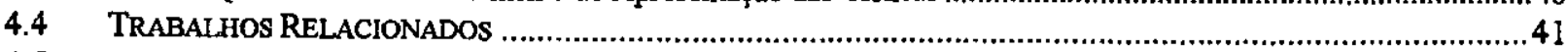

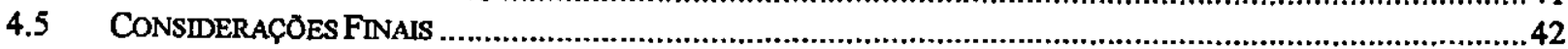

UMA FERRAMENTA DE CRÍTICA PARA A ESCRITA DE INTRODUÇÕES...........................................44

5.1 UMa Estrutura Dual para ANotar ARTigos Técnicos DE UMa COMUNIDADE DE PESQUISA............... 45

5.1.l Análise de Corpus: Introduçöes de Artigos Cientificos ................................................................. 45

5.1.2 Utilização de uma Estrutura Dual em Artigos da Colmunidade de Pesquisa CHI ................................ 47

5.2 UM MODELO COMPUTACIONAL PARA A CONSTRUÇÃo DE FERRAMENTAS DE CRITtiCA PARA A ESCRITA

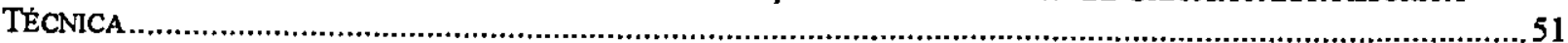

5.3 METODOLOGIA PARA A CONSTRUÇÃo DO CONHECIMENTO UTILIZADO NAS FERRAMENTAS DE CRÍTICA.......53

5.4 O PROTÓTTPO DE UMA FERRAMENTA DE CRITICA PARA A ESCRITA DE INTRODUÇŐES ..................................59

5.4.1 Plataforma Multiagente Distribuida Subjacente ao Protótipo........................................................60

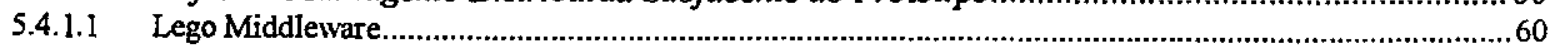




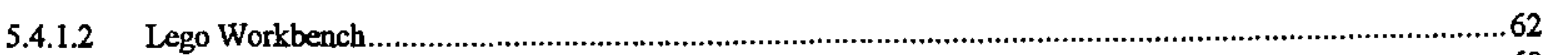

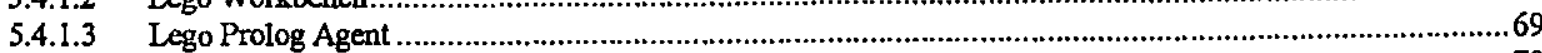

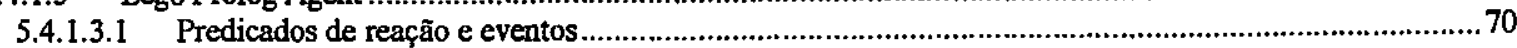

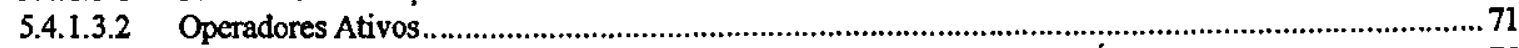

5.4.2 Uma Linguagem para Representação de Artigos como Estruturas em Árvore............................... 72

5.4.3 O Agente Gerador de Criticas: $O$ Critico ............................................................................75

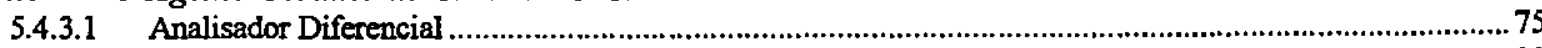

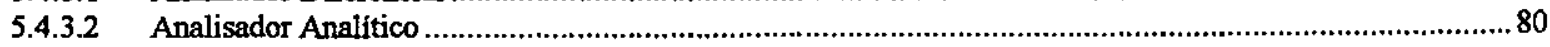

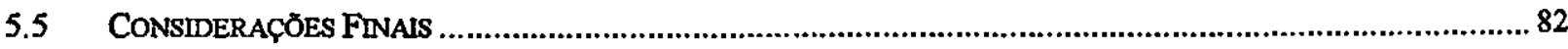

AVALIAÇÃO DO PROTÓTIPO DA FERRAMENTA DE CRITICA ...........................................................84

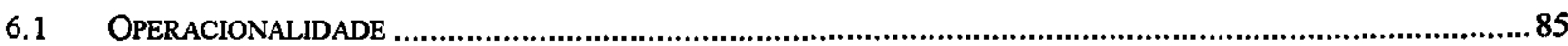

6.1.1 Interação Entre um Usuário Inexperiente e o Protótipo...............................................................85

6.1.2 Interaçâo Entre um Usuário de Nivel Intermediario e o Protótipo.................................................93

6.1.3 Interação Entre um Usuário com Ntvel de Conhecimento Avançado e o Prototipo ....................... 100

6.2 PRATICIDADE.............................................................................................................................101

6.2.1 Estendibitidade de Guidelines, Casos e Estruturas de Novas Seções ou de Novos Tipos de Arttgos 101

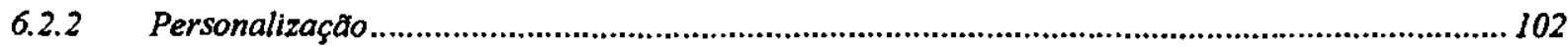

6.2.3 Portabitidade para uma Nova Comunidade de Pesquisa...........................................................103

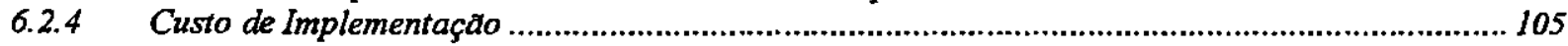

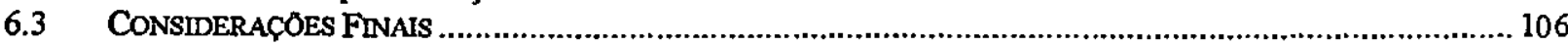

CONCLUSĀ

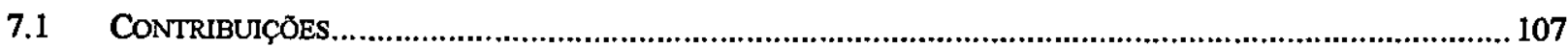

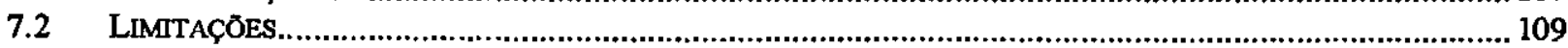

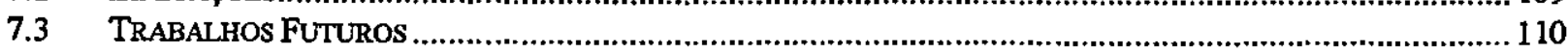

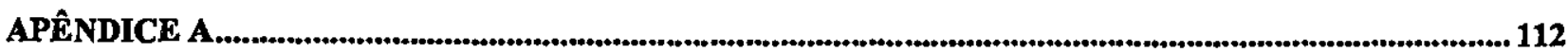

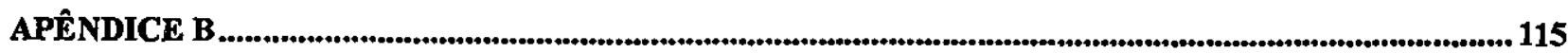

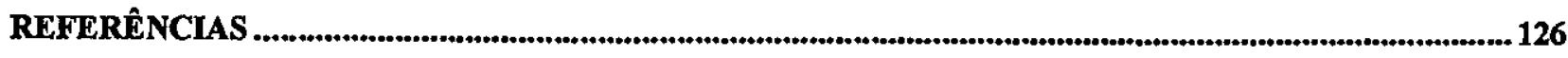




\section{Lista de Figuras}

FigURA 1.1: FERRAMENTAS do AMmIENTE AMADEUS ENFATIZANDO o ConHECIMENTO UTILIZADO .........................

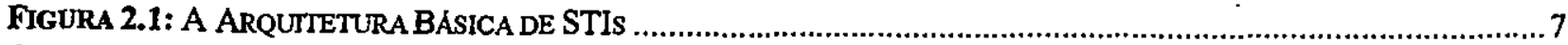

FIGURA 3.1: MÓDULO DE AUXtuo LINGỚSTIICO DO AMBENTE AMADEUS .....................................................20

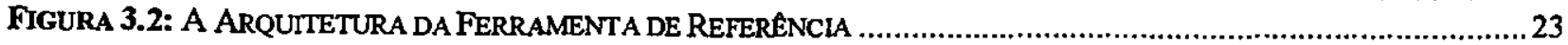

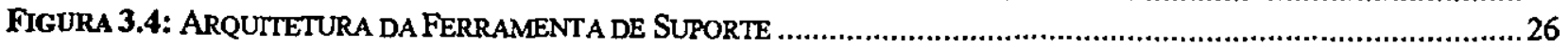

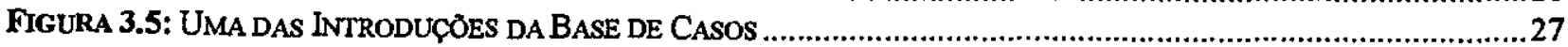

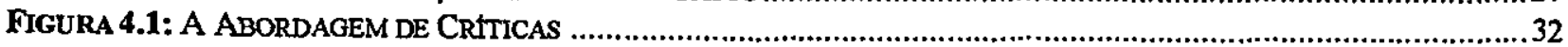

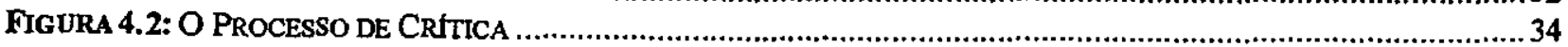

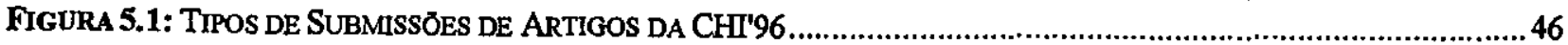

FigURA 5.2: A ESTRUTURA DUAL PARA UMA INTRODUÇȦo ClASSIFICADA COMO TIPO SYSTEM ..................................50

FIGURA 5.3: MODELO COMPUTACIONAL PARA FERRAMENTAS DE CRITICA PARA A ESCRITA TÉCNICA .........................51

Figura 5.4: UM CASO CODIFICADO NO PANORAMA PRO EM REL_AÇÃo Ȧ ESTRUTURA DE COMPONENTES ESQUEMÁTICOS

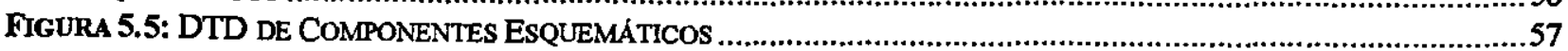

FiguRA 5.6: UM CASO CODIFICADO NO PANORAMA PRO EM RELAÇAO A ESTRUTURA DE COMPONENTES ESPECIFICOS

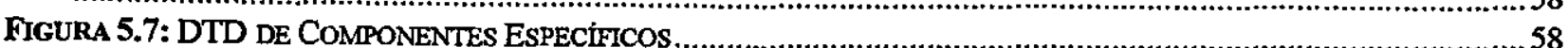

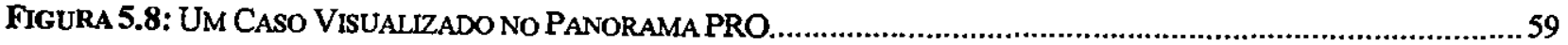

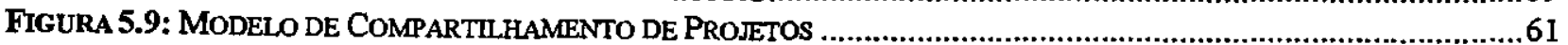

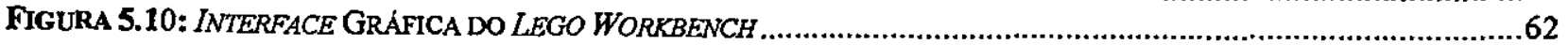

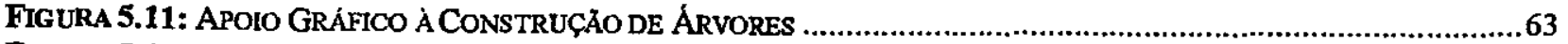

FIGURA 5.12: ALIVIANDO AMEMÓRIA COM A ADIÇAO DE UMA PALETTE...........................................................64

FIGURA 5.13: TRÊS MOMENTOS DA PALETTE DINÂMICA (SENSfVEL A CONTEXTO) EM AÇÃo ...................................65

FIGURA 5.14: SEQUÉNCIA DA SUBSTITUIÇĀO DE UM VOCẢBULO ABSTRATO QUANDO DE SUA FOCALIZAÇÃO (THEORYÉ

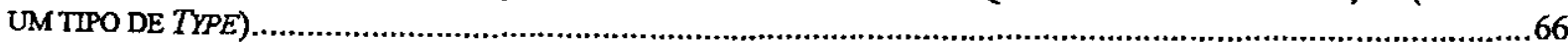

FIGURA 5.15: SEQŨENCIA DA SUBSTITUIÇÃo DE UM VOCÁBULO ABSTRATO QUANDO DE SUA INSERÇÃo .....................66

FIGURA 5.16: LEGO WORKBENCH: ĖNFASE EM ANOTAÇÕES DE REVISAOO ............................................................... 68

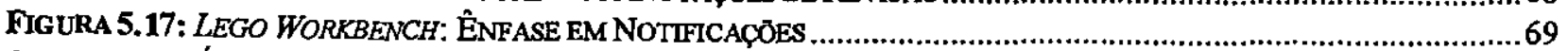

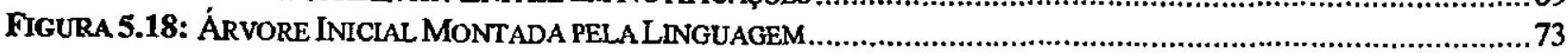

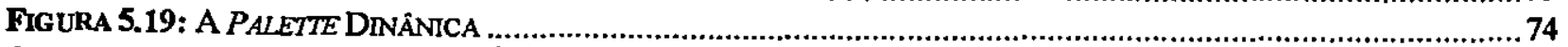

FIGURA 5.20: INSERÇÃO DE NÓS NA ÁRVORE EM APENAS UM NIVEL ...............................................................74

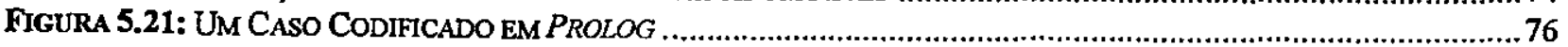

FIGURA 6.1: UMA ESTRUTURA INICIAL PROPOSTA POR UMUSUÁRIO INEXPERIENTE NO DOMÍNIO DA ESCRITA TÉCNICA

.86

FIGURA 6.2: VISUALIZAÇÃO DAS CRÍTICAS EMITIDAS PELO PROTÓTIPO AUM USUÁRIO INEXPERIENTE NO DOMINIO DA

ESCRTTA TÉCNCA.

FiguRa 6.3: NOVAS CRITICAS EMTTIDAS PELO PROTÓTIPO EM RESPOSTA A ALTERAÇÖES REALIZADAS POR UM

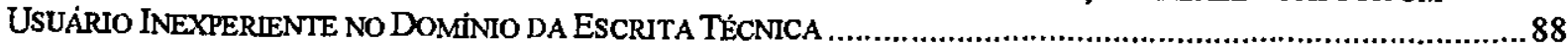

Figura 6.4: CRttiCA SOBRE RESUltados DA COMPARAÇAO DO CASO ESTRUTURADO COM OS CASOS DA BASE DE CASOS (USUARTO INEXPERIENTE NO DOMÍNIO DA ESCRITA TÉCNICA).

COMARACAO DO CASO EA)

Figura 6.5: CASO RECUPERADO PELO PANORAMA PRO MOSTRANDO A ESTRUTURA DE COMPONENTES ESQUEMÁTICOS (USUÁRIO INEXPERIENTE NO DOMÍNIO DA ESCRITA TÉCNICA)

FiguRA 6.6: MESMO CASO DA FIGURA 6.5, PORÉM MOSTRANDO A ESTRUTURA DE COMPONENTES ESPECfFICOS (USUÁRIO INEXPERIENTE NO DOMÍNIO DA ESCRITA TẺCNICA)

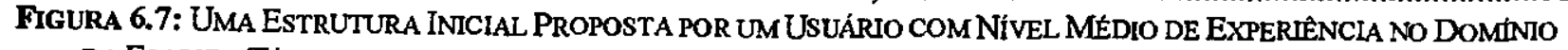
DA ESCRITA TÉCNICA

Figura 6.8: VISUALIZAÇÃo DAS CRTtICAS EMTTDAS PELO PROTÓTIPO AUM USUÁRIO COM NivEL MÉdIO DE EXPERIÊNCIA NO DOMINIO DA ESCRITA TÉCNICA

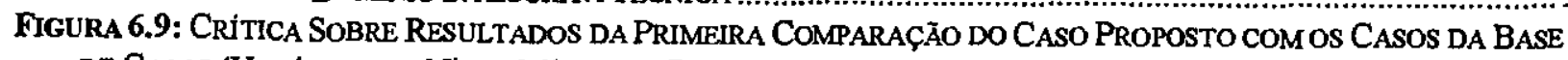
DE CASOS (USUÁRIO COM NIVEL MÉDIO DE CONHECIMENTO NO DOMÍNO DA ESCRITA TÉCNICA)

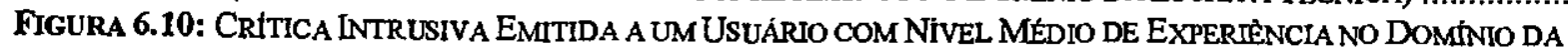


ESCRITA TÉCNICA EM RESPOSTA A UMA AÇÃo INCORRETA ...................................................................96

Figura 6.11: CRtTICA NA Forma dE INSTRUÇÃo EMTTIDA A UMUSUÁrio COM NIVEL MÉdIO de EXPERIÊNCIA No DOMINIO DA ESCRTA TÉCNICA.

FIGURA 6.12: NOVAS CRITICAS EMITIDAS PELO PROTÓTIPO A UM USUÁRIO COM NIVEL MÉDIO DE EXPERIÊNCIA NO DOMINIO DA ESCRTAA TÉCNICA.

Figura 6.13: CASOS RECUPERADOS PELO PANORAMA PRO EM RESPOSTA A UMA ESTRUTURA PROPOSTA POR UM USUÁRIO COM NAVEL MÉDIO DE EXPERIÊNCIA NO DOMINIO DA ESCRITA TÉCNICA.

Figura 6.14: AlTERAÇÃo da ORDEM DE COMPONENTES DA ESTRUTURA ESQUEMÁTICA REALIZADA POR UMUSUÁRTo COM NIVEL MÉDIO DE EXPERIÊNCIA NO DOMINIO DA ESCRTTA TÉCNICA

Figura 6.15: UMa ESTRUTURA INICLAL PROPOSTA POR UM USUÁrto EXPERIENTE NO DOMINIO DA ESCRITA TÉcNICA E AS CRITICAS EMITIDAS PELO PROTT́́TIPO. 100

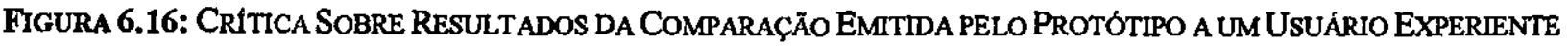
NO DOMÍNIO DAESCRTA TÉCNICA.

Figura B. 1: Visualização dos CoMponentes de CoMunicação do Protótipo da Ferramenta de Crítica e INICIO DO DESIGN.

FYGURA B. 2: DEFINIÇÃo PRECOCE DE UM TIPO DE ARTIGO

Figura B. 3: CRttica InTRusiva em Resposta a uma Decisão Precoce.

Figura B. 4: Mudança de Foco para CoMponentes Esquemáticos e IntCIO de Trabal ho com INSERÇÃode "INTRO".

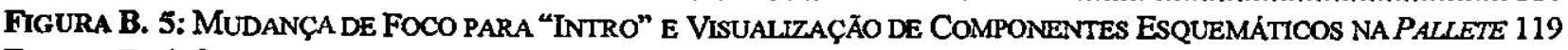

Figura B. 6: SEleçÃo do CoMponente Esquemático "STRUCTURE"

Figura B. 7: EscolHa do CoMponente "CONTENTS", VISUALIZAÇÃo de LISTA DE COMPONENTES ESQUEMÁticos E SELECÃO DO COMPONENTE "METHODOLOGY APPLIED".

Figura B. 8: MudanÇA DE Foco E VisualizAÇÃo de CRfTICAS................................................................. 120

Figura B. 9: PEdido ao ProtótIPo para QUe Recupere Casos Semellantes ao Esquematizado...................121

Figura B. 10: Resposta do Protóttipo aum Pedido de Recuperação de Casos SemelhaNtes ao ESQUEMATIZADO

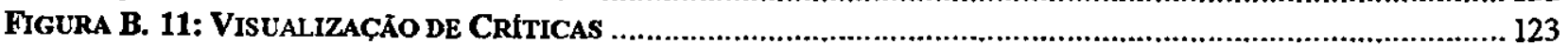

FigURA B. 12: ESTRUTURA DE UMA INTRODUÇÃo DE ARTIGO FINALIZADA ....................................................... 123

Figura B. 13: Crítica Que Indica os Casos da Base mais Semelhantes ao Caso Proposto.......................... 124

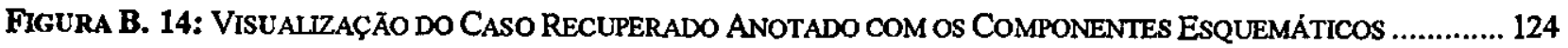

Figura B. 15: Visualização do Caso Recuperado Anotado com os Componentes Especificos................... 125 


\section{Lista de Tabelas}

TABELA 3.1: ERRos Típicos RELATADOS POR REVISORES DE SUBMISSÓES EM CONFERENCIAS CHI .29

TABRLA 5.1: COMPONENTES DA ESTRUTURA ESQUEMÁTICA DE ARTIGOS DA CHI'96.

TABELA 5.2: COMPONENTES DA ESTRUTURA DE CRTIÉRIOS ESPECIFICOS PARA SUBMISSÃo DE ARTIGOS DA CHI' 96.48

TABELA 5.3: PREDICADOS E EVENTOS DE LEGO PROLOG AGENT. 71

TABELA 6.1: CARACTERIZAÇÃo DAS CRITICAS EMITIDAS A UM USUÁRIO INEXPERIENTE NO DOMINIO DA ESCRITA TÉCNICA- COMPONENTE "INTRO"

TABELA 6.2: CARACTERIZAÇÃo DAS CRITICAS EMTTIDAS A UM USUÁRIO INEXPERIENTE NO DOMÍNIO DA ESCRTA TÉCNICA - COMPONENTES "DOMAN" E "LESSON(S) LEARNED"

TABELA 6.3: CARACTERIZAÇÃo DAS NOVAS CRITICAS EMITIDAS A UM USUÁRIO INEXPERIENTE NO DOMINIO DA ESCRITA TÉCNICA - COMPONENTE "INTRO"

TABEI 6.4: CARACTERIZAÇÃo DaS NOVAS CRÍTICAS EMITIDAS A UM USUÁRIO INEXPERIENTE NO DOMINIO DA ESCRITA TÉCNICA - COMPONENTES "PURPOSE", "RATIONALE" E "LESSON(S) LEARNED"

TABELA 6.5: CARACTERIZAÇÃo das CRITTICAS EMTTIDAS A UM USUÁRIO COM NIVEL MÉDIO DE EXPERIÊNCIA NO DOMINIO DA ESCRITA TÉCNICA - COMPONENTE "INTRO".

TABELA 6.6: CARACTERIZAÇÃo DAS CRITTICAS EMTTIDAS A UM USUÁRIO COM NIVEL MÉDIO DE EXPERIÉNCIA No DOMINIO DA ESCRITA TÉCNICA - COMPONENTES "DOMAIN", "INNOVATION(S)" E "PURPOSE",

TABEla 6.7: PasSOS REALIZADOS PARA A ANÁlISE E ANOTAÇÃo DO CORPUS .95 


\section{Lista de Abreviaturas}

AMADEUS AMiable Article DEvelopment for User Support

$\mathrm{CHI}$

DTD

Conference on Human Factors in Computing Systems

HTML

IRC

Document Type Definition

HyperText Markup Language

IUC

Internet Relay Chat

$\mathrm{RBC}$

Interação Usuário-Computador

SGML

STIs Raciocínio Baseado em Casos

WWW

Standard Generalized Markup Language

Sistemas Tutores Inteligentes

World Wide Web 


\section{Resumo}

Problemas com a escrita podem afetar o desempenho de profissionais de maneira marcante, principalmente no caso de pesquisadores e acadêmicos que precisam escrever com proficiência e desembaraço não apenas na língua materna, mas também em uma ou mais línguas estrangeiras. Atualmente, o inglês é a língua dominante para a escrita e divulgação de pesquisas técnicas e científicas. Para amenizar os problemas desses usuários da língua inglesa, que sofrem interferência da língua materna quando escrevem em inglês ou se sentem incapazes de gerar construções e composições lingüisticas de tal idioma, foi desenvolvido o ambiente modular de auxílio e ensino da escrita técnica, chamado AMADEUS (AMiable Article DEvelopment for User Support). A estrutura do AMADEUS consiste em várias ferramentas inter-relacionadas ferramenta de referência, ferramenta de suporte, ferramenta de critica e ferramenta tutorial. A ferramenta de crítica, objeto de estudo deste trabalho, fornece conhecimento estrutural em um nível textual maior que um parágrafo, ou seja, visa indicar o conjunto mais apropriado de componentes das estruturas esquemática e de componentes específicos de cada uma das várias seções de um artigo. Essa ferramenta proporciona o desenvolvimento da criatividade no processo de escrita de um texto, assim como a escrita de textos apropriados a um propósito e audiência específicos (por exemplo, para a comunidade de Inteligência Artificial). Este trabalho explora a abordagem de críticas para ensinar a escrita técnica utilizada por uma comunidade de pesquisa específica, a CHI (Conference on Human Factors in Computing Systems). Apresentamos tanto um modelo para a construção de ferramentas de crítica para a escrita técnica, quanto um modelo de documentos (artigos técnicos) que deixa explícito os objetivos e convenções da comunidade escolhida e usamos essa teoria explícita para ensinar a escrita de novos artigos neste domínio. Baseado neste modelo de ferramenta foi construído um protótipo de uma ferramenta de crítica para a comunidade $\mathrm{CHI}$, utilizando um corpus de artigos da CHI'96. Finalmente, o protótipo foi avaliado de acordo com os critérios de operacionalidade e praticidade. A questão da operacionalidade foi avaliada através da análise da interação de usuários com diferentes graus de competência da escrita técnica em inglês. Para a questão da praticidade, a estendibilidade, portabilidade, personalização, e custo de implementação foram estudados. 


\section{Abstract}

Writing scientific papers in English, the lingua franca of Science, is often a severe limitation for the career of many a non-native English user. In addition to difficulties in choosing appropriate sentences and collocations which appear with high frequency in scientific texts, non-natives also face problems related to interference from their mother tongue ( $\mathrm{Ll}$ interference). In order to overcome some of these difficulties, we developed a learning environment for scientific writing named AMADEUS (Amiable Article DEvelopment for User Support). AMADEUS targets the understanding of the diverse processes involved in the creation of successful scientific papers. Its overall architecture embodies both advising and tutoring tools, which are called Reference, Support, Critic and Tutoring tools. The Critic Tool helps less-experienced writers to create sections of papers. The tool offers hints (or critiques) as to how better structure the section rather than offer a rigid frame of schematic and specific components for each section. It helps the writing of papers suitable for a purpose and specific audience (for example, the Artificial Intelligence community). The aim of this research is to explore the critiquing approach to teach the scientific writing used by a specific community. We present both, a model for the development of critiquing tools dedicated to the scientific writing and a model of documents which makes explicit the goals and idiosyncrasies of the target community. A prototype system has been implemented and evaluated for the CHI community (Conference on Human Factors in Computing Systems). A critical analysis of the system's architecture and function focusses on two questions: does it work? and is it practical? To anwer the workability question, samples of the system's interaction with users with different writing backgrounds are analyzed. To answer the practicality question, the extendibility, tailorability, portability, and cost-effectiveness of the system is studied. 
1. Introdução

\subsection{Contextualização}

7 roblemas com a escrita podem afetar o desempenho de profissionais de maneira marcante, principalmente no caso de pesquisadores e acadêmicos que precisam escrever com proficiência e desembaraço não apenas na língua materna, mas também em uma ou mais línguas estrangeiras. Atualmente, o inglês é a língua dominante para a escrita e divulgação de pesquisas técnicas e científicas. Para amenizar os problemas de usuários da língua inglesa que sofrem interferência da língua materna quando escrevem em inglês, e que se sentem incapazes de gerar construções e composições lingüísticas de tal idioma, foi desenvolvido o ambiente modular de auxilio e ensino da escrita técnica, chamado AMADEUS (AMiable Article 
DEvelopment for User Support) (Fontana, 1993; Aluísio, 1995; Aluísio \& Oliveira Jr., 1995a, 1995b).

A estrutura do AMADEUS consiste em várias ferramentas inter-relacionadas ferramenta de referência, ferramenta de suporte, ferramenta de crítica e ferramenta tutorial. Essas ferramentas apresentam tipos diferentes de interação usuário-sistema, abordagens distintas e diferentes tipos de conhecimento a respeito (1) da estrutura (expressões e orações, parágrafos e seções), (2) do propósito e (3) do tipo de audiência dos diversos tipos de artigos (empirical, system, opinion, experience, theory, methodology, review etc). Cada uma dessas ferramentas é direcionada a um conjunto de problemas específicos caracterizados pelos niveis diferentes de facilidade de escrita na segunda língua e pela experiência de escrita técnica de cada usuário.

No modelo do ambiente AMADEUS, a primeira das ferramentas concebidas foi a ferramenta de referência, que se caracteriza por conter o conhecimento enciclopédico do sistema, isto é, o conhecimento das expressões padrões que são utilizadas para descrever tabelas, figuras e procedimentos experimentais, comparar resultados, ou fornecer suporte para argumentaçoes, por exemplo. A segunda das ferramentas desenvolvidas foi a ferramenta de suporte, que contém o conhecimento de estratégias retóricas necessárias para montar um parágrafo. Essas estratégias asseguram coesão e coerência em pequenos trechos textuais. A ferramenta de crítica, por sua vez, provê conhecimento estrutural em um nível textual maior que um parágrafo, isto é, visa indicar os componentes e as seqüências mais apropriadas dos componentes para cada uma das várias seções de um artigo. Neste trabalho, a seção escolhida foi a Introdução. Essa ferramenta permite o desenvolvimento da criatividade no processo de escrita de um texto, assim como a escrita de textos apropriados a um propósito e audiência específicos (por exemplo, para uma comunidade de pesquisa específica dentro da Computação). Finalmente, a ferramenta tutorial familiariza o usuário com o vocabulário das três ferramentas até então descritas. Uma caracterização dessas ferramentas quanto ao conhecimento utilizado é mostrada na Figura 1.1. 


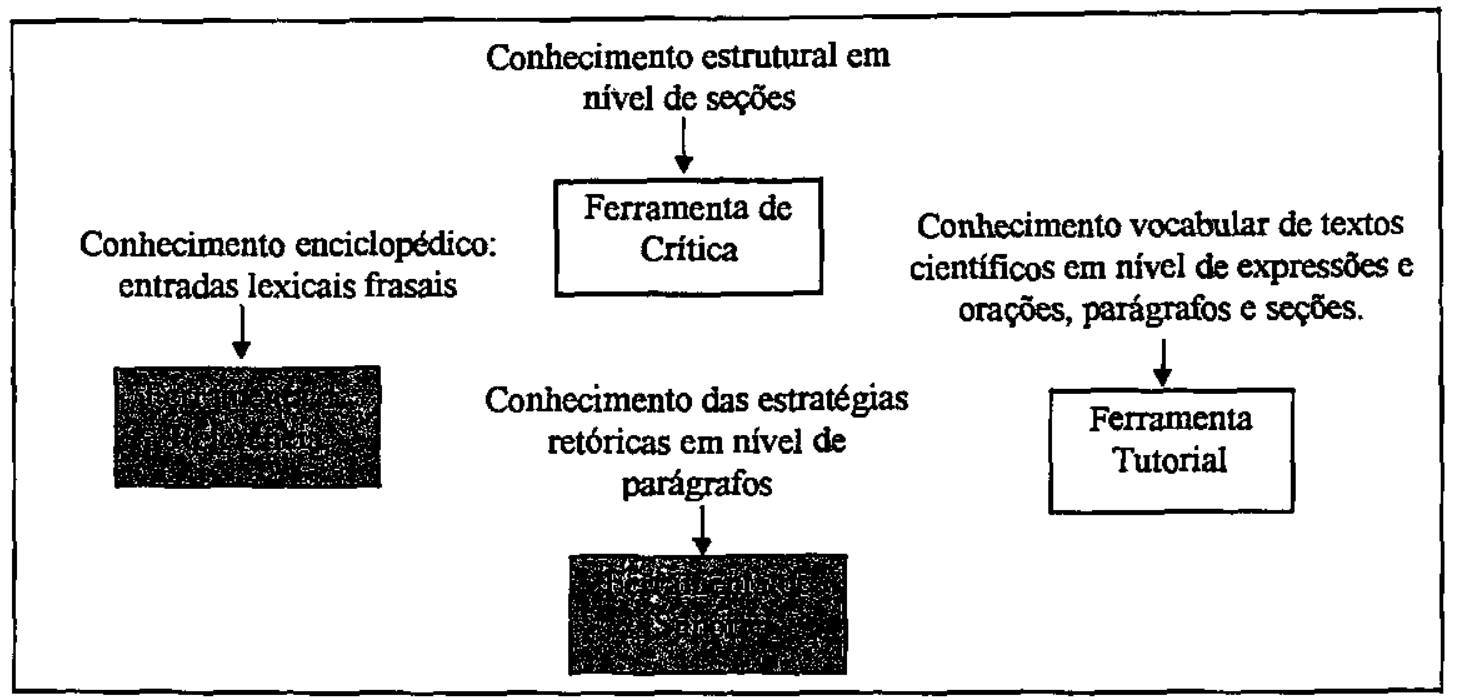

Figura 1.1: Ferramentas do Ambiente AMADEUS Enfatizando o Conhecimento Utilizado

A figura acima fornece o contexto em que está inserido este trabalho de mestrado. As duas ferramentas hachuradas (ferramenta de referência e de suporte) já foram desenvolvidas para auxiliar a escrita de artigos curtos em inglês, para o domínio de Física Experimental, e para auxiliar a escrita de Introduções para o mesmo dominio, respectivamente.

$\mathrm{Na}$ próxima subseção, apresentamos a motivação e a relevância da escolha da abordagem de críticas para a construção de sistemas que ensinam a escrita de uma seção dos vários tipos de artigos técnicos (empirical, experience, system, theory, methodology e opinion papers) aceitos nas conferências $\mathrm{CHI}$.

\subsection{Motivação e Relevância}

Ambientes clássicos de software com fim pedagógico seguem o paradigma dos Sistemas Tutores Inteligentes (STIs), nos quais o sistema dirige a interação com o usuário. Nesses sistemas tutores clássicos assume-se que o sistema sabe como resolver o problema melhor do que o usuário; o sistema permite que o usuário prossiga sozinho enquanto estiver desempenhando bem as suas funções, mas interrompe-o quando tem uma resposta melhor. Os domínios tratados são bem definidos (ou prescritivos), e geralmente possuem respostas corretas únicas.

Recentemente, surgiu uma abordagem baseada no aprendizado colaborativo para o desenvolvimento de ambientes computacionais que evitam o modelo tutor/aprendiz (Blandford, 1994; Fischer, 1995; Renié \& Chanier, 1995). Colaboração é um processo em que dois ou mais 
agentes trabalham juntos para resolver metas comuns. A colaboração se caracteriza como uma atividade síncrona e coordenada, resultado da tentativa constante de se construir e manter uma concepção compartilhada do problema (Blandford, 1994; Burton \& Treasure-Jones, 1997). Através desta definição, podemos diferenciar trabalho colaborativo de trabalho cooperativo, pois cooperação utiliza a divisão de trabalho entre os participantes com cada um sendo responsável por uma parte, não necessariamente mantendo o engajamento mútuo, como é o caso do trabalho colaborativo.

A colaboração (i) permite que o aprendiz seja um agente (ou ator) no ambiente; (ii) permite que o aprendiz tenha acesso ao conhecimento do sistema quando ele realmente desejar; e (iii) encoraja a interação, o que, consequentemente, incrementa o aprendizado.

Os domínios tratados por sistemas de aprendizado colaborativos são aqueles onde existem várias respostas aceitáveis. $\mathrm{O}$ domínio da escrita é propício para a implementação das abordagens colaborativas, pois o conhecimento envolvido nem sempre pode ser prescrito.

De acordo com Silverman (1992), Rankin (1993) e Fischer (1995) um sistema de crítica apresenta uma opinião/crítica, não necessariamente negativa, de um produto ou ação gerada por um agente humano/colaborador ${ }^{2}$. A abordagem de críticas constitui no uso efetivo de bases de conhecimento que auxiliam tanto na resolução de problemas como em atividades de aprendizado (Fischer et al., 1991, 1993; Fischer, 1995). Em sistemas de crítica, o usuário e o sistema trabalham colaborativamente, compartilhando do processo de solução de problemas, tomando decisões baseadas nos objetivos e conhecimentos do usuário e no domínio da tarefa em questão. Além disso, o sistema examina a solução proposta pelo usuário e fornece um retorno específico tanto para uma ação que ele executou de modo errôneo ou não adequado (Silverman, 1992) quanto para uma que foi executada corretamente.

A abordagem de críticas favorece o aprendizado, pois consegue capturar um momento de falha ou sucesso no conhecimento do usuário. Este momento é propício para o ensino se, além da crítica, for fornecida uma explicação ou justificativa para ela. Neste ponto, a abordagem de críticas proposta difere do modelo clássico de sistemas que utilizam críticas sem apresentar justificativas como o de Miller (1983a) e o de Rennels et al. (1987).

\footnotetext{
${ }^{2}$ Neste trabalho, os termos agente humano, colaborador e usuário são utilizados indistintamente e possuem o mesmo significado.
} 


\subsection{Objetivos}

Das quatro ferramentas do ambiente AMADEUS, citadas na Figura 1.1, as de referência e de suporte são dedicadas ao auxilio da escrita e foram implementadas para o domínio da Física Experimental, como citado na Seção 1.1. O objetivo do projeto de mestrado em questão é fornecer uma visão geral da abordagem de críticas, enfatizando a sua utilização em sistemas de aprendizado da escrita técnica em inglês. Particularmente, este trabalho propõe uma estrutura dual de artigos técnicos de uma comunidade de pesquisa, a CHI, e também um modelo para a construção de ferramentas de crítica para a escrita técnica. A principal atividade planejada é a construção de um protótipo de uma ferramenta de crítica, para a comunidade $\mathrm{CHI}$, seguindo este modelo, e a sua avaliação.

\subsection{Organização da Monografia}

No Capítulo 2, apresentamos a evolução dos STIs e exemplos de alguns ambientes de aprendizado. A abordagem a STIs tornou-se necessária pelo fato de entendermos que os sistemas de crítica são uma evolução dos STIs. No Capítulo 3, abordamos o domínio escolhido, ou seja, a escrita técnica em inglês como língua estrangeira e apresentamos detalhes do ambiente AMADEUS. No Capítulo 4, introduzimos conceitos da abordagem de críticas. O Capítulo 5 é direcionado à descrição do protótipo da ferramenta de crítica e a metodologia utilizada para a construção do conhecimento utilizado pela ferramenta. No Capitulo 6, apresentamos uma análise crítica da arquitetura e funcionamento do protótipo no que se refere a duas questões: operacionalidade e praticidade e, finalmente, no Capítulo 7 apresentamos as conclusões deste trabalho e considerações sobre os trabalhos futuros. 


\section{Sistemas Tutores Inteligentes e Ambientes de Aprendizado}

\subsection{Sistemas Tutores Inteligentes}

istemas Tutores Inteligentes são sistemas educacionais computadorizados que tentam simular a capacidade de ensino de tutores humanos (professores) (Turine, 1994). A arquitetura de STIs pode variar de aplicação para aplicação e não precisa, necessariamente, apresentar os mesmos módulos ou a mesma quantidade de módulos. Existe, entretanto, um certo consenso quanto à sua estrutura básica, como apresentado na próxima subseção. 


\subsubsection{Arquitetura Básica}

Existem quatro elementos que são considerados básicos e mínimos para a caracterização de um STI: (1) Módulo do Domínio, (2) Modelo do Estudante, (3) Módulo Tutorial e (4) Módulo de Comunicação (Rypa \& Feuerman, 1995). A inter-relação entre os módulos é mostrada na Figura 2.1 (Turine, 1994).

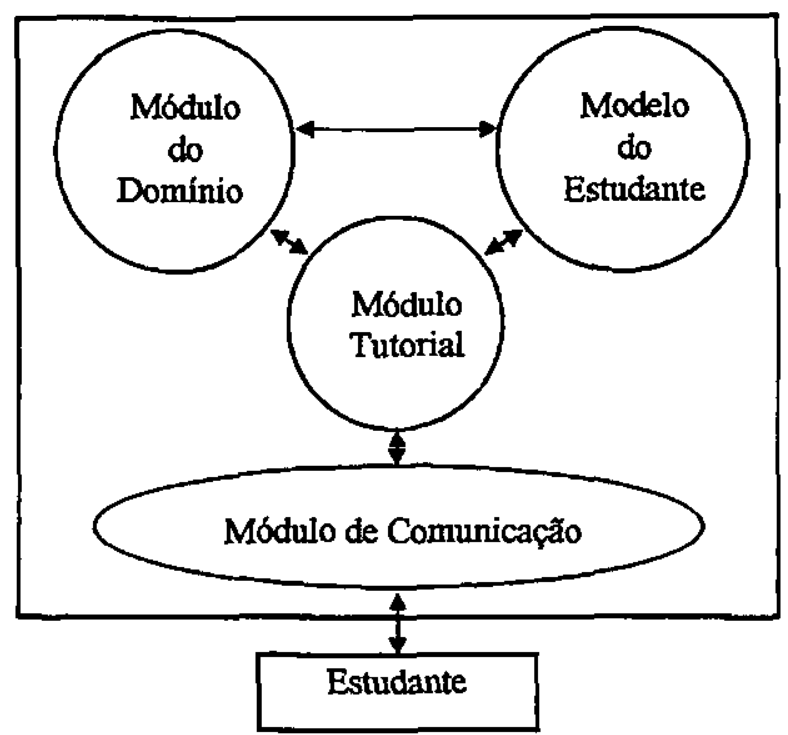

Figura 2.1: A Arquitetura Básica de STIs

\subsubsection{O Módulo do Domínio}

O Módulo do Domínio contém o conhecimento a ser ensinado, normalmente representado através de vários conceitos do domínio que o estudante deverá adquirir. Em domínios de natureza descritiva e teórica (por exemplo, Geografia ou História), a representação utilizada é geralmente declarativa (através de Redes Semânticas ou Lógica). Em domínios orientados à execução de uma determinada tarefa (por exemplo, Matemática ou Física), a representação tende a ser procedimental (Regras de Produção, por exemplo). O Módulo do Domínio objetiva exercer duas funções principais:

- Servir como fonte de conhecimento do assunto a ser ensinado ao estudante, o que implica a capacidade de geração de explicações e respostas ao estudante, bem como tarefas e questões a serem realizadas; e 
- Servir como um padrão para avaliar o desempenho geral do estudante. Para isto, o sistema deve ser capaz de gerar soluções para os problemas no mesmo contexto do estudante, e então, compará-las para, pelo menos, identificar uma resposta incorreta.

\subsubsection{O Modelo do Estudante}

Esse módulo contém informações sobre o nível de conhecimento do estudante no domínio e é atualizado dinamicamente pelo sistema, fornecendo um "quadro" (uma posição ou situação) que representa o desempenho de determinado estudante em determinado momento.

Construir um Modelo do Estudante não é fácil, pois idealmente ele deveria conter aspectos relacionados ao comportamento do estudante durante o aprendizado (por exemplo, ritmo de aprendizado, nível de interesse e motivação, sua área de especialidade). A perfeição do Modelo do Estudante é praticamente impossível, pois o canal de comunicação entre sistema e estudante (o teclado ou a tela) é bastante restrito, ao contrário dos tutores humanos, que combinam dados de uma grande variedade de fontes (por exemplo, diferentes entonações de voz, gestos, expressão facial).

De acordo com Turine (1994), o Modelo do Estudante possui algumas funções básicas, como:

- Função de diagnóstico (ajudar a diagnosticar os bugs $^{3}$ do conhecimento do estudante);

- Função corretiva (ajudar a eliminar bugs do conhecimento do estudante). Neste caso, o modelo deve identificar a diferença existente entre o que o estudante entende e o conhecimento correto do assunto ensinado;

- Função elaborativa (ajudar a complementar o conhecimento do estudante). Neste caso, o sistema deve identificar quais assuntos necessitam ser mais intensamente explorados;

- Função estratégica (ajudar a promover mudanças nas estratégias de ensino);

- Função de prognóstico (ajudar a prever as possíveis respostas do estudante ao tutor). Neste caso, o Modelo do Estudante é utilizado para antecipar o efeito de uma ação sobre o estudante, ou seja, funciona como um "simulador de ações"; e

- Função avaliativa (ajudar a avaliar tanto o estudante como o próprio STI).

\footnotetext{
${ }^{3}$ Em geral, um bug é alguma falha estrutural (parte defeituosa) revelada por algum comportamento inesperado (defeituoso). $\dot{E}$ uma parte incorreta de um determinado procedimento.
} 


\subsubsection{O Módulo Tutorial}

Esse módulo, também conhecido como Módulo Pedagógico ou Módulo de Estratégias de Ensino, é o componente do STI que planeja e administra as interaçðes com o estudante. Esse módulo contém as estratégias e o material que será apresentado ao estudante.

Para obter sucesso, esse módulo deve consultar o Modelo do Estudante e avaliá-lo para então decidir de que forma e qual material irá apresentar ao estudante, isto é, decidir qual a estratégia e o conteúdo de ensino. As estratégias definidas no Módulo Tutorial abordam, principalmente: a forma de divisão do controle, ou seja, controle total do sistema sobre a forma de aprendizagem, controle de aprendizado balanceado entre sistema e estudante ou controle total do estudante sobre o aprendizado; e critérios de quando interromper o estudante e o que dizer, que se constituem na mais importante decisão pedagógica deste módulo, além de definir quais os critérios de avaliação do estudante.

\subsubsection{O Módulo de Comunicação}

Esse módulo consiste num dos principais requisitos para o sucesso do sistema, pois um sistema interativo terá sucesso ou não dependendo da qualidade de sua interface com o usuário. Deve estimular o estudante, ser rica e simples. O Módulo de Comunicação tem alguns objetivos a serem atingidos, que são: facilitar o diálogo, dar respostas dentro do limite de tempo aceitável, fornecer o máximo de suporte possivel para não onerar o estudante com questionários excessivos, dentre outros.

\subsection{Desafios de Pesquisa para Ambientes de Aprendizado}

Muitos STIs recentes, como por exemplo o CALLE, proposto por Rypa e Feuerman (1995), apresentam, na sua essência, ambientes de aprendizado sofisticados que o estudante pode manipular para investigar as propriedades do sistema.

Existem três estilos de ensino utilizados em ambientes de aprendizado: a abordagem de treinamento, a abordagem colaborativa e a abordagem adversária (Blandford, 1994; Fischer, 1995). A abordagem de treinamento geralmente consiste de um ambiente de aprendizado onde o usuário pode manipular diretamente, e de um treinador que busca orientar o estudante se ele 
considera que o uso do ambiente não esteja sendo totalmente ótimo. Nessa metodologia de ensino, o treinador permanece silencioso, ou seja, sem se manifestar, enquanto ele considera que o estudante esteja desempenhando bem, mas interrompe com orientações que são relevantes para a situação quando ele avalia que o estudante pode se beneficiar de tal orientação. Na abordagem colaborativa, por exemplo no WOMBAT (Blandford, 1994), o sistema e o usuário trabalham juntos e nenhum deles é considerado totalmente correto. A abordagem adversária é aquela que encoraja a argumentação do usuário e trabalha com a apresentação de exemplos e contraexemplos relacionados com a discussão atual, fazendo perguntas simples como "Por que?". Um exemplo de sistema com abordagem adversária é o DECIDER, citado por Blandford (1994).

O surgimento de ambientes de aprendizado reflete um entendimento, na comunidade de STIs, de que existe vantagem pedagógica em permitir que estudantes tenham acesso a informações que explicam um modelo, apontando para uma situação de envolvimento ativo do usuário com o sistema e, portanto, promovendo o aprendizado. Porém, uma exploração não supervisionada pode consumir muito tempo e não ajudar o estudante a descobrir resultados básicos e cruciais. Nesse caso, é necessária uma intervenção apropriada para direcionar a interação com o estudante (Blandford, 1994).

Segundo Blandford (1994), a maioria dos trabalhos em teoria da educação não é suficientemente detalhada para informar o projeto de Sistemas Tutores Inteligentes capazes de conduzir um diälogo com o estudante. A abordagem de ensino mais conhecida na literatura é o ensino socrático que implica no professor questionar tópicos pertinentes, os quais levam os estudantes a alcançar conclusões corretas por eles mesmos. Collins e Stevens implementam essa estratégia no STI chamado WHY, abordado por Blandford (1994), que ensina sobre processos de chuva. A estratégia de ensino do WHY é codificada como uma série de regras de produção. Embora eles ilustrem a ampla aplicabilidade do trabalho deles através de vários domínios, todos os tópicos abordados nos domínios têm estruturas cognitivas semelhantes e não fica claro que a abordagem seja aplicável a domínios com estruturas diferentes. Em particular, o alvo ainda parece ser transferência de conhecimento, com nenhuma atenção sendo dada para motivar ou encorajar o estudante a refletir o conhecimento obtido. Na prática, um professor geralmente possui muitos objetivos simultâneos, tais como divulgar a informação, encorajar argüições, conservar a motivação de estudantes e facilitar a aquisição de habilidades para a solução de problemas, e mesmo uma explicação individual pode se destinar a vários objetivos. 
Assuntos relacionados à motivação têm dificilmente sido considerados em pesquisas de STIs. Grande parte da existência de motivação diz respeito ao relacionamento entre estudante e tutor; se o estudante é tratado como um parceiro responsável no seu próprio aprendizado, então é mais provável que ele responda positivamente ao tutor do que se ele for tratado como um objeto qualquer a ser simplesmente preenchido com conhecimento (Blandford, 1994). Claramente, alguns tópicos relacionados com motivação são mais enfocados em domínios fechados, nos quais uma resposta é certa ou errada e deste modo o estudante pode ser elogiado ou encorajado de acordo com o seu nível de sucesso. Em domínios abertos (ou não prescritivos), onde muitas respostas podem ser consideradas como corretas, essas considerações motivacionais se tornam mais dificeis de serem utilizadas.

Grande parte dos domínios abordados na literatura tem uma única resposta correta. Atualmente, entretanto, várias abordagens ao projeto de STIs para domínios menos prescritivos têm emergido e serão vistas na seqüência.

\subsection{Sistemas Tutores Inteligentes em Domínios Náo Prescritivos}

Como já mencionado na Subseção 1.4, entendemos que os sistemas de crítica são uma evolução dos STIs. Essa evolução se caracteriza através da divisão dos sistemas de críticas em primeira e segunda geração.

A primeira geração da abordagem de críticas para domínios não prescritivos (Miller, 1983a, 1983b; Miller \& Black, 1984; Miller, 1985; Miller et al., 1986; Rennels et al., 1987) exige que o estudante proponha uma solução para o problema, a qual o sistema irá comparar com a sua própria solução preferida para o mesmo problema. Essa abordagem admite a possibilidade de existirem diferentes soluções possíveis, com méritos ou desvantagens relativas, mas assume que o estudante já formulou um plano para proceder. Essa abordagem é semelhante àquela adotada por um especialista procurando por uma segunda opinião de um outro especialista. Contudo, nos sistemas citados acima ela não conduz um diálogo/iteração; o usuário é induzido através de menus padronizados a especificar um plano e, em seguida, o sistema produz vários parágrafos em resposta. Nesta primeira geração os sistemas de crítica não pedem nenhuma justificativa do usuário pelo plano proposto e nem poderiam ser usados efetivamente por um completo novato, pois normalmente são destinados a usuários com certo conhecimento sobre o domínio abordado. 
Outros exemplos de trabalhos com domínios não prescritivos envolvem o aprendizado colaborativo onde o usuário e um "companheiro" investigam e interagem durante o processo de resolução de problemas (Blandford, 1994; Renié \& Chanier, 1995; Burton et al., 1997; Cho et al., 1997; Dillenbourg et al., 1997; Hietala \& Niemirepo, 1997; Lester et al., 1997; Paiva, 1997; Suthers \& Jones, 1997).

No que diz respeito à colaboração natural entre humanos, podemos afirmar que o sucesso da colaboração envolve um amplo grau de engajamento mútuo, tomada de decisão e discussão conjunta. Segundo Blandford (1994) e Burton et al. (1997), colaboração é definida como atividade coordenada e síncrona que é o resultado de uma tentativa contínua de construir e manter uma concepção compartilhada de um problema, ou seja, é um processo onde dois ou mais agentes trabalham juntos para resolver metas comuns. Isso serve para produzir uma distinção entre trabalho colaborativo e cooperativo, pois cooperação envolve a divisão de trabalho entre participantes, com cada participante sendo responsável por uma parte da solução do problema, não necessariamente mantendo um engajamento, como é o caso da colaboração.

Burton et al. (1997) define colaboração como uma divisão (dinâmica) de processos cognitivos entre os participantes. Sabemos ainda que, durante a utilização de ambientes colaborativos, em determinadas circunstâncias, os parceiros podem estar concentrados em aspectos diferentes do diálogo, o que conseqüentemente gera conflitos de hipóteses, ocasionando necessidade de interação, o que nos leva a concluir que a colaboração pode ser educacionalmente benéfica. A necessidade de interaçăo induz ao raciocínio, onde o agente ajuda o aprendiz a entender os processos cognitivos e a inferir estratégias que podem levá-lo ao aprendizado. Em ambientes de aprendizado onde usuário e sistema interagem para alcançarem uma meta comum, é imprescindível a existência da colaboração, pois esta encoraja a interação com o usuário e permite que este seja um ator no ambiente de computador, tendo acesso a conhecimento especialista quando necessário (Zellermayer et al., 1991; Fischer et al., 1993; Blandford, 1994; Fischer, 1995; Renié \& Chanier, 1995; Fischer, 1996).

Em contrapartida, uma das principais dificuldades impostas pela colaboração é o ajuste do nível de discussão do ambiente com o aprendiz humano (Hietala \& Niemirepo, 1997). O ambiente não deve interromper ou exigir feedback todo o tempo, nem deve se adaptar à velocidade de trabalho de aprendizes muito lentos. O propósito da interação é dar suporte ao aprendiz no desempenho de suas atividades, e progressivamente diminuir esse suporte até que o aprendiz seja capaz de resolver as atividades individualmente (Blandford, 1994). 


\subsubsection{Trabalhos Relacionados}

Na seqüência apresentamos dois trabalhos relacionados à área de aprendizado colaborativo, nos quais procuramos enfocar arquitetura e resultados de testes com estudantes.

\section{Design-A-Plant}

O Design-A-Plant (Lester et al., 1997) é um ambiente de aprendizado com agentes pedagógicos animados que atua no domínio de anatomia e fisiologia botânica. Ele aumenta a eficácia do processo de resolução de problemas por disponibilizar ao estudante conselhos individualizados e em múltiplos niveis, conselhos estes relacionados à maneira como o estudante deve "projetar" plantas para que elas sobrevivam em diferentes condições ambientais. $O$ agente deste ambiente se chama Herman, o percevejo, e se apresenta em cinco versões diferenciadas, cada qual atuando com comportamento distinto e nivel diferente de aconselhamento. Quanto aos niveis de aconselhamento, os agentes foram classificados da seguinte forma: (1) Adormecidos: esse agente não pode prover conselhos sobre componentes da planta que são afetados por fatores ambientais; (2) Conselho verbal sobre tarefa especifica: esse agente pode prover apenas conselhos verbais sobre uma tarefa específica; (3) Conselho verbal baseado em princípios: esse agente pode prover apenas conselhos verbais baseados em princípios; (4) Conselho verbal/animado baseado em princípios: esse agente é limitado a prover apenas conselhos animados baseado em princípios através de descrições faladas; e (5) Completamente expressivo: esse agente, por sua vez, apresenta todos os tipos de comportamento comunicativo, ou seja, pode dar conselhos animados baseado em princípios para desafiar o estudante ou pode oferecer um conselho falado de uma tarefa específica se o estudante está tendo dificuldades.

Este ambiente foi submetido a testes com estudantes. Para medir o conhecimento dos usuários sobre o domínio, foram aplicados testes escritos, tanto antes como após a utilização do ambiente. Os resultados do estudo apontaram que, de um modo geral, agentes pedagógicos animados podem produzir importantes beneficios educacionais, principalmente para problemas mais complexos, pois por disponibilizar conselhos em diferentes níveis, pode melhorar o processo de resolução de problemas, além de trazer beneficios motivacionais e de desempenho para o usuário. 


\section{EduAgents}

No ambiente EduAgents (Hietala \& Niemirepo, 1997), o aprendiz tenta resolver problemas matemáticos com equações elementares, auxiliado por agentes companheiros de ensino. $O$ ambiente dispõe de quatro agentes (ou quatro estratégias), com nomes e aparências distintas, além de terem níveis de habilidades e maneiras de se pronunciar diferentes. Destes quatro agentes, dois deles, um garoto e uma garota, possuem um bom nível de conhecimento sobre o domínio e não cometem erros, ainda que suas respostas não sejam sempre ótimas. Desta forma, são rotulados de companheiros fortes de aprendizado; os outros dois agentes (novamente um garoto e uma menina), possuem um nível de conhecimento do domínio mais pobre e cometem erros no processo de resolução de problemas, especialmente no início do processo; por isso, são chamados de companheiros fracos de aprendizado. Os quatro agentes são posicionados sempre em locais diferentes na tela para evitar que o aprendiz escolha sempre o mesmo agente no mesmo local. Eles iniciam o processo com uma pequena quantidade de conhecimento do domínio e vão adaptando-se aos níveis de habilidade, através da observação e da extração de conhecimento adicional do diálogo entre aprendiz e companheiro. A colaboração entre agente companheiro e aprendiz se dá quando o aprendiz solicita ao agente companheiro para que este sugira o próximo passo ou explique uma sugestão feita, o que permite perguntas recíprocas e divisão de responsabilidade.

Após submeter esse ambiente a testes com estudantes voluntários, constatou-se que uma de suas principais características é a sua habilidade em engajar, descobrir e sustentar a atividade do aprendiz no sentido de utilizar sua própria habilidade na solução de problemas.

\subsection{Consideraçōes Finais}

Neste capitulo descrevemos brevemente o que são STIs através de uma pequena explicação de sua arquitetura básica. Em seguida, abordamos o que vem a ser ambientes de aprendizado, focalizando os três estilos de ensino normalmente utilizados nesses ambientes, que são, (i) a abordagem de treinamento, (ii) a abordagem colaborativa e (iii) a abordagem adversária e suas características. Na seqüência, citamos trabalhos relacionados à área de ambientes de aprendizado com abordagem colaborativa. $O$ aprendizado colaborativo surgiu recentemente como uma nova preocupação para os pesquisadores que queriam escapar da tradicional arquitetura dos STIs e 
construir ambientes de computador que evitassem o modelo tutor/aprendiz (Blandford, 1994; Fischer, 1995, Renié \& Chanier, 1995], como comentado no Capítulo 1.

A colaboração é benéfica para tarefas que originam conflitos de hipóteses entre os participantes da interação, visto que os ambientes de aprendizado não têm um caminho prédefinido. Desta forma, é importante que o aprendiz entenda quais atitudes provocaram erros, para não mais repeti-las (Renié \& Chanier, 1995). Entre as várias formas de interação incluindo aprendizes e computadores, interessa-nos a interação com um sistema de computador onde o aprendiz pode solicitar algo ao sistema, que então responde à solicitação e desta forma iniciam uma interação. A situação do agente e do aprendiz é igual, pois se tratando de domínios não prescritivos, tanto o sistema como o aprendiz devem auxiliar o outro a encontrar uma solução e não impor a sua solução para o problema em questão.

Uma má interação é normalmente devida a divergências na percepção de objetivos do aprendiz e do agente. Como sabemos, idealmente, aprendiz e agente devem interagir como parceiros que possuem o objetivo comum de solucionar um problema. Desta forma, é necessário reafirmar todos os objetivos durante a sessão de trabalho. De maneira óbvia, é muito dificil obter esse estado natural de interação. Veremos a seguir a natureza do domínio não prescritivo a ser tratado nesta dissertação. O Capítulo 5 trará a solução dada ao problema de ensino de escrita técnica para uma audiência e propósito especifico: a abordagem da segunda geração de sistemas de crítica. 


\section{A Escrita Técnica em Inglês como Língua Estrangeira}

tualmente, a escrita técnica de artigos se constitui em uma severa limitação para
escritores não nativos, podendo afetar o desempenho de profissionais de maneira
marcante, principalmente no caso de pesquisadores e acadêmicos que precisam escrever com proficiência e desembaraço não apenas na língua materna, mas também em uma ou mais linguas estrangeiras, principalmente o inglês. Mesmo considerando que esses profissionais possuam um conhecimento operacional da segunda língua, as dificuldades surgem principalmente de dois fatores. $O$ primeiro é devido à diversidade sócio-lingüística, pois línguas diferem em nível léxico, sintático e pragmático (Wolfson, 1989 apud Aluisio, 1995). Consequentemente, diferentes línguas utilizam diferentes padrões retóricos para organizar o discurso. O segundo fator causador da dificuldade para não nativos está relacionado aos processos de compreensão e produção de uma língua. Sabe-se que a compreensão é mais facilmente alcançada do que a produção. De fato, pessoas aprendendo uma nova língua são capazes de entender formas e funções que elas não conseguem utilizar na escrita ou fala. 


\subsection{Alguns Erros Cometidos por Estudantes Brasileiros na Escrita em Inglês}

Um estudo das dificuldades mais comuns enfrentadas por estudantes brasileiros de pós-graduação foi realizado em 1989 por Fontana (Fontana \& Oliveira Jr., 1991; Fontana et al., 1993). Nessa ocasião foram colhidas amostras de erros cometidos por estudantes brasileiros de pós-graduação no Reino Unido, na produção de teses, artigos e trabalhos acadêmicos, que foram então categorizados e analisados. As constatą̧ðes da análise de erros foram:

- erros localizados, isto é, aqueles que podem ser tratados isoladamente não causam tantos danos à comunicação como aqueles que afetam o significado global do texto ou o significado de várias orações. Erros dentro dos limites de uma oração podem ser corrigidos facilmente com o uso de um dicionário, uma gramática ou suas correspondentes ferramentas de software.

- as deficiências dos textos não se restringem ao uso de vocabulário inadequado ou estruturas gramaticais incorretas, mas são geradas também pelo mau uso ou omissão de expressões convencionais para desempenhar funções específicas do texto acadêmico, como por exemplo, expor a importância de um trabalho, área ou autor, argumentar, introduzir um tópico ou dar exemplos, comparar e contrastar resultados. Estas funçбes exigem o conhecimento de expressões padronizadas e dos conectivos lógicos adequados que são utilizados nas relaçðes
inter-oraçoes.

Nessa análise da escrita de não nativos do inglês foi constatada a falta de expressões do tipo:

- Still on the subject of $X, \ldots$

- A further point about $Y, \ldots$

- As far as $X$ is concerned,...

- In the light of $X, \ldots$

- Viewed from the angle $Y . .$.

Erros ou omissões dessa natureza afetam a coerência do texto e podem ser tratados mais adequadamente com uma ferramenta para a escrita que forneça material lingüístico como ilustrado nas expressões acima. 


\subsection{Ambientes de Software e Ferramentas para o Auxilio e Ensino à Escrita} Técnica

Várias ferramentas e ambientes de software (Cherry, 1982; Smith et al., 1986; Dale, 1990; WTG, 1991; RSI, 1992; Sharples, 1994; Pemberton et al., 1996) têm sido criados para auxiliar o processo de escrita, muitos dos quais já estão disponiveis comercialmente. A grande maioria deles é dedicada ao pós-processamento do texto visando corrigi-lo tanto do ponto de vista gramatical, como do ponto de vista de clareza, estilo e concisão das idéias apresentadas. Apesar de serem extremamente úteis para usuários com dificuldades lingüísticas, essas ferramentas são limitadas quanto à escrita numa língua estrangeira, pois proporcionam somente mecanismos de correção de um texto acabado. Entretanto, muitas vezes o usuário não é capaz de gerar um texto passível de ser apenas melhorado. Existem outras ferramentas dedicadas ao ensino de uma lingua, seja ela a lingua nativa do usuário ou não. As ferramentas geralmente se dividem em ensino do vocabulário (Bos \& Van de Plassche, 1994; Goodfellow, 1995; Renié \& Chanier, 1995; Segalowitz, 1995), da gramática (Bolt, 1991; Yazdani, 1991), e de gêneros de texto — por exemplo, textos comerciais (Beeken et al., 1992) e textos técnicos (Andeweg et al., 1992).

Existem dois ambientes de software especificamente devotados para a escrita técnica de não-nativos do inglês: o sistema Composer (Pemberton et al., 1996; Shurville et al., 1997) e o ambiente AMADEUS (Aluísio, 1995; Aluísio \& Gantenbein, 1997). Composer foi fortemente baseado na ferramenta Writer's Assistant (Sharples \& Pemberton, 1990), um ambiente composto de ferramentas para o planejamento e composição de textos que foi fundamentado em teorias cognitivas do processo de escrita. Atualmente, Composer apresenta inovações que focalizam problemas de não-nativos do inglês escrevendo artigos técnicos. Entretanto, Composer é um sistema de auxilio à escrita enquanto que o ambiente AMADEUS prevê ferramentas de auxilio e também de ensino.

AMADEUS foi fundamentado nos estudos de (Fontana \& Oliveira Jr., 1991; Fontana et al., 1993), descritos na Subseção 3.1, que mostraram que algumas das deficiências de alunos brasileiros, realizando cursos de pós-graduação no exterior, estão relacionadas ao mau uso ou omissão de expressões mais ou menos convencionais que desempenham funções especificas do texto acadêmico. Uma solução para este problema consiste na utilização de expressões aprendidas com a prática adquirida na leitura de artigos - acreditamos ser essa estratégia largamente difundida entre estrangeiros que precisam escrever em inglês. Ou seja, numa situação de dúvida, o 
escritor recorre a textos escritos por pessoas de reconhecida competência. Para otimizar o uso desta estratégia, foi feita uma compilação de expressões e orações extraídas de artigos e livros científicos (Oliveira et al., 1992). Uma verificação surpreendente foi que um número relativamente pequeno de expressões e orações pode ser suficiente para cobrir uma grande proporção das expressões e orações usadas numa certa área do conhecimento ${ }^{4}$. Isto ocorre porque as expressð̌es e orações são empregadas de maneira sistemática, quando se descrevem tabelas, figuras e procedimentos experimentais, quando se comparam resultados ou se empregam argumentos para dar suporte a afirmações. Anteviu-se, a partir dessa constatação, a possibilidade de se criar ferramentas de software que utilizem essa estratégia de reutilização de trechos de textos.

\subsubsection{O Ambiente AMADEUS}

Como foi comentado na Introdução, AMADEUS é um ambiente modular de auxilio e ensino da escrita técnica, cujo módulo lingǘstico possui ferramentas inter-relacionadas ferramenta de referencia, ferramenta de suporte, ferramenta de crítica e ferramenta tutorial. Cada uma das ferramentas se aplica especificamente a um conjunto de problemas caracterizados por diferentes niveis de facilidade na segunda língua e grau de experiência na escrita técnica, como ilustra a Figura 3.1.

\footnotetext{
${ }^{4}$ Esta verificação está de acordo com trabalhos em análise linguiística do discurso (Liddy, 1991; Paice, 1990) que, além de levantarem a estrutura esquemática de abstracts de trabalhos experimentais, verificaram a existência de expressões e oraçðes que revelam esta estrutura.
} 


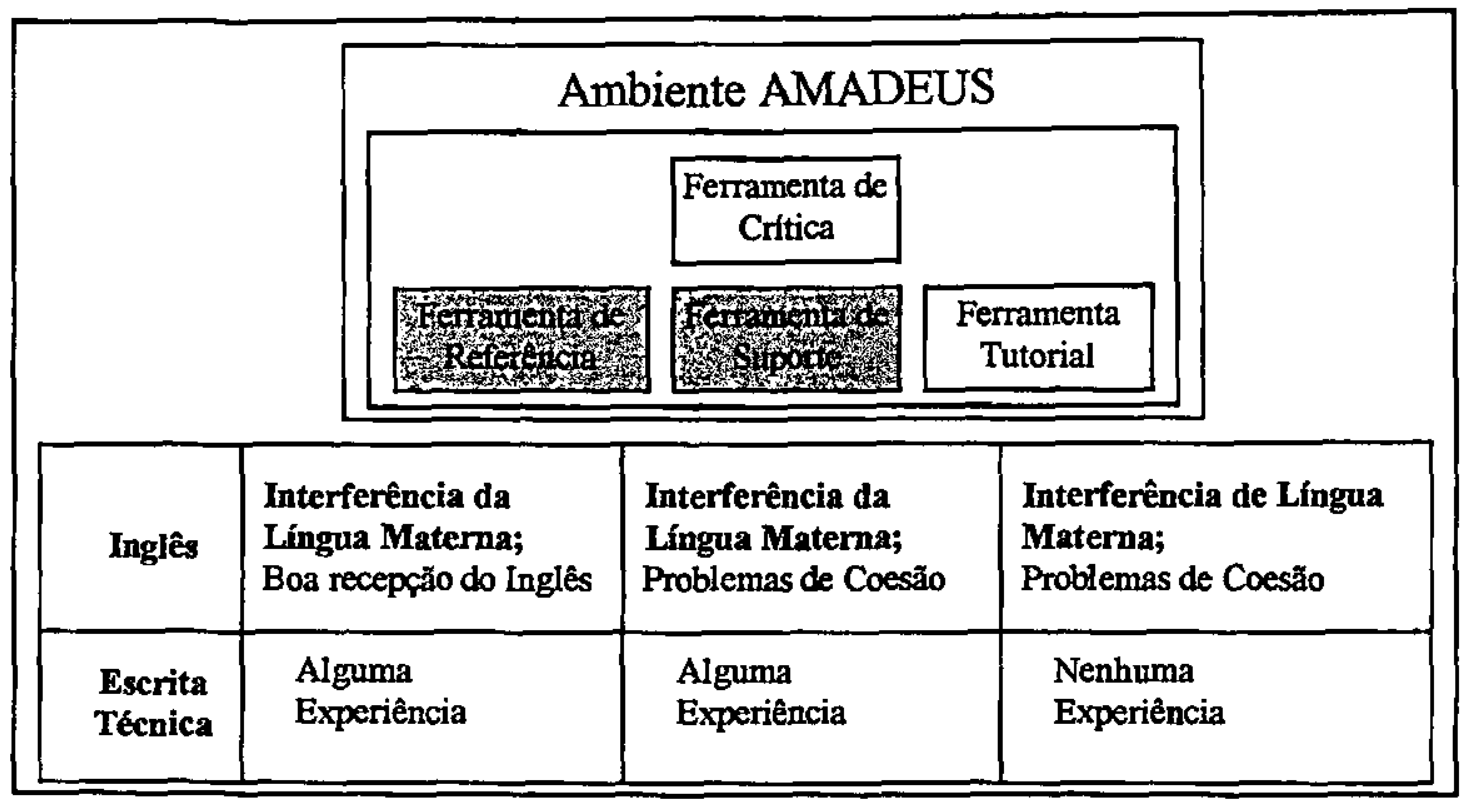

Figura 3.1: Módulo de Auxílio Lingüístico do Ambiente AMADEUS

\subsubsection{Ferramenta de Referência}

Diante das dificuldades apontadas na seção anterior, como o problema da interferência da língua materna e todos os outros que afetam a coerência de textos escritos por não nativos, Oliveira (Oliveira, 1991 apud Aluísio, 1995), propôs um recurso empírico que consiste em fornecer ao escritor material lingüístico na forma de expressões-padrão alocadas em uma bā̌e de expressões. Este recurso constitui uma resposta alternativa à necessidade de ajuda técnica, configurada na estratégia de solicitação de ajuda (Huckin, 1991 apud Aluísio, 1995), cujo emprego parece ser consensual na produção escrita.

Para facilitar o uso do recurso durante a edição de artigos e trabalhos acadêmicos, a base compilada foi implementada como uma ferramenta de referência (reference tool). Expressões autênticas foram compiladas de artigos científicos das áreas de física e informática e apresentam lacunas (para indicar a falta de palavras) que devem ser preenchidas com o material factual da pesquisa do escritor.

Exemplos são mostrados abaixo:

a) Importance of the field, general interests, etc.

There has been substantial interest in the fabrication of... 
b) Description of an effect, phenomenon, etc.

The phenomenon of... induced by ... has not only provided a sensitive and convenient probe for monitoring ... (membrane breakdown) but has also revealed the irreversible changes that can occur during...

c) Previous reports on related work.

Several papers have reported measurements aimed at obtaining evidence for, and insight into,... processes in ...

d) What is lacking in the field.

Althought significant advances have been made in the understanding of how (something) influences... (another), very little further attention appears to have been given to the...

e) Difficulties faced in a particular analysis.

Further difficulties arise from the limited.. available and the requirement for a ...

f) Improvements on previous works, models etc.

This is an improvement over the existing practice of simply inserting (calculating, determining etc)...

g) What the present work does.

The purpose of the work reported here was to study the influence of... on the ...

h) Relevance of this work to the field or other areas.

The surface properties of... apart from the pure physical chemical interest will help to elucidate the role of ... in many ... phenomena.

i) Layout or Outline of the paper.

The organisation (outline) of the (this) paper is as follows. In the Section II we describe... The... is presented in section III. In Sec. II we solve the... equation giving expressions for... . This is necessary for the work of Sec. III, in which the extended... equation is derived. Numerical results 
of the theory are given in Sec. $I V$, together with a comparison with... and ... calculations.

\subsection{Arquitetura da Ferramenta de Referência}

De acordo com Aluísio (1995) existem dois grandes processos na arquitetura da ferramenta de referência: aquisição de material lingüístico e composição de texto, como ilustra a Figura 3.2.

$O$ processo de aquisição toma como entrada as palavras-chave, as funções retóricas, expressões padrões de artigos e os componentes/subcomponentes da estrutura esquemática de artigos e os transforma em recursos para serem utilizados no processo de composição. Na aquisição, novos padrões podem ser inseridos para cada componente/subcomponente da estrutura esquemática e podem ser associados às suas funções retóricas se são representativos de alguma. Novas palavras-chave e outras funções podem também ser anexadas, bem como alguma nova subdivisão para a estrutura esquemática. Com esse processo, a ferramenta de referência pode ser totalmente personalizada, e inclusive pode servir à escrita de outros gêneros correlatos como os relatórios técnicos, artigos de revisão (review articles) etc. As palavras-chave também podem representar itens léxicos que são problemáticos para não nativos do inglês, como as palavras homófonas, as quase homógrafas e os falsos cognatos (stationary/stationery, real/royal, principal/principle, actually/really, por exemplo), conectivos de discurso (because, therefore, as a result etc) fornecendo um meio alternativo de acesso às funções retóricas. 


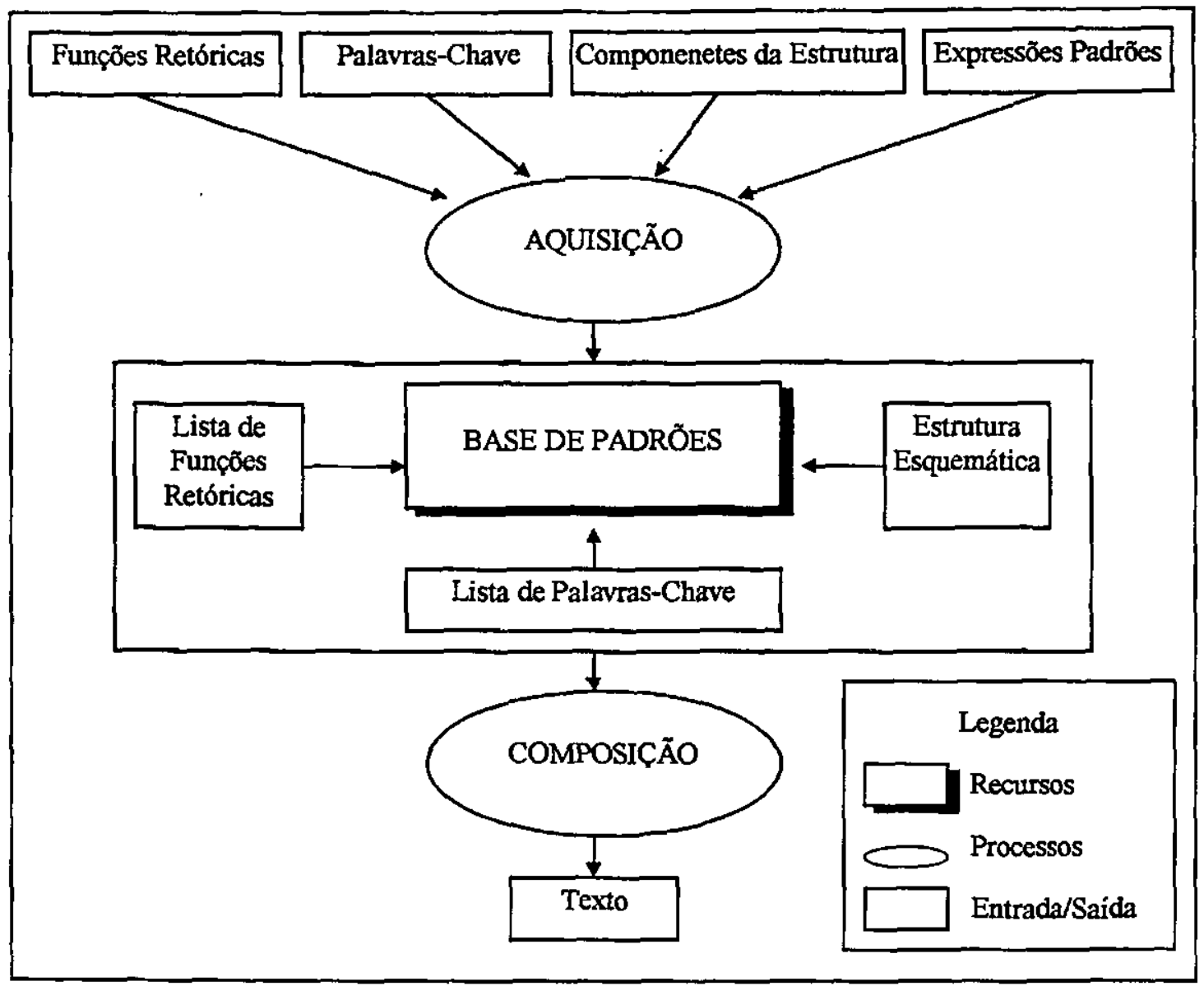

Figura 3.2: A Arquitetura da Ferramenta de Referência

Os recursos utilizados na implementação da ferramenta de referência são:

- Uma lista de componentes e subcomponentes da estrutura funcional/retórica para artigos, proposta por Deyes (Deyes, 1982 apud Aluísio, 1995), com ponteiros para a Base de Padrões;

- Uma lista de funções retóricas como causas, comparações, definições e exemplificações que também apontam para suas respectivas entradas na Base de Padrões;

- Uma lista de palavras-chave características do gênero (report, paper, model, technique, methodology, figure section etc) que permite o acesso às expressões padrões da Base de Padrões através de um processo simples de busca capaz de mostrar todas as orações que satisfazem a busca de uma dada palavra-chave; $\mathrm{e}$

- Expressões padrões tomadas de artigos autênticos da área de fisica experimental e informática.

O processo de composição permite o acesso às expressões padrões através da seleção de um componente ou subcomponente da estrutura esquemática, da seleção de uma dada função 
retórica ou de uma dada palavra-chave.

\subsubsection{Ferramenta de Suporte}

Apesar da utilidade da ferramenta de referência, ela não é adequada para usuários com problemas textuais de ordenação dos componentes do artigo, de escolha do melhor conectivo lógico entre períodos e escolha do melhor padrão retórico de orações que é adequado para o texto sendo construído. Este tipo de problema textual parece ser melhor solucionado se forem fornecidas ao usuário estratégias retóricas que mostram como selecionar e ordenar idéias, formando periodos compostos ou vários periodos através de conectivos lógicos, marcadores temporais, paralelismo estrutural e referências textuais adequadas. Para ajudar usuários com esses tipos de problemas, a ferramenta de suporte foi implementada.

A ferramenta de suporte é destinada à escrita da seção introdutória de artigos curtos (Letters) da área de pesquisa experimental. Sua implementação teve a intenção de avaliar a aplicação do Raciocínio Baseado em Casos (RBC) e de técnicas utilizadas em lingüística computacional para ferramentas de suporte à escrita. A arquitetura dessa ferramenta é descrita a seguir.

\subsubsection{Arquitetura da Ferramenta de Suporte}

A ferramenta de suporte é uma implementação protótipo da abordagem baseada em casos com adaptações interativas aplicada à ferramentas de escrita

A Base de Casos contém cinqüenta e quatro instâncias de introduções autênticas, sendo que cada caso é representado em um formalismo computacional e tem associado o texto da introdução correspondente. A Base de Regras de Revisão é responsável por manter a Estrutura Esquemática para Introduções, o Dicionário de Padrões e os quatro típos de Regras de Adaptaçбes de Casos. A ferramenta interage com o usuário em três estágios:

- Para a coleta de informações sobre a estrutura esquemática de introduções;

- Para a seleção do melhor caso dentre os vários recuperados; e

- Durante a fase de adaptações do melhor caso. 
Como mostrado na Figura 3.4, existem três fontes de conhecimento na ferramenta de suporte:

- A Base de Casos;

- A Base de Regras de Revisão; e

- As Regras e Medidas de Similaridade.

A Base de Casos e parte da Base de Regras (a estrutura esquemática) foi obtida do processo de Análise de corpus de introduções de artigos da área de física experimental. Os textos das introduções foram obtidos através do processo de digitalização, pois na época em que foi realizada a análise de corpus os textos não estavam disponíveis eletronicamente. As quatro regras de adaptação são genéricas pois servem para adaptar qualquer uma das trinta estratégias e suas quarenta e cinco mensagens associadas. As Regras e Medidas de Similaridade também são genéricas, pois são baseadas em regras de similaridade entre listas e na medida de similaridade conceitual chamada nearest neighbours matching, bastante conhecida na área de RBC.

A interação com o usuário é realizada pelos processos: Coleta de Features, Seleção Dirigida pelo Usuário e Adaptações Interativas. A entrada inicial de dados (ou requisição) fornecida pelo usuário alimenta o processo de Recuperação de Casos. Este processo toma: as Features Retóricas fornecidas para a introdução a ser escrita, as Estruturas Retóricas de cada caso da base e as Regras e Medidas de Similaridade e devolve ao usuário os casos mais próximos à sua requisição. Dentre estes casos, o usuário escolhe o melhor e através do processo de Adaptações Interativas e da entrada de material lingüístico relativo à sua pesquisa/trabalho, compõe o Texto da Introdução. Entretanto, é possível também que o usuário escreva seu texto a partir dos vários casos recuperados, isto é, sem a ajuda do processo de adaptações interativas, produzindo assim o texto da Introdução a partir dos casos. Finalmente, o usuário pode iterar dois processos: a seleção Dirigida pelo Usuário e as Adaptações durante o processo de composição de seu texto da introdução. 


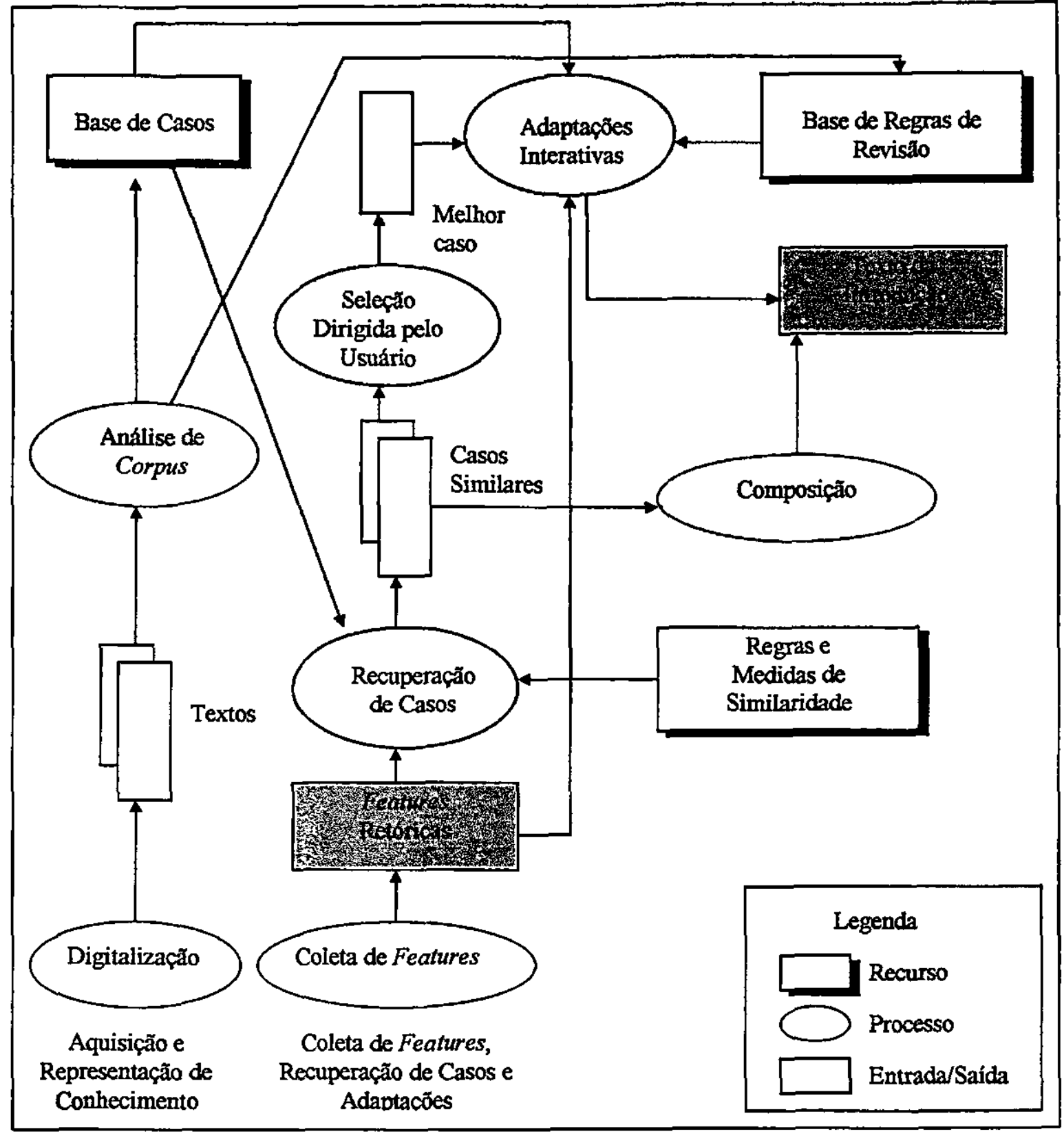

Figura 3.4: Arquitetura da Ferramenta de Suporte

A Figura 3.5 mostra o arquivo que está associado a uma das introduções da base. 


\section{SETTING: FAMILIARIZING TERMS OR OBJECTS OR PROCESSES}

1) Conductive LB films of charge transfer complexes based on TCNQ, TTF and related donors [1], are characterized by strong one-dimensional interactions and are therefore susceptible to stacking defects and Peierls instability.

\section{REVIEW: REQUIREMENTS FOR THE PROGRESS IN THE AREA}

2) It should be possible to overcome such defects and thus produce films of higher conductivity if a complex of higher dimensionality is chosen.

3) Indeed, Nakamura et al.[2] have shown that monovalent salts of a range of long-chain alkylammonium salts of $M(d m i t) 2$, where $M=A u, N i, P d$, or Pt may be deposited as $L B$ films and oxidised with bromine or iodine to yield molecular films with conductivities in the range $0.001-30 \mathrm{~S} / \mathrm{cm}$.

\section{GAP: UNRESOLVED CONFLICT OR PROBLEM AMONG PREVIOUS STUDIES}

4) However, owing to their instability at the air-water interface, it was necessary in most cases to deposit the complexes as 1:1 mixtures with icosanoic acid.

PURPOSE: PRESENTING AN EXTENSION OF A PREVIOUS AUTHOR'S WORK + INTRODUCING MORE PURPOSES

5) In a preliminary report [3], we have shown that it is possible to deposit LB films of the pure didodecyldimethylammonium salts of the divalent metal complexes $[M(d m i t) 2] 2-$ and [M(mnt)2]2-

6) In this report we describe further investigations into the behavior of these compounds (complexes 1 and 2 respectively) at the air-water: interface and extend our studies to the monovalent salt (complex 3) for comparison.

(Taylor, D.M. et alli. Monolayer characterization and multilayer deposition of conducting Langmuir-Blodgett films, Thin Solid Films, 210/211 (1992) pp. 287-289)

Figura 3.5: Uma das Introduções da Base de Casos 


\subsubsection{Ferramenta de Critica}

Este trabalho de mestrado objetivou o desenvolvimento da ferramenta de crítica. A ferramenta de crítica proposta segue a abordagem colaborativa da segunda geração dos sistemas baseados em crítica (Fischer et al., 1991; Silverman, 1992; Fischer et al., 1993; Rankin, 1993; Fischer, 1995).

A escrita técnica se constitui em um domínio não prescritivo e desta forma se toma bastante adequado para a implementação das abordagens colaborativas, pois, no máximo, a ajuda que um autor pode receber de teorias da escrita como (Hayes \& Flower, 1980) é um conjunto de guidelines ao invés de um algoritmo preciso.

É desta forma que abordagens colaborativas são interessantes, pois o sistema e o escritor se ajudam mutuamente no processo, um complementando as fraquezas do outro. $O$ sistema pode tornar rapidamente disponível grande quantidade de conhecimento (padrões linguísticos, por exemplo) enquanto que o escritor pode, por exemplo, delinear uma área de pesquisa, selecionar os itens mais relevantes da literatura para serem citados, decidir quais são os resultados importantes a incluir e assim por diante. Particularmente, em domínios abertos:

- Não se tem uma descrição definitiva, isto é, que não será questionada ou que não precise de mudanças;

- Não se consegue precisar quando a escrita foi finalizada, pois é comum autores reescreverem várias vezes um mesmo texto;

- A decisão se resume a resolver se um trecho de texto é bom ou ruim e não certo ou errado;

- A qualidade do texto escrito pode variar com o tempo (como comentado acima, autores costumam reescrever o texto inúmeras vezes, visando melhorias); e

- Não existe uma quantidade finita de bons textos para nos basearmos na hora de escrever um outro similar.

Ainda, se pensarmos nos vários estágios do processo de escrita, isto é, planejamento, escrita propriamente dita (ou composição) e revisão (Hayes \& Flower, 1980), temos que a fase de revisão pode ser muito mais ajudada por meio de guidelines como as encontradas nas normas do CHI'96 para artigos curtos (CHI'96 Guide To Successful Short Papers Submissions) da Tabela 
3.1, do que a fase inicial de seleção do material a ser incluído no artigo e a sua organização em seções. Esta última é menos explícita para os autores. Temos, ainda, a complicação gerada pelas variações de acordo com o tipo de artigo.

Tabela 3.1: Erros Típicos Relatados por Revisores de Submissões em Conferências CHI

O trabalho não foi finalizado, os resultados são desconhecidos ou ainda inspiram dúvidas, então a hipótese não foi validada.

O trabalho não compara e contrasta o trabalho do autor com trabalhos importantes da literatura publicada no campo de interação usuário-computador.

O autor não demonstra um bom entendimento do estado da arte como documentado na literatura (por exemplo, os proceedings $\mathrm{CHI}$ dos anos anteriores).

O trabalho não esboça conclusões ou não focaliza as lições aprendidas.

O trabalho não relata os resultados da pesquisa, mas simplesmente fornece informações do contexto e discussões sobre a importância do tópico.

O autor apresenta afirmações sem fundamentá-las; as conclusões vão além dos resultados do trabalho.

Um trabalho experimental/relatando uma experiência não descrevendo as lições aprendidas; quanto mais gerais as lições aprendidas, mais importante para a conferência.

\subsubsection{Ferramenta Tutorial}

Finalmente, a última ferramenta proposta no ambiente AMADEUS - a ferramenta tutorial — foi concebida parcialmente colaborativa e difere da de crítica, pois esta não é adequada - quando o usuário é completamente novato ou quando existe algum tópico que ele desconheça inteiramente. Neste momento é desejável uma interação tutor/aprendiz, pois o sistema tem mais conhecimento que o usuário. Assim, a ferramenta tutorial pode ser vista como gerenciadora de dois agentes - um companheiro e um tutor _-, sendo que o agente companheiro é responsável pela colaboração, pois assume compartilhamento de conhecimento e o agente tutor é acionado 
quando o usuário necessita aprender um tópico. A abordagem companheiro/tutor foi utilizada por Chan e Baskin (1990).

\subsection{Consideraçōes Finais}

Neste capítulo abordamos a natureza do problema de escrita técnica em inglês como língua estrangeira e os ambientes e ferramentas da literatura, desenvolvidas para torná-lo menor, dando um enfoque maior para o ambiente AMADEUS e as ferramentas que o compõe. No próximo capítulo veremos como a segunda geração da abordagem de críticas pode ser utilizada para a elaboração de ferramentas de ensino da escrita técnica em inglês. Esse capítulo nos dará os subsídios para a proposta de trabalho desta monografia. 


\section{A Abordagem de Críticas}

\subsection{Sistemas de Crítica}

$\mathrm{U}$

m sistema de crítica é composto por dois agentes, um computador e um usuário, trabalhando em colaboração. Ambos os agentes contribuem com o que conhecem sobre o domínio do problema a ser solucionado. A tarefa básica do sistema é o reconhecimento e a indicação de pontos positivos ou deficiências no produto ou ação do usuário e não necessariamente a resolução do problema - a maioria dos sistemas de crítica fazem sugestð̃es de como melhorar o produto. Com essas sugestões, o usuário pode solucionar o problema ou procurar obter explicações adicionais. O papel do usuário é inicialmente gerar um produto/solução e depois fazer mudanças nele, participando juntamente com o sistema do processo de resolução do problema. A tarefa do sistema é analisar os produtos/soluções, produzindo uma crítica que permite ao usuário iniciar a próxima iteração deste processo, como ilustra a Figura 4.1 (Fischer et al., 1991). 
Um sistema de crítica apresenta uma opinião sobre um produto ou uma ação gerada por um usuário, além de prover uma forma efetiva de interação entre usuário-computador auxiliando o usuário no desenvolvimento de produtos. Um produto pode ser, por exemplo, um programa de computador, um projeto de uma cozinha ou um plano de tratamento médico, enquanto que uma ação pode ser uma seqüência de teclas pressionadas em um editor de textos para corrigir um erro ou uma seqüência de comandos de um sistema operacional, entre outras. Um agente que é capaz de criticar é classificado como um crítico e pode ser uma máquina ou um ser humano (Fischer et al., 1991; Silverman, 1992; Fischer et al., 1993; Rankin, 1993; Fischer, 1995).

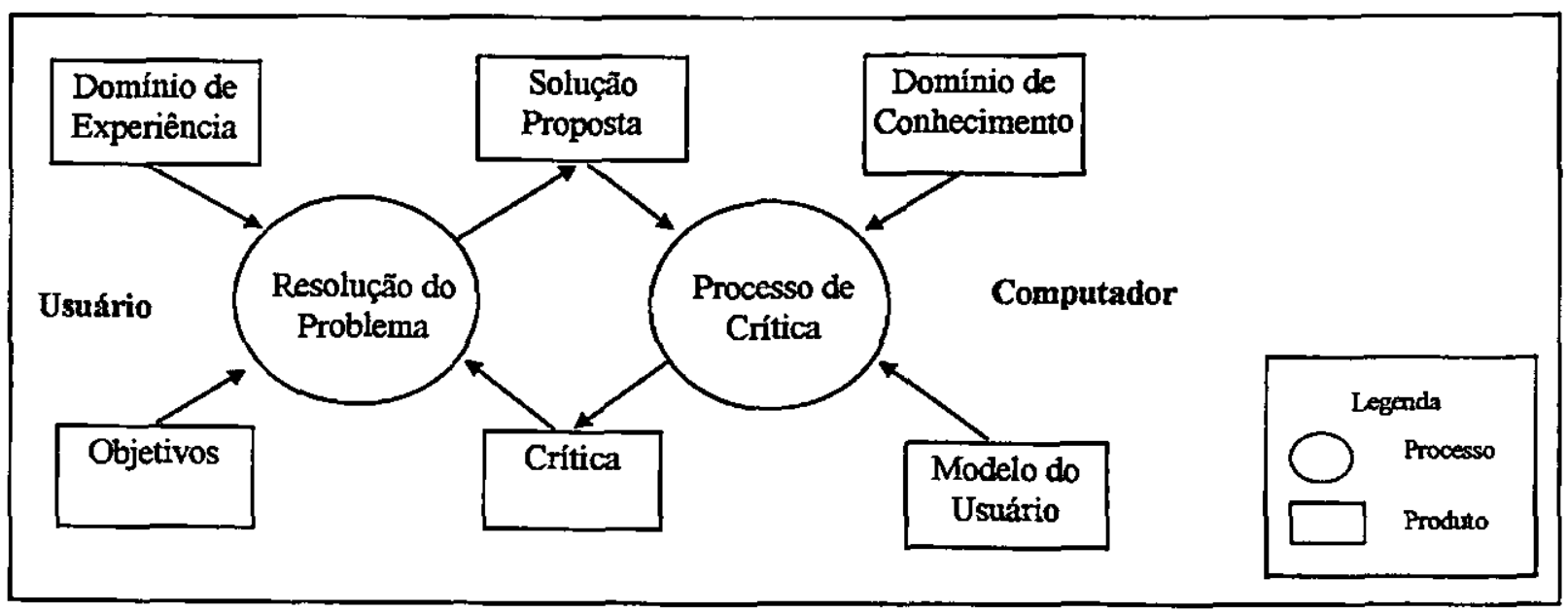

Figura 4.1: A Abordagem de Críticas

\subsection{Mecanismos de Critica}

Um sistema de crítica normalmente simula um ambiente de projeto orientado a um determinado domínio. Este sistema deve conter mecanismos de crítica relevantes e relacionados ao domínio para que o usuário tenha condições de realizar um bom projeto.

Três tipos de mecanismos de crítica incorporados em ambientes de projeto computacional são explorados na literatura (Fischer et al., 1993):

- Criticas genéricas são compostas de um conjunto padrão de críticas para avaliação da situação geral da construção em questão, baseando-se na suposição do que o projetista deseja para projetar um bom produto. Elas se constituem no conhecimento que é aplicado a todos os projetos. 
- Criticas especificas avaliam a situação da construção, baseando-se em especificações parciais, ou seja, existem as críticas genéricas, porém, em determinados casos ocorrem exceções a essas críticas, provocando a não utilização de críticas genéricas em prol de críticas específicas. Críticas específicas refletem o conhecimento do projeto que está vinculado a uma situação especifica e que nem todos os projetos irão compartilhar. Por exemplo, se, em um projeto posicionamento de móveis e eletrodomésticos em uma cozinha, as críticas genéricas propõem que a máquina de lavar pratos fique à direita da pia e se a cozinheira é canhota, a crítica genérica não será utilizada, sendo aplicada a especifica.

- Críticas interpretativas permitem que o projetista interprete a situação do projeto de acordo com os seus interesses. As críticas interpretativas são associadas com perspectivas, que são mecanismos de criação, gerenciamento e seletividade na ativação de diferentes conjuntos de críticas. O projetista sempre trabalha com uma perspectiva particular, ou seja, em qualquer momento ele pode selecionar uma perspectiva diferente. Por exemplo, caso a cozinheira seja canhota, a máquina de lavar pratos deve ser colocada no lado esquerdo da pia, porém, se a perspectiva do dono do imóvel é vendê-lo, então é plausivel que tal máquina seja instalada do lado direito da pia, visto que a maioria das pessoas é destra.

As três classes de críticas citadas acima correspondem a três dimensões de incorporação a sistemas de críticas: críticas genéricas são incorporadas na construção; críticas específicas nas especificaçōes parciais e críticas interpretativas na hierarquia de perspectivas que suportam a evolução de pontos de vista alternativos do projeto (Fischer et al., 1993).

\subsection{O Processo de Critica}

Segundo Fischer et al. (1991), os componentes do processo de crítica são: Aquisição de Objetivos, Análise do Produto e Apresentação de Críticas, Explicações e Conselhos, embora nem todos eles precisam necessariamente estar presentes em todos os sistemas de críticas. $O$ usuário inicia o processo de crítica apresentando um produto ao sistema. Para avaliar o produto, - sistema obtém os objetivos/metas do usuário por um processo de Reconhecimento Automático ou por uma Especificação Externa fornecida pelo usuário. Existem duas abordagens na literatura para avaliar o produto: a avaliação diferencial e a avaliação analítica, abordadas na Seção 4.3.2. O componente de apresentação usa a análise do produto para formular 
uma crítica, fornecer ajuda/conselhos sobre melhorias no produto do usuário e fornecer explicações. Estratégias de Crítica e, opcionalmente um Modelo do Usuário, controlam o tipo de crítica, sua forma e o momento de apresentação. Com base na crítica, o usuário gera uma nova versão do produto e o ciclo se repete, integrando o auxílio recebido. A Figura 4.2 (Fischer et al., 1991) ilustra este processo.

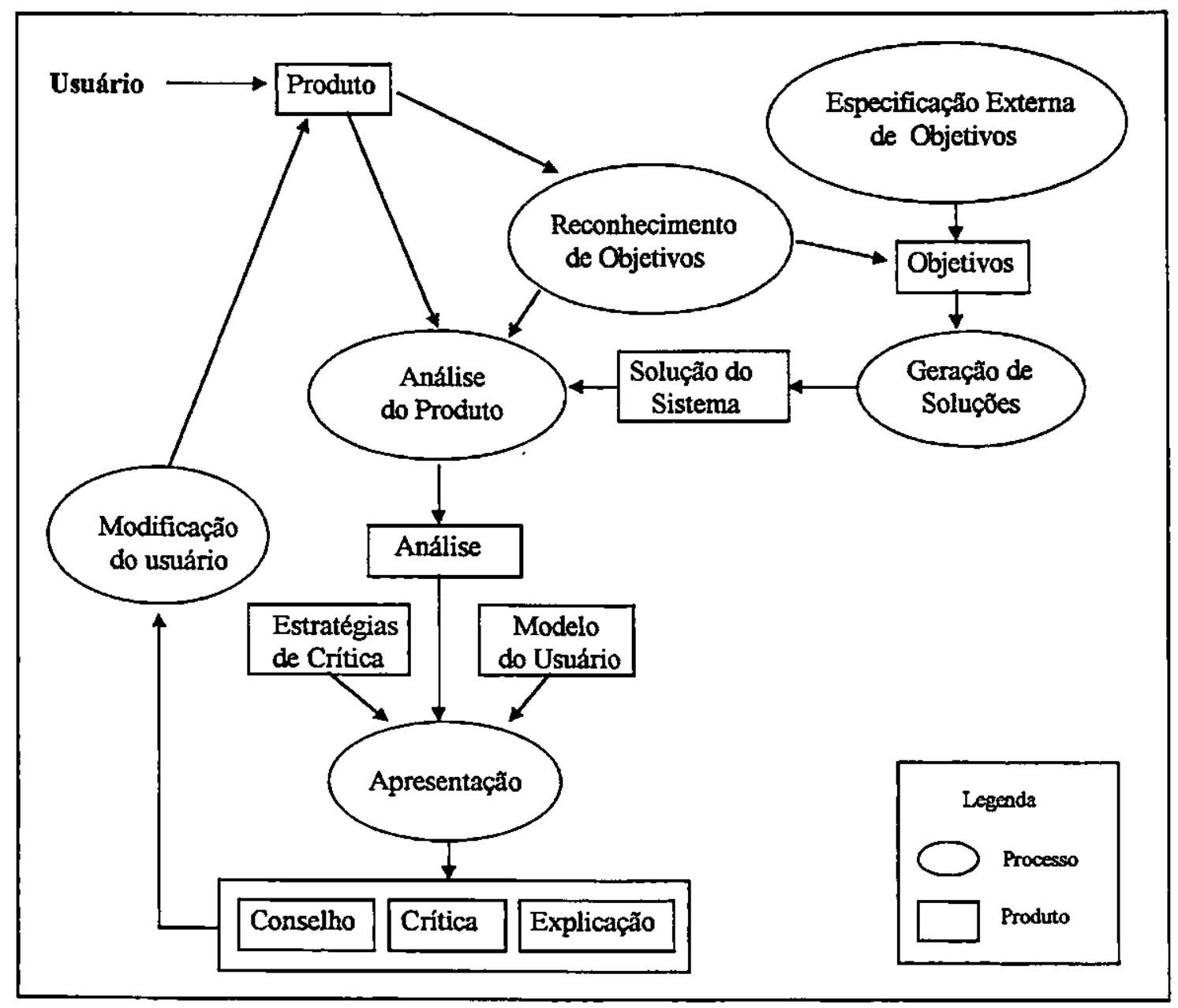

Figura 4.2: O Processo de Crítica

\subsubsection{Aquisição de Objetivos}

A crítica a um produto é acentuada se o sistema tem conhecimento dos propósitos particulares do produto, que pode ser separado em conhecimento do domínio e conhecimento de objetivos. $\mathbf{O}$ conhecimento do domínio sem nenhum conhecimento do objetivo particular do usuário limita a crítica sobre caracteristicas que pertençam a todos os produtos do dominio. Por exemplo, o 
conhecimento do domínio permite ao JANUS $^{5}$ (Fischer et al., 1991) apontar que fogões não devem ser colocados perto de portas porque essa combinação constitui risco de acidente.

Para uma avaliação mais extensa do produto, algum conhecimento sobre os objetivos específicos do usuário e a situação é necessário. JANUS, assim como a maior parte dos sistemas de críticas, não possui esse conhecimento. $O$ objetivo do usuário é reconhecido como sendo o projeto de uma cozinha residencial funcional. O crítico não avalia nenhuma exigência particular, como, por exemplo, o tamanho da cozinha ou o número de pessoas da familia que irá utilizá-la.

Sistemas de critica que trabalham com conhecimentos de objetivos específicos, podem tomar conhecimento deles através de perguntas ao usuário (especificação externa de objetivos) ou pela análise do produto que o usuário tenha produzido até então (reconhecimento de objetivos). Uma cozinha com uma mesa e cadeiras localizadas no seu centro, sugere que o usuário pretende fazer suas refeições no local. A mesa e as cadeiras permitem ao sistema de crítica da cozinha reconhecer o objetivo e então prover a área adequada para comportar a mesa e as cadeiras.

Um sistema de crítica pode também ter acesso a especificações externas do problema a ser resolvido. Por exemplo, usuários podem informar ao sistema que eles precisam de uma cozinha com área suficiente para comportar mesa e cadeiras para realizar refeições. Isto pode ser feito através de questionários ou com técnicas sofisticadas de comunicação por linguagem natural.

Para exemplificar um sistema de critica, vejamos um pouco mais sobre o JANUS. Este sistema contém dois subsistemas integrados: JANUS-CRACK e JANUS-VIEWPOINTS. JANUS$C R A C K$ é um ambiente baseado em conhecimento que dá suporte ao projeto de construção de cozinhas usando blocos de construção orientados ao domínio denominados unidades de projeto. JANUS-VIEWPOINTS é um sistema de hipertexto que contém princípios gerais de projeto de cozinha. A integração desses dois subsistemas permite argumentação para a resolução de situações problemáticas que ocorrem quando o sistema de crítica detecta a violação de regras.

JANUS-CRACK sabe como distinguir bons e maus projetos e pode explicar esse conhecimento baseado em princípios, que englobam três categorias: (1) construção de código ("A área de janela deve ser menor que $10 \%$ da área de assoalho"), (2) padrões de segurança ("O fogão não deve estar a menos de 12 polegadas de uma porta") e (3) preferências funcionais ("O triângulo de trabalho deve ter menos de 23 pés").

\footnotetext{
${ }^{5}$ JANUS (Fischer et al., 1991) é um sistema de crítica voltado para o projeto de ambientes, mais especificamentc para o projeto de cozinhas. Ele permite ao projetista construir o layout de cozinhas residenciais e aprender princípios básicos sobre a projeção de móveis e eletrodésticos.
} 
JANUS permite duas metodologias de projeto: projeto por composição (usando uma paleta) e projeto por modificação (usando um catálogo). A utilização do catálogo permite o processo de aprendizado, pois reutiliza um projeto pronto (tanto correto como incorreto), permitindo alteraçōes. O sistema critica tais projetos, de modo que eles possam ser melhorados, permitindo ao usuário aprender com exemplos negativos. $O$ novo projeto do usuário pode ser armazenado no catálogo.

O usuário pode modificar e estender o ambiente de projeto JANUS-CRACK através da modificação ou adição de unidades de projeto, regras de crítica e relacionamentos, o que é importante principalmente quando o usuário discorda de críticas fornecidas. Os "padrões de construção de códigos" e os "padrōes de segurança" não devem ser mudados, mas as "preferências funcionais" mudam de projetista para projetista e devem ser adaptadas, permitindo ao usuário expressar-se. Nesse contexto, durante a utilização do sistema pode acontecer do usuário não ter conhecimento das regras de segurança ou pode não tê-las entendido por completo e, nesse caso, uma explicação é desejável. Esta explicação, assim como as críticas, são fornecidas pelo JANUS-VIEWPOINTS.

\subsubsection{Análise do produto}

Segundo Fischer et al. (1991) e Rankin (1993), existem duas abordagens principais para analisar o produto: analítica e diferencial. $\mathrm{Na}$ abordagem diferencial, o sistema de crítica gera sua própria solução para o problema e então a compara com a solução apresentada pelo usuário e aponta para as principais diferenças entre as duas versōes. Esta abordagem é bastante indicada para problemas bem estruturados, cujas soluçōes podem ser avaliadas de acordo com os principais objetivos, ou seja, onde uma solução pode ser avaliada como sendo mais apropriada que outra em um determinado aspecto. Por exemplo, quando uma das soluções propostas consome menos recursos que uma segunda. A abordagem analítica de críticas é aplicada a problemas menos estruturados, cuja solução incide mais sobre guidelines ou princípios subjetivos. Por exemplo, em projetos de interfaces, nos quais existem muitos itens a serem exibidos na tela, não existe uma regra rígida que obrigue essa exibição através de um menu pop-up.

As abordagens de crítica analitica e diferencial não são mutuamente exclusivas, e sim complementares, podendo ambas serem usadas em um mesmo sistema. Por exemplo, segundo 
Miller (1983a, 1983b), no sistema Attending que critica o uso de anestesia, quando deve ser feita a administração de um anestésico, a escolha da droga envolve riscos e não existe apenas uma droga melhor em determinada situação, então a crítica analítica pode ser empregada. Ao mesmo tempo, anestesiar o paciente é apenas um passo no plano de tratamento e outros passos podem ser erroneamente omitidos pelo sistema, pelo fato de estar usando a abordagem de crítica diferencial. Por exemplo, existem etapas no decorrer de um tratamento que devem ser seguidas, então, pode-se aplicar a abordagem de críticas diferencial.

\subsubsection{Estratégias de Crítica}

Estratégias de crítica determinam quais os aspectos de um projeto que permitem a existência de crítica e como e quando intervir no processo de trabalho do usuário. Estratégias de crítica diferem dependendo do uso predominante do sistema e atuam para ajudar um usuário a resolver seu problema ou a aprender.

Estratégias de crítica podem ser úteis ou não, podem ser um auxílio na realização de objetivos ou apenas interferências no trabalho. Estratégias de crítica podem interferir para melhor ou pior, dependendo da freqüência do feedback, da complexidade das tarefas e da experiência do usuário.

Críticas educacionais, cujo objetivo principal é o suporte ao aprendizado, e críticas de desempenho, cujo objetivo principal é ajudar na produção de produtos melhores, têm diferentes necessidades. Uma crítica de desempenho deve auxiliar usuários a criar produtos de alta qualidade no menor espaço de tempo possível, utilizando poucos recursos. Críticas educacionais, por outro lado, devem maximizar o grau de retenção de informações pelos usuários, para assim melhorar o desempenho futuro deles.

\subsubsection{Como Intervir: as Várias Formas de Críticas}

A maior parte das críticas opera de um modo negativo, isto é, elas apontam para aspectos subótimos do produto dos usuários ou da solução. Uma crítica positiva reconhece as partes boas de uma solução e informa ao usuário sobre elas. Uma crítica positiva ajuda usuários a reter os bons aspectos do produto para futuras revisões; uma crítica educacional positiva reforça o desejo de ação e auxílio no aprendizado. É desta forma que o trabalho de Kukulska-Hulme (1997) nos 
ajuda a entender o conjunto possível de tipos de críticas. Esta autora apresenta uma excelente classificação para críticas realizadas por "referees" de periódicos eletrônicos, de colegas de trabalho dando opiniões sobre versões preliminares de artigos, de comentários de editores e tutores da "The Open University", Inglaterra. As cinco formas de críticas são: elogios, críticas (críticas diretas e críticas indiretas), sugestões positivas (sugestões impessoais para melhorias e sugestões diretas e instruções), comentários sobre os comentários realizados e palavras-chave. Assim, pode-se criticar um trabalho oferecendo também sugestões construtivas. As críticas podem incluir formas especiais de verbos (pode ser, deve ser, deve fazer com que, não seria ruim, etc.), comentários positivos precedendo os negativos (primeiro o elogio) e formas impessoais (por exemplo, utilizar "o artigo pode ser melhorado por..." é melhor que utilizar "você deve..."). Segundo esta autora, a linguagem de críticas deve ser uma mistura de expressões formais e informais, de modo a prender a atenção do usuário. Abaixo ilustramos essas cinco formas de críticas, com os vários exemplos das formas lingüísticas utilizadas:

\section{Elogios:}

In general, the paper made very clear and enjoyable reading.

The writing is clear and direct.

The text is generally clear, and the points are built up carefully.

\section{Críticas:}

\section{Críticas Diretas:}

The results are not clear.

This section raises many questions.

The language is very abstract.

Críticas Indiretas através de perguntas:

What is the wider significance of these facts?

What is the difference, if any, between these methods?

What approaches have others taken? 
Sugestōes Positivas:

Sugestões Impessoais para Melhorias:

The paper could be improved by a more balanced discussion of the results.

This will become more accessible if you provide examples.

Future papers would benefit from a little more detail on your findings.

Sugestões Diretas e Instruções:

I suggest that the introduction be clarified.

Ckeck whether any words can be removed.

Give an example to illustrate this concept.

Comentários sobre os Comentários Realizados

My comments are not exhaustive.

I have two main suggestions.

Apart from the detailed points above, there are a mumber of other matters.

Palavras-chave:

Palavras sobre elementos de escrita:

argument

discussion

structure

Descrições de textos, escrita e linguagem:

clear

direct

specific

Palavras que podem ser usadas para "suavizar" certas afirmaçōes:

a little

not fully

only

Expressões informais:

grasp ideas

make sense of

go on to explain 
Palavras que expressam atitudes e o modo como as coisas podem ser feitas:

clearly

directly

implicitly

\subsubsection{Quando Intervir: o Momento de Apresentaçäo das Críticas}

De acordo com Fischer et al. (1991), em sistemas de critica podemos ter níveis de intervenção diferentes, ou seja, quando e como uma crítica deve acontecer. Sob esse aspecto, estes sistemas podem ser divididos em Sistemas de Crítica Ativos e Sistemas de Crítica Passivos.

Os sistemas de crítica ativos exercem controle sobre a estratégia de intervenção; eles funcionam como agentes ativos monitorando ações de usuários continuamente, realizando críticas quando julgam que uma ação pode ser melhorada ou está incorreta. Para este tipo de intervenção, com o sistema intervindo imediatamente após o acontecimento de uma ação sub-ótima, existe a vantagem de que o contexto do problema está ativo na memória do usuário, porém pode existir a desvantagem de uma crítica interromper um processo cognitivo do usuário, causando a perda do encadeamento de raciocínio. Nesse contexto, será dificil para um usuário disperso retomar a todo instante a sua linha de pensamento após intervenções do sistema de crítica.

Sistemas de crítica ativos podem usar vários modos de intervenção, que diferem no nível que a atenção do usuário é atraída: ele pode forçar o usuário a prestar atenção na crítica, não permitindo que ele continue com o seu trabalho ou pode mostrar as mensagens de crítica em uma janela separada na tela. Isso dá ao usuário a escolha de ler e processar a mensagem imediatamente ou após completar a ação em andamento.

Sistemas de crítica passivos não possuem um controle sobre a estratégia de intervenção. Esta modalidade de sistema deve ser acionada pelo usuário para que exerça sua crítica sobre uma determinada ação. Neste tipo de intervenção, as vantagens e desvantagens são opostas à modalidade anterior, ou seja, a crítica propriamente dita não irá interromper um processo cognitivo, pois foi acionada pelo usuário em um momento apropriado, porém, pode ocorrer do usuário não se lembrar de como chegou a uma determinada ação sobre a qual incidiu uma crítica e esta precisa ser remodelada. 


\subsection{Trabalhos Relacionados}

Descrevemos abaixo, sucintamente, dois sistemas de crítica da literatura. O primeiro deles é, na verdade, uma família de sistemas para a área médica e se encaixa na primeira geração de sistemas de crítica. O segundo, Wombat, é um exemplo de sistema da segunda geração.

\section{ATTENDING/ICON/ROUNDSMAN}

A família de sistemas de auxílio médico $A T T E N D I N G$ é composta de vários softwares: (1) o próprio ATTENDING (Miller, 1983a, 1983b), cujo domínio é relacionado à critica do plano préoperatório de um médico, no que diz respeito ao gerenciamento de anestésico; (2) o $H T$ ATTENDING (Miller \& Black, 1984), projetado para criticar o processo de gerenciamento de medicação de pacientes com hipertensão; (3) o VQ-ATTENDING (Miller, 1985), que é um sistema de crítica direcionado á aspectos do gerenciamento de ventiladores aplicado a um paciente que está recebendo suporte respiratório mecânico; (4) o ICON (Miller et al., 1986), que se destina à crítica do processo de diagnóstico radiológico diferencial, com domínio restrito a pacientes com doença de Hodgkin; e (5) o ROUNDSMAN (Rennels et al., 1987), que é um sistema de crítica que age sobre representações estruturadas de literatura clínica, visando criticar planos para o gerenciamento do câncer de mama. Para utilizar tais sistemas, o cirurgião deve introduzir informações sobre o paciente, como os atuais problemas clínicos e o procedimento clínico, especificando as técnicas a serem utilizadas. Na seqüência, o sistema realiza o processo de crítica do plano, baseando-se nas informações anteriores e nos riscos que o processo implica, além de discutir com o médico os riscos e beneficios da abordagem proposta e propor algumas alternativas razoáveis, permitindo dessa forma, um ótimo processo de feedback para o cirurgião.

\section{WOMBAT}

WOMBAT (Blandford, 1994) é um sistema educacional inteligente que engaja o estudante num processo de resolução de problemas colaborativo e se caracteriza por estar nem sempre certo ou nem sempre errado, e sim, aberto à perguntas e críticas. Para ensinar éstratégias de tomada de 
decisões e estimular o desenvolvimento de habilidades como avaliação crítica e argumentação, ele ensina através de exemplos.

Uma sessão com o WOMBAT é inicializada quando um usuário entra com uma definição do problema a ser resolvido; esta definição de problema é caracterizada como uma lista de necessidades, desejos de critérios a serem otimizados e palavras-chave. A interação acontece com o sistema exteriorizando sentenças no topo do vídeo e o usuário construindo respostas pela digitação em uma caixa de diálogo de texto livre ou pela utilização de botões apropriados.

A interą̧ão entre usuário e sistema se dá através de um diálogo, que possui características importantes, como:

- O desenrolar do diálogo é dependente das declarações de ambos os participantes e é possivel imaginar um número quase infinito de diálogos diferentes que começaram todos no mesmo ponto, onde cada participante responde dentro do contexto do diálogo e suas declarações são entendidas no mesmo contexto; o sistema não possui um plano de como o diálogo vai se desenrolar e sim decide o que dizer depend endo do contexto e do desenrolar da interação;

- O sistema não força uma tomada de decisão e sim tenta fazer com que o usuário pense sobre o que ele está dizendo, pois sistema e usuário têm diferentes papéis na interação;

- O sistema não é prescritivo, pois não se comporta como se soubesse todas as respostas; ele pode aceitar discussões sobre as quais não possui informações e não possui uma noção préconcebida de que tipo de resposta deve ser dado a uma pergunta, sendo capaz de negociar um acordo; e

- O sistema é capaz de discutir não apenas aspectos do problema, mas também como o problema pode ser resolvido.

\subsection{Considerações Finais}

A utilização de sistemas de crítica integrados ao ambiente de projeto é um importante passo em direção à criação de sistemas baseados em conhecimento que sejam úteis e efetivos (Fischer et al., 1993). O objetivo dos sistemas de crítica é criticar o objeto certo, no momento certo, e com isso disponibilizar críticas eficientes e coerentes e que propiciem, acima de tudo, o aprendizado. Segundo Fischer (1996), nós precisamos de ambientes computacionais que suportem novas estruturas de educação, integração de trabalho e aprendizado, aprendizado 
direcionado, informação contextualizada e aprendizado colaborativo. Para atingir esses objetivos, é necessário o entrelaçamento de tecnologia com aprendizado e trabalho. 


\section{Uma Ferramenta de Crítica para a Escrita de Introduções}

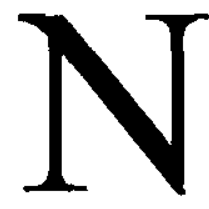

o capítulo anterior revisamos as pesquisas sobre a abordagem de críticas. Neste capítulo apresentamos as decisões de projeto para a construção de uma ferramenta de ensino à escrita técnica em inglês, baseada na abordagem de críticas, e destinada à escrita da seção introdutória de artigos científicos.

Este capítulo inicia com a descrição da estrutura dual utilizada na anotação dos cinqüenta e um (51) artigos do corpus da comunidade de pesquisa CHI (Subseção 5.1). Detalhes da análise de corpus são também abordados. A seguir descrevemos os módulos e processos de um modelo computacional para ferramentas de crítica (Subseção 5.2). Na Subseção 5.3 o enfoque principal é dado à metodologia utilizada para a definição e implementação do conhecimento utilizado no protótipo da ferramenta de crítica e, para finalizar (na Subseção 5.4) é feita uma descrição da arquitetura do protótipo desenvolvido. 


\subsection{Uma Estrutura Dual para Anotar Artigos Técnicos de uma Comunidade de Pesquisa}

Esta seção aborda informações sobre (i) seleção e análise de um corpus de artigos da comunidade CHI, (ii) a estrutura dual utilizada para anotar o corpus e (iii) apresentação de um exemplo de artigo marcado/anotado com a estrutura dual.

\subsubsection{Análise de Corpus: Introduções de Artigos Científicos}

A análise do corpus referente a este trabalho se restringiu à seção de Introdução das publicações da CHI'96 da seção de papers (outra possibilidade seria a seção de short papers). Escolhemos analisar Introduções porque elas são uma das partes mais dificeis de serem escritas. É na Introdução que o autor deve convencer a comunidade de pesquisa sobre a relevância de seu trabalho, principalmente nesta era de crescimento exponencial e făcil acesso da literatura. Ele possui a função de resumir as informações que o leitor vai encontrar no artigo, às vezes descrevendo sucintamente ou fornecendo indicações do que se encontrará em outras seções (veja figura 5.3 para um exemplo de Introdução), sendo, juntamente com o abstract, um elemento decisório de escolha do leitor por continuar a leitura do artigo ou não. Além disso, possui uma posição estratégica no artigo e as primeiras impressões realmente importam. Dentre os cinqüenta e três (53) artigos disponiveis da seção de papers, foram excluídos dois (02) por se constituírem de exemplos de introduções destoantes dos demais (eram longas demais e abusivas em termos de itemização), totalizando, desta forma, um corpus de cinqüenta e um (51) artigos, chamados aqui de casos. Não se pode garantir que todos os artigos tenham uma excelente qualidade de escrita, mesmo tendo sido publicados em uma conferência bastante conceituada como é a $\mathrm{CHI}$. Entretanto, se fosse utilizada uma seleção por inspeção, seria incluída a variável de um julgamento subjetivo e a amostra poderia estar viciada, já que seria dada prioridade aos estilos prediletos $\mathrm{do}(\mathrm{s})$ inspetor(es).

Os artigos publicados na CHI'96 foram escolhidos não somente porque ela é uma conferência bastante prestigiada, mas também porque eles devem obedecer diversos requisitos rigorosos para serem aceitos. Além disso, ela apresenta uma grande variedade de tipos de artigos cujo conhecimento relativo aos tipos de informações que diferencia cada tipo pode ser reutilizado se a ferramenta for portada para uma nova comunidade.

Os artigos foram escolhidos de forma a constituirem amostras para cada um dos seis (06) 
tipos de submissões/artigos aceitos naquela conferência (Figura 5.1), sendo que cada tipo está sendo representado por publicações de autores diferentes, com exceção da classe opinion que não foi contemplada nesta conferência. Para cada tipo de artigo, temos a seguinte quantidade de representantes para cinco das seis classes: dezesseis (16) do tipo empirical, oito (08) do tipo methodology, sete (07) do tipo theory, sete (07) do tipo experience e treze (13) do tipo system.

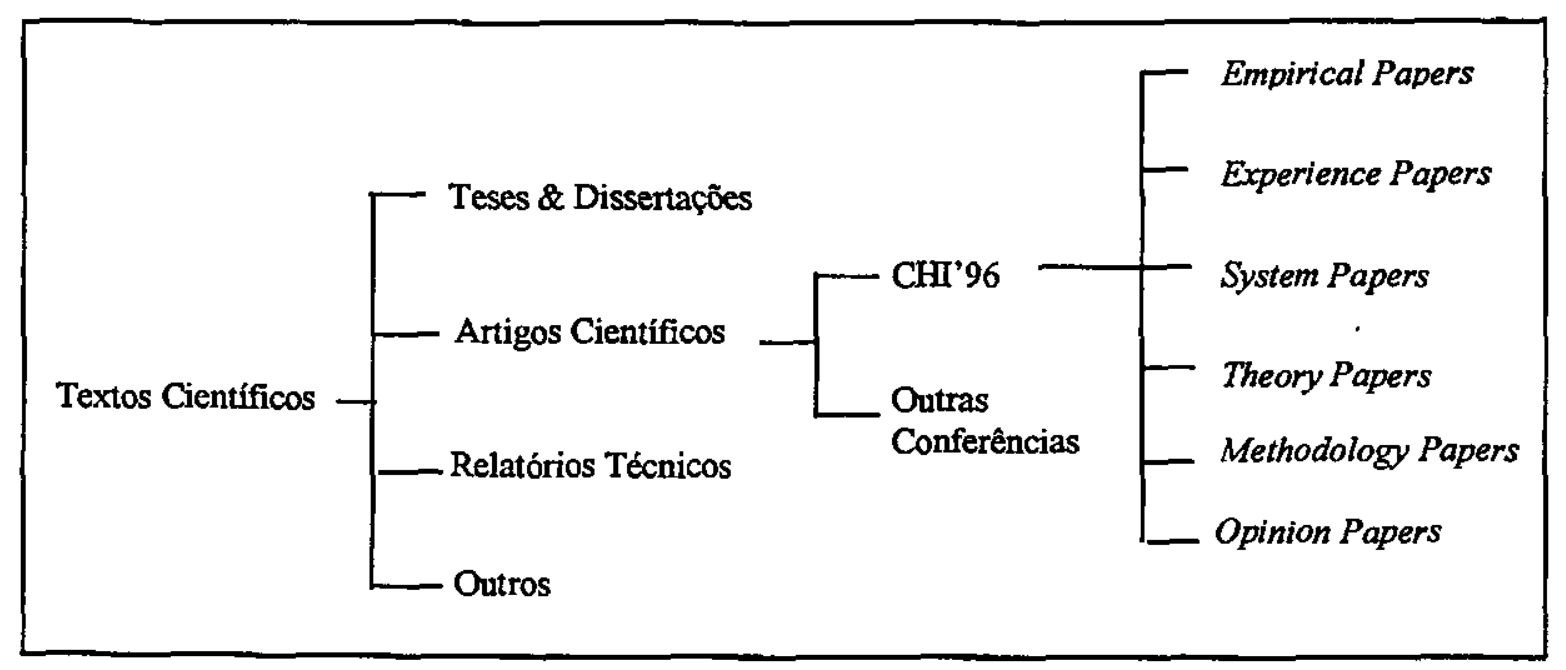

Figura 5.1: Tipos de Submissões de Artigos da CHI'96

Abaixo descrevemos cada tipo de submissão:

- Empirical Papers: descrevem a coleção e interpretação de dados relativos ao projeto ou uso de um artefato de Interação Usuário-Computador (IUC);

- Experience Papers: descrevem a aplicação de métodos, teoria ou ferramentas para o projeto ou desenvolvimento de um artefato de IUC;

- System Papers: descrevem o software e tecnologia associada e/ou uma nova aplicação interativa, característica de interface com usuário, o projeto de interface com usuário ou ferramenta de desenvolvimento;

- Theory Papers: descrevem princípios, conceitos ou modelos sobre os quais os trabalhos empíricos, de experiência ou metodologia se baseiam;

- Methodology Papers: enfocam um novo método para o projeto ou avaliação de um artefato de IUC; e

- Opinion Papers: apresentam uma opinião bem argumentada sobre algum aspecto de IUC. 
5.1.2 Utilização de uma Estrutura Dual em Artigos da Comunidade de Pesquisa CHI

A estrutura dual utilizada neste trabalho é composta de uma estrutura esquemática (nos moldes do trabalho de Aluísio (1995)) e de uma estrutura de critérios especificos para os cinco tipos de artigos representados na conferência. As informações utilizadas para a elaboração dos componentes e subcomponentes da estrutura dual para a comunidade $\mathrm{CHI}$ foram obtidas da chamada de trabaihos da CHI'96. Para a elaboração da estrutura esquemática utilizamos os critérios genéricos de papers e, para a estrutura de critérios específicos, os próprios critérios específicos para a submissão dos seis tipos de artigos da $\mathrm{CHI}$ '96, constante na chamada de trabaihos, encontrada na World We Web http:/www.acm.org/turing/sigs/sigchi/chi96/call/papers/. Os componentes e subcomponentes da estrutura de componentes esquemáticos são apresentados na Tabela 5.1. Na Tabela 5.2 são apresentados os componentes dos 5 tipos de artigos contemplados na CHI'96. Ao lado de cada componente/subcomponente, mostramos a sua tradução, pois grande parte da interface trabalha com termos em inglês.

Tabela 5.1: Componentes da Estrutura Esquemática de Artigos da CHI’96

Contexto: área de pesquisa (Context)

- Domínio do assunto a ser tratado (Domain)

Contribuições: relações do trabalho com trabalhos similares na área (Contribution(s))

- Trabalhos Relacionados (Related Work(s))

- O que está faltando na literatura/Necessidade de mais investigação (Background)

Conteúdo: a mensagem principal do artigo e o porquê a audiência deve acreditar nessa mensagem (Content)

- Propósito (Purpose)

- Descrição do que foi feito/Resultados Alcançados (What 's been done)

- Metodologia que foi aplicada (Methodology applied)

- Justificativas (Rationale)

Conseqüências: as implicações práticas conseguidas se a audiência utilizar as idéias da pesquisa (Consequence(s))

- Lições Aprendidas (Lesson(s) learned)

- Inovaçőes (Innovation(s))

- Trabalhos futuros (Future work(s))

Estrutura: relata a estrutura do artigo (Structure) 
Tabela 5.2: Componentes da Estrutura de Critérios Especificos para Submissão de Artigos da CHI'96

\begin{tabular}{|c|c|}
\hline Empirical Papers & $\begin{array}{l}\text { - Descrição da coleção de dados (entrevistas, observações, } \\
\text { levantamento/estudo ou manipulações experimentais) } \\
\text { - Interpretação dos dados (através de análise quantitativa - testes } \\
\text { estatísticos - ou qualitativa) }\end{array}$ \\
\hline Experience Papers & $\begin{array}{l}\text { - Descrição da aplicação de métodos, teorias ou ferramentas } \\
\text { - Descrição das reflexð̌es abstrádas da experiência } \\
\text { - Declaração do valor da experiência para outros projetistas ou } \\
\text { pesquisadores trabalhando em métodos, teorias ou ferramentas } \\
\text { relacionadas }\end{array}$ \\
\hline Theory Papers & $\begin{array}{l}\text { - Descrição dos princípios, conceitos ou modelos } \\
\text { - Posicionamento das idéias dentro de um contexto abrangente de } \\
\text { frameworks e teorias } \\
\text { - Declaração do valor do conteúdo térico para a prática e/ou } \\
\text { pesquisa }\end{array}$ \\
\hline System Papers & $\begin{array}{l}\text { - Descrição do software e tecnologia utilizados } \\
\text { - Descrição da arquitetura do sistema } \\
\text { - Descrição do comportamento do sistema } \\
\text { - Descrição do que da arquitetura foi implementado } \\
\text { - Descrição do que foi avaliado através de critérios de engenharia de } \\
\text { software ou usabilidade }\end{array}$ \\
\hline Methodology Papers & $\begin{array}{l}\text { - Descrição de um novo método para projeto ou para avaliação } \\
\text { - Declaração de qual é a audiência pretendida (pesquisa ou } \\
\text { desenvolvimento) } \\
\text { - Declaração de qual é a utilidade para a audiência a que se destina } \\
\text { o método }\end{array}$ \\
\hline
\end{tabular}

Existe na literatura pelo menos um exemplo de uso de uma estrutura dual para representar documentos: o trabalho de Branting e Lester (1996a, 1996b). Eles advogam o uso de estruturas ilocutória e retórica, explícitas e separadas para serem usadas em um protótipo de geração automática de documentos legais. As vantagens dessa abordagem são pelo menos três:

- Ela facilita a aquisição de conhecimento, pois separando as estruturas dependentes de domínio (por exemplo, uma jurisdição particular) das dependentes do gênero de textos legais, não há 
duplicação de conhecimento do sistema sempre que uma nova jurisdição for acomodada - o conhecimento retórico permanece para um novo domínio;

- Ela facilita a validação, pois cada componente pode ser testado separadamente; e

- Ela facilita a manuteņ̧ão, pois tanto a estrutura retórica como a ilocutória pode ser modificada sem afetar uma a outra.

Nosso trabalho foi motivado pelo trabalho desses autores e a justificativa no nosso caso para o uso das estruturas esquemática e de critérios especificos de submissão de artigos, se dá também pelas três vantagens acima. A estrutura esquemática para os vários tipos de artigos parece ser um consenso para a Computação e outras áreas, e a estrutura de critérios específicos vai variar de comunidade para comunidade, pois cada conferência explicita os tipos de submissões que são aceitos.

Um exemplo de estrutura dual para um artigo da CHI'96 pode ser visto na Figura 5.2, que ilustra uma introdução de artigo do tipo System. Na estrutura de critérios específicos, encontramos a palavra "Indicação" sempre que o trecho de texto funciona como um ponteiro para o que será encontrado no corpo do artigo. Outra op̧̧ão seria a trecho realmente descrever algum componente. 
Contribuiçōes:

Trabalhos

relacionados

Contexto:

Domínio do

assunto a ser

tratado

Contribuições: $\rightarrow$ Background

Conteúdo:

Propósito

Conteúdo:

Descrição do que foi feito

\section{Estrutura}

1) Software agents are the focus of much interest in the popular press and are a hot research topic in humancomputer interaction $[3,5,7,8,9,10,12]$, artificial intelligence [16], and distributed computing [15].

2) $\mathrm{HCl}$ research on agents can be distinguished by its users-centered approach. The focus is on how agents can empower users to work more effectively in the vast, rich, ever-changing world of electronic communication and information.

3) One of the major promises of agents is personal assistance -- each user can have an agent that serves his or her individual goal and preferences. This means that the agent must acquire appropriate knowledge about the user.

4) This paper advocates an end-user programming, human-computer collaboration [13] approach to this problem.

5) We have created a system called the Agent Manager that embodies the approach.

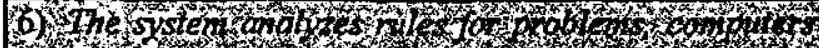

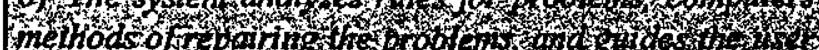

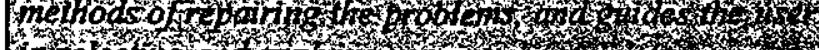

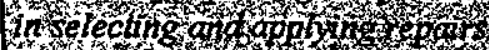

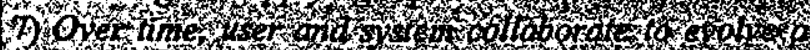

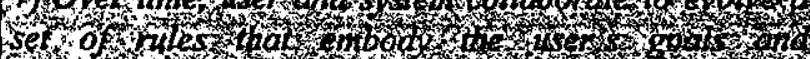
preferences

8) We begin the paper by presenting a framework for agents that lets us identify the type of knowledge a person agent requires.

9) We then analyze existing approaches to agent personalization, showing when an end-user programming approach is appropriate and motivating the unique features of our system.

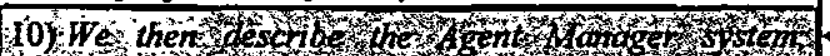

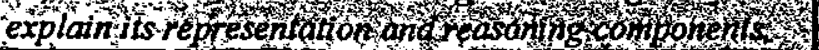

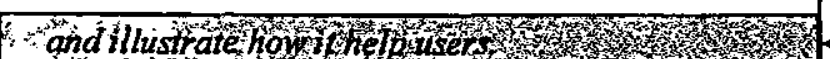

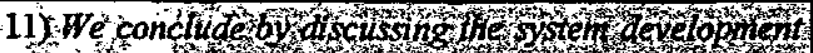
process; its culrentstaft, w,

and our future plans.

Terveen, L.G. and Murray, L.T. Helping Users Program Their Personal Agents. CHI'96.
Descrição do comportamento do sistema
Indicação de: Descrição da arcuitetura Indicação de: Comportamento do sistema Indicação de: Descrição do que da arquitetura foi realmente implementado

Figura 5.2: A Estrutura Dual para uma Introdução Classificada como Tipo System 


\subsection{Um Modelo Computacional para a Construção de Ferramentas de Crítica para a Escrita Técnica}

Como abordado anteriormente (Subseção 4.3), Fischer (1991) propôs um modelo para ferramentas de crítica que consta de determinados módulos e processos. Realizamos então, uma análise mais aprofundada desse modelo, com a intenção de projetarmos um modelo próprio para construção de ferramentas de crítica que atue no domínio da escrita técnica. Para a nossa aplicação nem todos os módulos e processos do modelo de Fischer se fizeram necessários, assim como outros elementos poderiam ser inseridos.

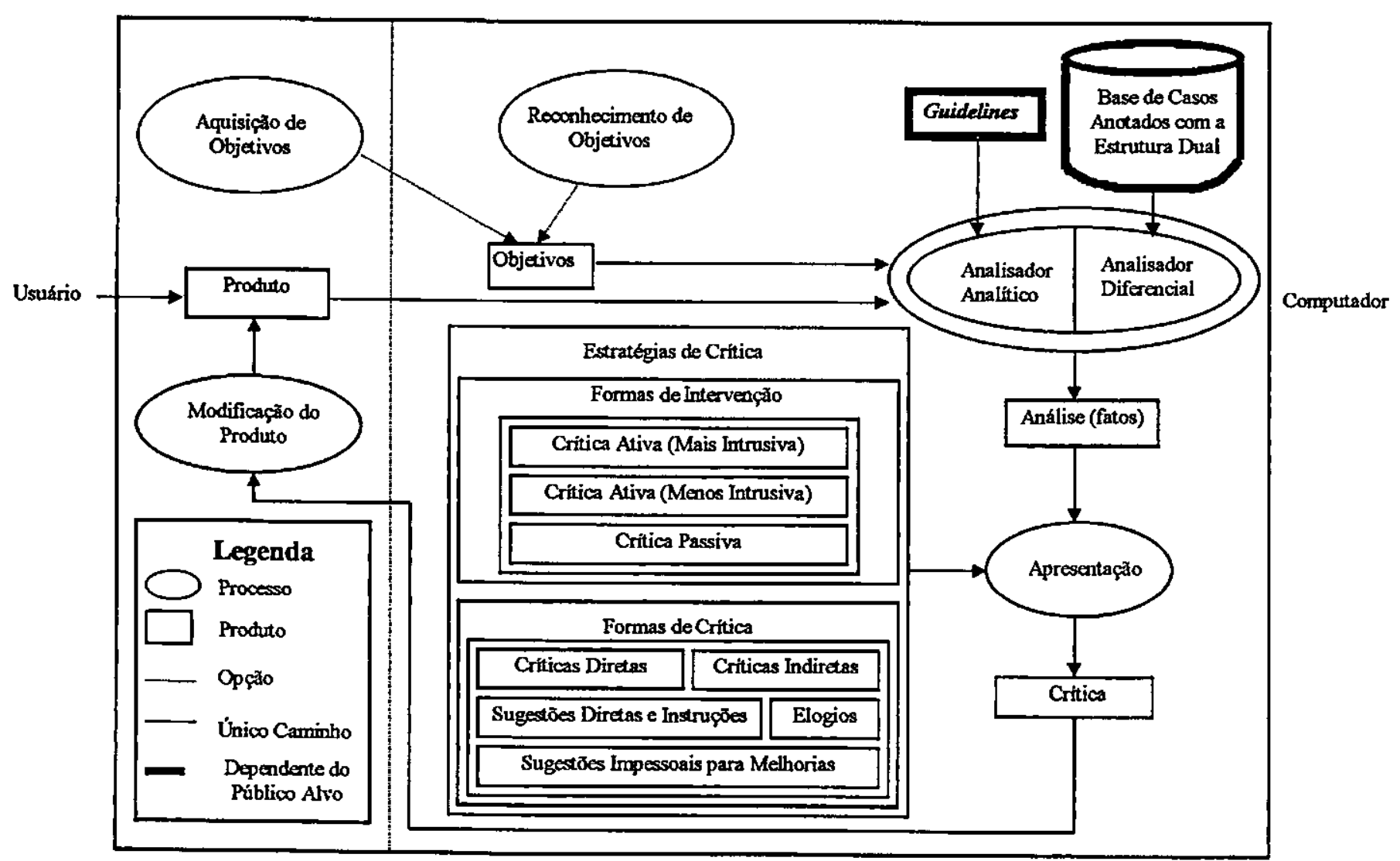

Figura 5.3: Modelo Computacional para Ferramentas de Crítica para a Escrita Técnica

Como ilustra a Figura 5.3, o processo de crítica projetado e proposto neste trabalho se inicia assim que o usuário apresenta um produto para a ferramenta. Por exemplo, no nosso domínio o produto se compõe da estrutura dual descrita na Subseção 5.1. Nada impede que as críticas sejam dirigidas à sintaxe da escrita ou à escolha de itens lexicais do texto. Para criticá-lo, a ferramenta deve obter o(s) objetivo(s) do usuário. Isto pode ser feito através de dois processos 
mutuamente exclusivos: (1) Reconhecimento de Objetivos, em que o sistema reconhece o objetivo do usuário através das escolhas utilizadas no produto, ou (2) Aquisição de Objetivos, em que o sistema utiliza informações explícitas fornecidas pelo usuário durante uma entrevista a parte.

Certamente, se o crítico tem um grande conhecimento sobre os objetivos pretendidos para o produto, as críticas serão mais eficientes. Esta aquisição de objetivos pode ser, por exemplo, a escolha do tamanho do artigo a ser trabalhado (short paper ou long paper), e/ou a escolha do usuário por um determinado tipo de artigo. Para o protótipo atual, utilizamos somente informaçð̃es sobre a estrutura esquemática. Nenhuma crítica é dirigida à estrutura de critérios específicos. Esta parte será realizada em trabalhos futuros.

Tendo os objetivos do usuário, o nosso modelo utiliza dois tipos de analisadores para avaliar o produto: o Analisador Analítico e o Diferencial. $O$ Analítico analisa o produto através de regras heurísticas/guidelines encontradas em chamadas de trabalhos de conferências, que servem para ajudar o escritor a adequar o seu artigo para a comunidade em questão ou para ajudar o revisor avaliar o artigo. O Diferencial age a partir dos resultados da comparação do produto com diversos casos armazenados em uma base, num esquema típico de RBC. Como indicado na Figura 5.1, o conhecimento desses dois analisadores é dependente do público alvo, ou seja, devem ser mudados se houver a intenção de se utilizar o protótipo construído para outra comunidade de pesquisa.

No caso específico do protótipo implementado, o Analisador Analítico é responsável, por exemplo, por apontar (i) a ausência de componentes essenciais ao artigo, (ii) uma boa escolha de componentes ou mesmo (iii) a irrelevância de certas ações, como alterar a ordem de componentes específicos ou inserir componentes iguais consecutivos. Este analisador trabalha baseado nas regras heurísticas/guidelines que foram extraidas da chamada de trabalhos da CHI'96.

O Analisador Diferencial, por sua vez, escolhe casos relevantes ao estágio atual de construção e ressalta as diferenças e semelhanças destes com o produto apresentado. Dessa forma, este analisador pode, por exemplo, recuperar casos que permitam ao usuário visualizar estruturas e consequentemente fazer alterações na ordem em que os componentes estão dispostos, ao constatar (i) que há casos cujo conjunto de componentes é semelhante ao do produto, mas (ii) que, em nenhum deles, a ordem em que esses componentes aparecem se assemelha à do produto.

Os dois analisadores geram fatos a respeito da análise do produto a partir das regras 
heurísticas/guidelines e de suas diferenças/semelhanças com os casos da base. $\mathrm{O}$ componente Apresentação vai então mostrar estes fatos ao usuário da forma mais adequada possível, baseando-se em um conjunto de Estratégias de Crítica. Então, alimentado com críticas apresentadas em cinco possíveis formas ${ }^{6}$ (Elogios, Críticas Diretas, Críticas Indiretas, Sugestões Diretas e Instruções e Sugestões Impessoais para melhorias), o usuário gera uma nova versão do produto e o ciclo se repete.

Quanto ao momento de ativação da crítica, de acordo com a classificação de Fischer (1996), os sistemas de crítica podem apresentar intervenções ativas e/ou passivas. Uma crítica passiva só é gerada quando explicitamente requisitada pelo usuário, no momento em que ele bem desejar; enquanto que uma crítica ativa é automaticamente apresentada pelo sistema no decorrer da sua utilização.

Quanto às críticas ativas, elas podem ser mais ou menos intrusivas, isto é, se a crítica ativa for mais intrusiva, o usuário deverá interromper o que estiver fazendo, se voltar para a crítica e somente depois prosseguir suas atividades; por outro lado, se a crítica ativa for menos intrusiva, 0 usuário poderá continuar sua atividade e se voltar para a crítica quando desejar. $O$ pequeno grau de intrusão da crítica ativa menos intrusiva se caracteriza simplesmente pelo aparecimento da crítica na tela, que, mesmo deixando o usuário prosseguir a sua ação, chama-lhe a atenção, desviando, mesmo que ligeiramente, da sua linha de raciocínio.

Na Subseção 5.4 apresentamos uma instância deste modelo utilizado na construção de um protótipo para a comunidade $\mathrm{CHI}$.

\subsection{Metodologia para a Construção do Conhecimento Utilizado nas Ferramentas de Crítica}

Esta seção tem por objetivo descrever as tarefas que devem ser realizadas na definição e implementação do conhecimento utilizado pelo protótipo de uma ferramenta de crítica para a escrita técnica de artigos de uma comunidade de pesquisa - e que foram executadas durante a realização deste trabalho para a comunidade da $\mathrm{CHI}$. $\mathrm{O}$ protótipo construído pode também ser

\footnotetext{
${ }^{6}$ A classificação utilizada para as criticas foi baseada no trabalho de Kukulska-Hulme (1997), apresentado na Subseção 4.3.3.1.
} 
adaptado para ser utilizado por outra comunidade alvo. Esta adaptação é feita em cinco (5) passos:

A primeira tarefa constitui da escolha do(s) tipo(s) de texto científico e da coleta do material que irá formar o corpus a ser analisado.

A segunda tarefa consiste do levantamento dos componentes e subcomponentes presentes em uma determinada seção dos artigos, por exemplo, na Introdução - como foi realizado neste trabalho. Estes padrões de textos devem ser elaborados levando-se em consideração as informações obtidas na chamada de trabalhos da qual o corpus foi coletado. Se a chamada de trabalhos for sucinta e superficial quanto a esta informação deve-se recorrer a livros sobre escrita técnica, como por exemplo, Weissberg (1990) e Swales (1990). Neste trabalho de mestrado, como já mencionado anteriormente, o corpus foi coletado da CHI'96 e os padrões de textos foram organizados de acordo com informações obtidas na chamada para trabalhos da conferência. Como resultado obtivemos duas estruturas: uma genérica que pode ser utilizada para várias comunidades - chamada estrutura esquemática - e uma específica para a $\mathrm{CHI}$, chamada estrutura de critérios específicos de artigos da CHI'96 (apresentadas na Subseção 5.1.2).

A terceira tarefa é a análise e anotação do corpus coletado. $\mathrm{Na}$ análise inicial deve-se realizar a leitura dos Abstracts e, se necessário, de outras seções componentes do artigo, para que o artigo em questão possa ser classificado corretamente como um dos tipos aceitos na conferência. Ainda nesta etapa, deve-se identificar em cada um dos artigos, os componentes da estrutura dual. Esta etapa se constitui como uma das mais importantes, pois a correta identificação e segmentação dos componentes são fundamentais para o sucesso da ferramenta, uma vez que esta análise irá gerar a base de casos anotados utilizados pelo protótipo.

Como quarta tarefa, deve ser realizada a codificação do corpus em casos (utilizando qualquer forma de representação de conhecimento utilizado em IA, como, por exemplo, frames ou redes semânticas). A base de casos mantém informações sobre a estrutura de componentes esquemáticos e a estrutura de componentes específicos.

Ainda nesta etapa, pode ser realizada uma análise mais aprofundada do corpus, para que se possa extrair e codificar regras heurísticas/guidelines (como as que podem ser vistas na Seção 5.4.3.2). As regras heurísticas/guidelines checam o produto do usuário e geram críticas que são apresentadas aos usuários do protótipo. Para a extração de regras heurísticas podem ser utilizados algoritmos de aprendizado de máquina. 
Os casos, as estruturas e as regras heurísticas/guidelines compõem o conhecimento do sistema.

A quinta tarefa é preparar os textos dos artigos que contém a estrutura dual anotada para serem visualizados com um software de apresentação, como um browser HyperText Markup Language (HTML) ou Standard Generalized Markup Language (SGML). Por exemplo, o Panorama PRO é um browser SGML para a WWW que permite ao usuário um maior controle de como mostrar documentos, uma vez que permite a criação de múltiplas formatações de textos e estes são anotados na forma de tags. Um exemplo de como os artigos devem ser anotados no Panorama PRO, em relação à estrutura esquemática, é mostrado na Figura 5.4; na Figura 5.5 visualizamos o Document Type Definition (DTD) para a esta estrutura. A Figura 5.6 ilustra um artigo anotado em relação à estrutura de critérios específicos, e seu DTD relacionado aparece na Figura 5.7. A maneira como os casos são visualizados no Panorama PRO pode ser visualizada na Figura 5.8.

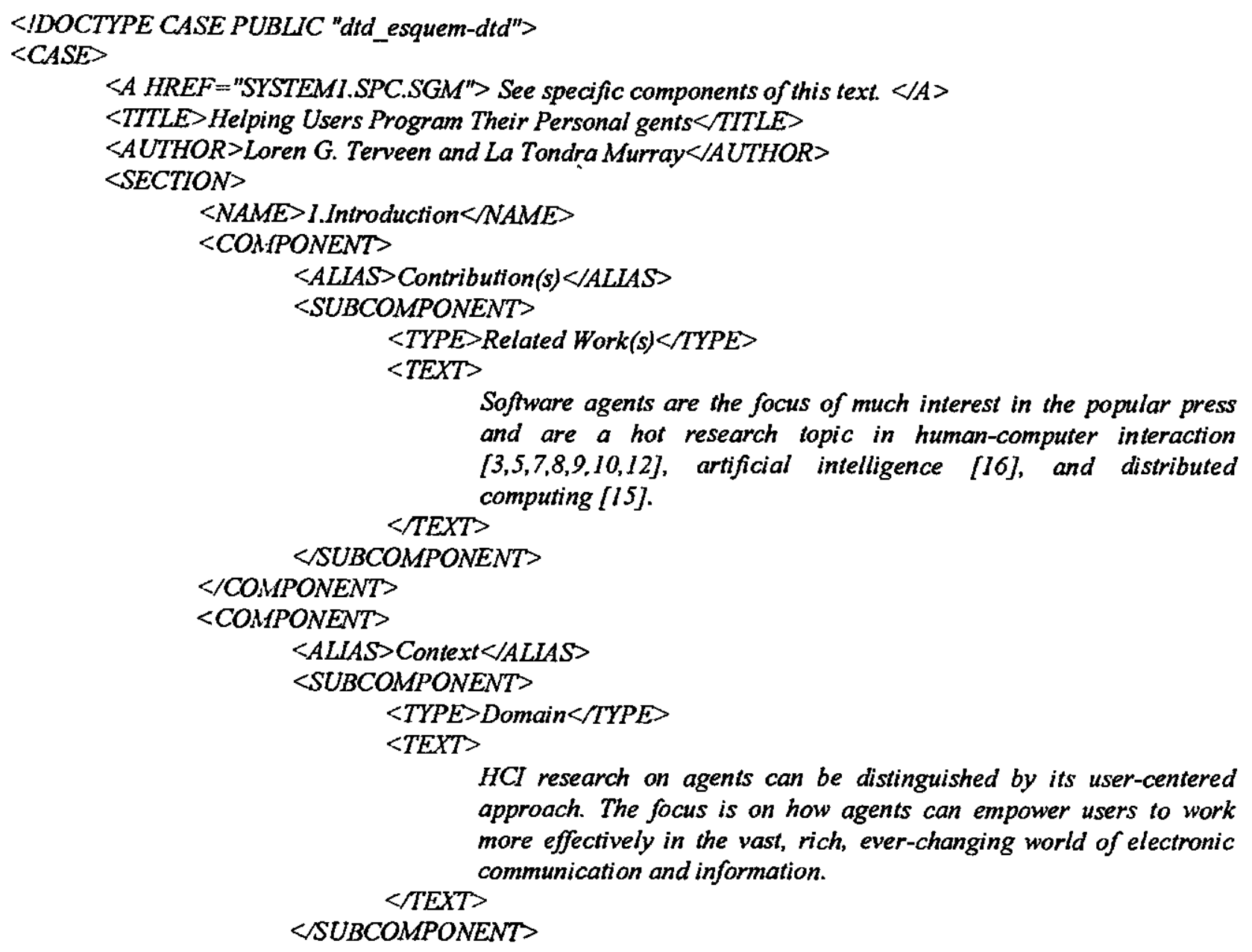

Software agents are the focus of much interest in the popular press and are a hot research topic in human-computer interaction $[3,5,7,8,9,10,12]$, artificial intelligence [16], and distributed

$H C I$ research on agents can be distinguished by its user-centered approach. The focus is on how agents can empower users to work more effectively in the vast, rich, ever-changing world of electronic $</ T E X T>$ communication and information. 


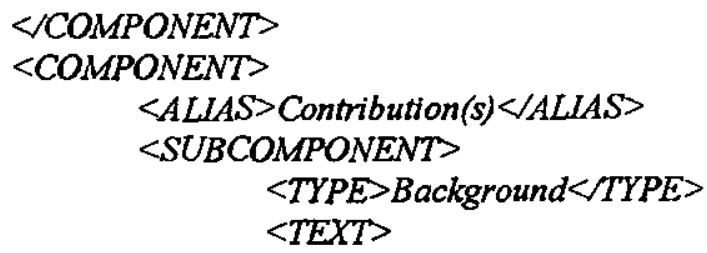

One of the major promises of agents is personal assistance - each user can have an agent that serves his or her individual goals and preferences. This means that the agent must acquire appropriate knowledge about the user.

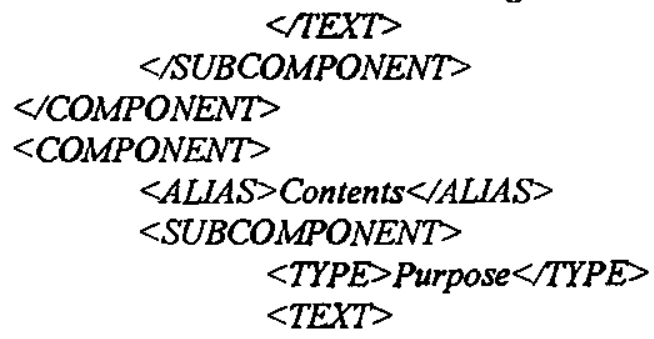
$<T E X T>$

This paper advocates an end-user programming, human-computer $\langle T E X T>$ collaboration [13] approach to this problem.

We have created a system called the Agent Manager that embodies the approach. Users state rules with a domain-specific graphical interface. The system analyzes rules for problems, computes methods of repairing the problems, and system collaborate to evolve a set of $<$ TEXT> rules that embody the user's goals and preferences.

$</ C O M P O N E N T\rangle$

$</ S U B C O M P O N E N T>$

$<$ COMPONENT $>$

$<A L I A S>$ Structure $</ A L I A S>$

$<$ SUBCOMPONENT $>$

$<T Y P E>$ Structure $</ T Y P E>$

$<$ TEXT>

We begin the paper by presenting a framework for agents that lets us identify the type of knowledge a personal agent requires. We then analyze existing approaches to agent personalization, showing when an end-user programming approach is appropriate and motivating the unique features of our system. We then describe the Agent Manager system, explain its representation and reasaning components, and illustrate how it helps users. We conclude by discussing the system $<$ TEXT> development process, its current status, and our future plans.

$</ S E C T I O N>$

$</ S U B C O M P O N E N T>$

$</ C A S E>$

$</ C O M P O N E N T\rangle$

Figura 5.4: Um Caso Codificado no Panorama PRO em Relação à Estrutura de Componentes Esquemáticos 


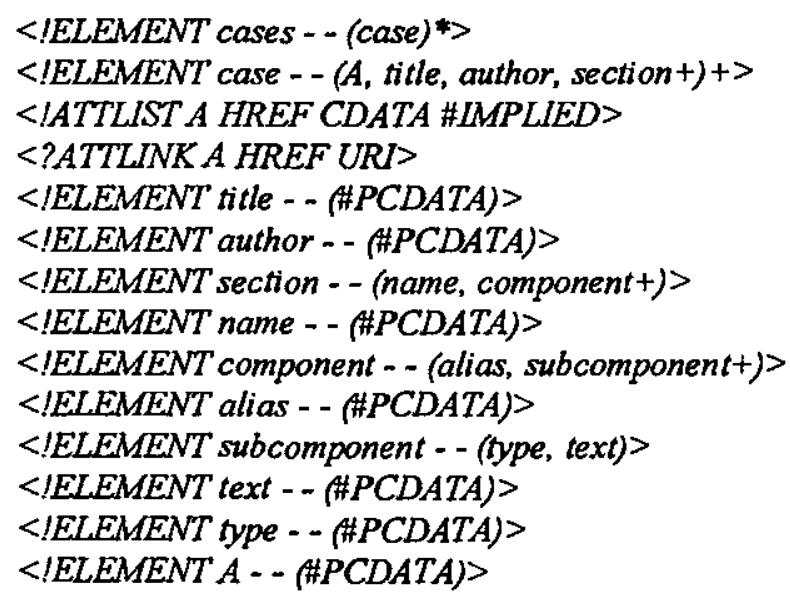

Figura 5.5: DTD de Componentes Esquemáticos

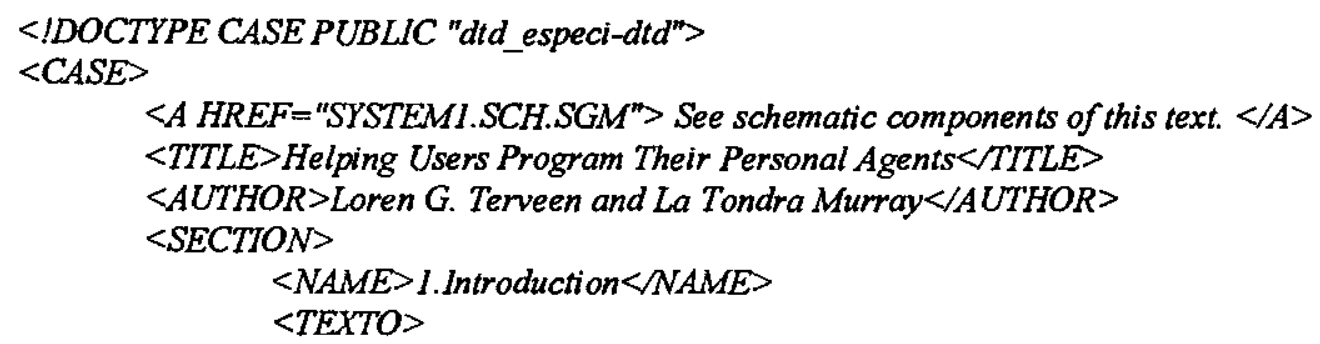

Software agents are the focus of much interest in the popular press and are a hot research topic in human-computer interaction $[3,5,7,8,9,10,12]$, artificial intelligence [16], and distributed computing [15]. $\mathrm{HCl}$ research on agents can be distinguished by its user-centered approach. The focus is on how agents can empower users to work more effectively in the vast, rich, ever-changing world of electronic communication and information.

One of the major promises of agents is personal assistance -- each user can have an agent that serves his or her individual goals and preferences. This means that the agent must acquire appropriate knowledge about the user. This paper advocates an end-user programming, human-computer collaboration [13] approach to this problem. We have created a system called the Agent Manager that embodies the approach. Users state rules with a domain-specific graphical interface. $<$ TEYTO >

$<C O M P O N E N T>$

$<A L L A S>$ System's behaviour $</ A L L A S>$

$<T E X T>$

The system analyzes rules for problems, computes methods of repairing the problems, and guides the user in selecting and applying repairs. Over time. user and system collaborate to evolve a set of rules that embody the user's $<T E X T>$ goals and preferences. 


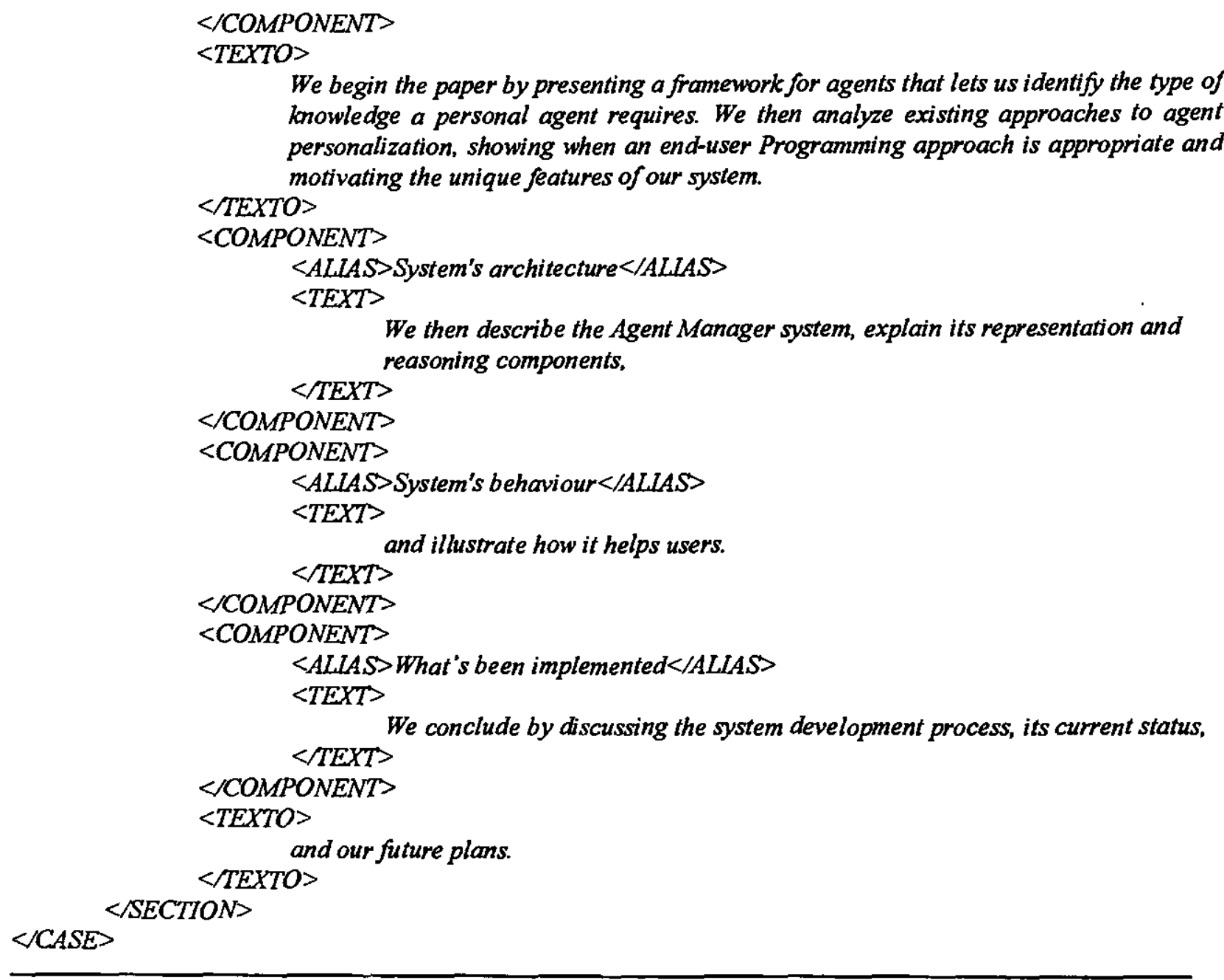

Figura 5.6: Um Caso Codificado no Panorama PRO em Relação à Estrutura de Componentes Específicos

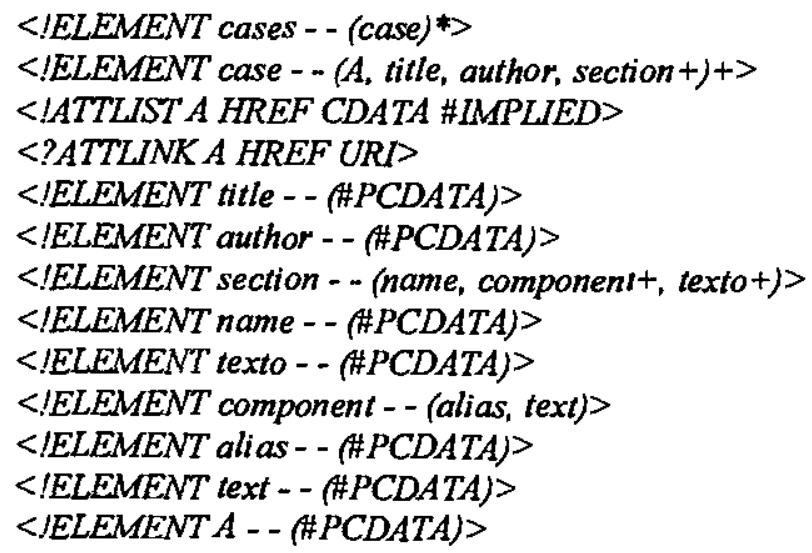




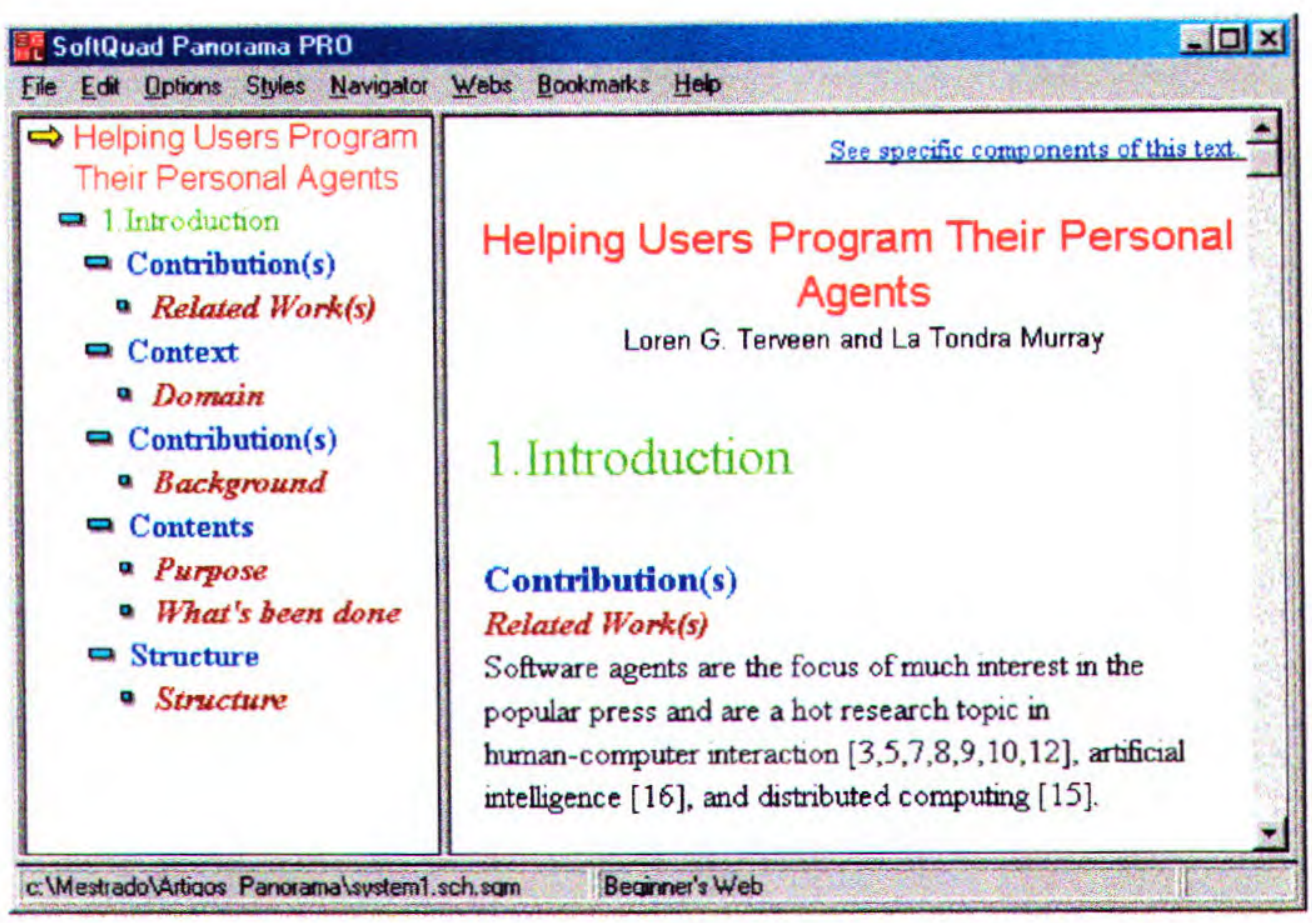

Figura 5.8: Um Caso Visualizado no Panorama PRO

\subsection{O Protótipo de Uma Ferramenta de Crítica para a Escrita de Introduções}

Um sistema de crítica pode ser visto como um sistema de colaboração entre agentes, um dos quais é artificial, o crítico (Fischer et al., 1991). Para o projeto e implementação desta abordagem, trabalhamos basicamente com:

- A elaboração de uma plataforma multiagente distribuída para a construção de estruturas em árvore, denominada Lego, composta por três módulos: Lego Middleware, Lego Workbench e Lego Prolog Agent;

- A geração de uma linguagem para representar artigos da $\mathrm{CHI}$ como estruturas em árvore, representando, em um alto nivel, os objetivos genéricos e específicos de um artigo; e

- A programação de um agente artificial (crítico) que auxiliasse o usuário a dominar a linguagem em questão. Nesse caso, espera-se que um usuário proficiente tenha aprendido a organizar e até escrever artigos segundo os critérios da $\mathrm{CHI}$.

Essas atividades são detalhadas nas três subseções seguintes. 


\subsubsection{Plataforma Multiagente Distribuída Subjacente ao Protótipo}

Foi desenvolvido um sistema que suporta adequadamente a colaboração entre diversos agentes (possivelmente heterogêneos e distribuídos) na construção de estruturas em árvore - outlines (veja Subseção 5.4.2 para maiores detalhes), para servir de plataforma à ferramenta de ensino da escrita técnica em Inglês seguindo a abordagem de criticas.

Este sistema resulta da articulação dos seguintes módulos: (a) Lego Middleware, um subsistema de comunicação inter-agentes, compreendendo um servidor simples de broadcast e uma pilha de protocolos para difundir primitivas de transformação estrutural e emissão de opiniões; (b) Lego Workbench, um ambiente gráfico de trabalho por meio do qual um usuário pode funcionar confortável e efetivamente como colaborador e que não só representa o fluxo inter-agentes de informação numa forma estruturada e amigável como também favorece o domínio do vocabulário em uso; e (c) Lego Prolog Agent, um arcabouço para agentes artificiais a serem programados em Prolog, munido de plenos poderes expressivos, sensibilidade às ações de seus colaboradores e predicados para reconhecer padrões na estrutura em construção ou quantificar a similaridade desta com outras preexistentes. Na seqüência, abordamos cada um desses módulos de forma mais detalhada.

\subsubsection{Lego Middleware}

Como já mencionado, para que agentes humanos e artificiais possam colaborar no desenvolvimento de um projeto, é necessário que eles sejam capazes de construir e manter uma concepção compartilhada do mesmo projeto. No jargão de computação, isso eqüivale a dizer que, sempre que um número de colaboradores procurar saber simultaneamente o estado atual de um projeto compartilhado, eles devem obter representações semanticamente equivalentes. Nos referimos a essa característica como compartilhamento de projeto.

No caso do protótipo Lego, buscando a independência de plataforma, maior simplicidade e flexibilidade no que dịz respeito à implementação dos possíveis agentes, o compartilhamento do projeto não é implementado como uma estrutura de dados única; em vez disso, o sistema permite que cada um dos agentes mantenha uma representação individual (estrutura privada) do projeto em andamento, semanticamente equivalente às representações dos seus colaboradores. Esse modelo, inspirado nos bate-papos (chats ou mais especificamente IRC - Internet Relay Chat) da 
Internet é ilustrado pela Figura 5.9 e descrito a seguir.

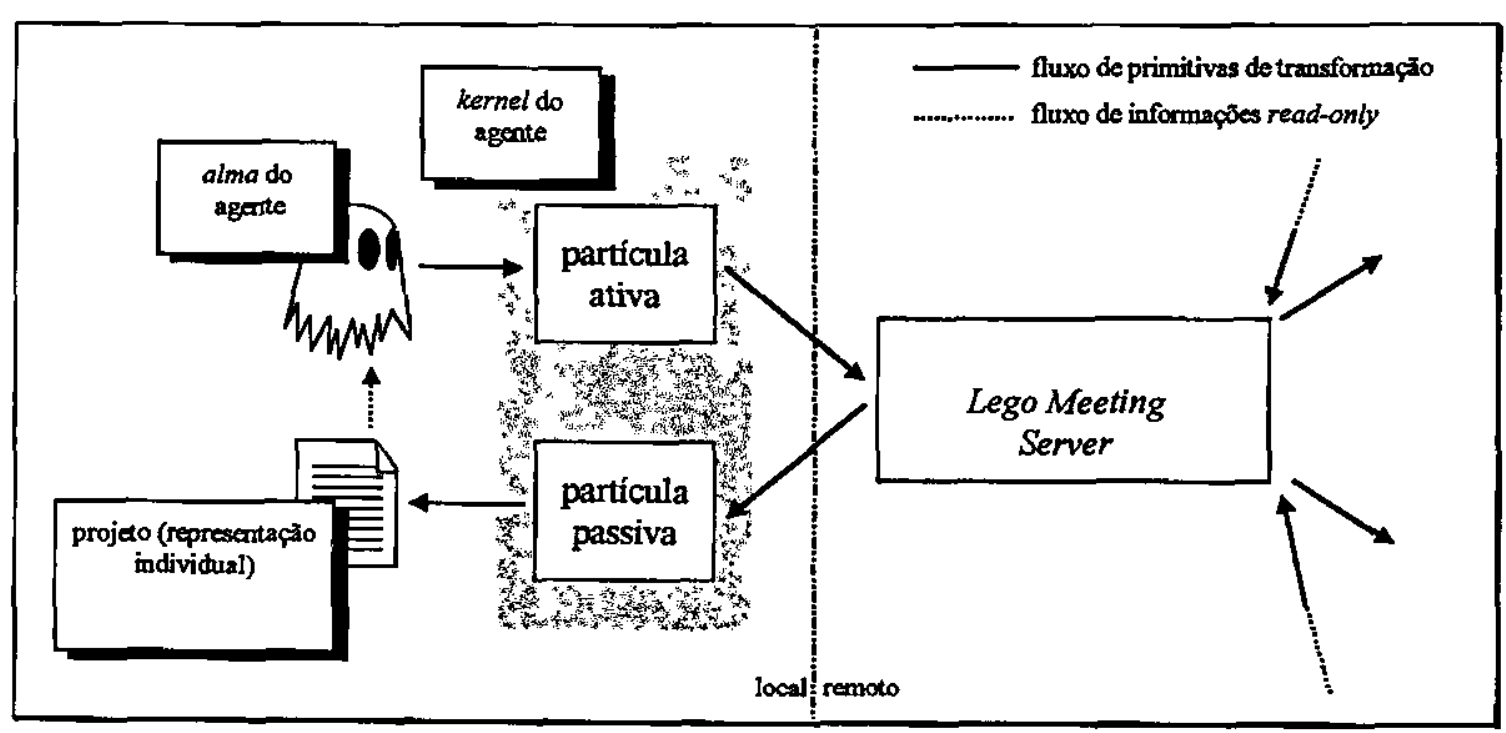

Figura 5.9: Modelo de Compartilhamento de Projetos

O núcleo (kernel) da implementação da entidade "agente" foi bipartido em uma partícula ativa e outra passiva. A partícula ativa é manipulada diretamente pela "alma do agente" (um ser humano ou um programa que possa ordenar mudanças no projeto, à partir do estado atual de sua representação individual) e transmite as ordens desta para uma instância, possivelmente remota, de Lego Meeting server. $\mathrm{O}$ meeting server concentra as mensagens enviadas por diversos agentes. Cada mensagem recebida referente ao projeto será retransmitida, na mesma ordem de chegada, a todos os agentes colaboradores desse projeto, inclusive ao emissor original da mensagem. As mensagens enviadas pelo meeting server para um agente são recepcionadas pela "partícula passiva" de seu kernel, que efetua as ações correspondentes. Dentre essas ações, estão operações de transformação sobre a estrutura de dados privada com que o agente em questão representa o projeto compartilhado. Os agentes reagem ao estado atual de sua representação individual do projeto, fechando o ciclo.

De acordo com as especificações atuais, uma instância de Lego Meeting Server só suporta o compartilhamento de um único projeto. Além disso, todos os agentes devem estar conectados antes que se insira o primeiro vocábulo, e ainda não se pode retomar um projeto interrompido. Esse é um ponto que merece mais estudo no sentido de superar essas limitaçס̃es. 


\subsubsection{Lego Workbench}

Lego Workbench é um ambiente que permite a criação de estruturas no formato de árvore, apoiando-se em um arquivo de especificação de vocabulário (extensão .voc). Esse arquivo contém, além da especificação do vocabulário com que o usuário quer trabalhar, um conjunto de regras, fornecido pelo criador do vocabulário em questão, para racionalizar a tarefa de codificação.

A aparência atual deste módulo pode ser visualizada na Figura 5.10. Nela podemos ver as funcionalidades que este pode proporcionar aos colaboradores, como a interface gráfica de fácil utilização. Para inserir componentes da estrutura de uma introdução, por exemplo, o usuário precisa apenas arrastá-los da palette à esquerda para a área de trabalho à direita. Outras operações naturalmente necessárias, como a exclusão ou a troca da posição de componentes, são realizadas de forma intuitiva para usuários acostumados ao uso de aplicações como o Windows Explorer.

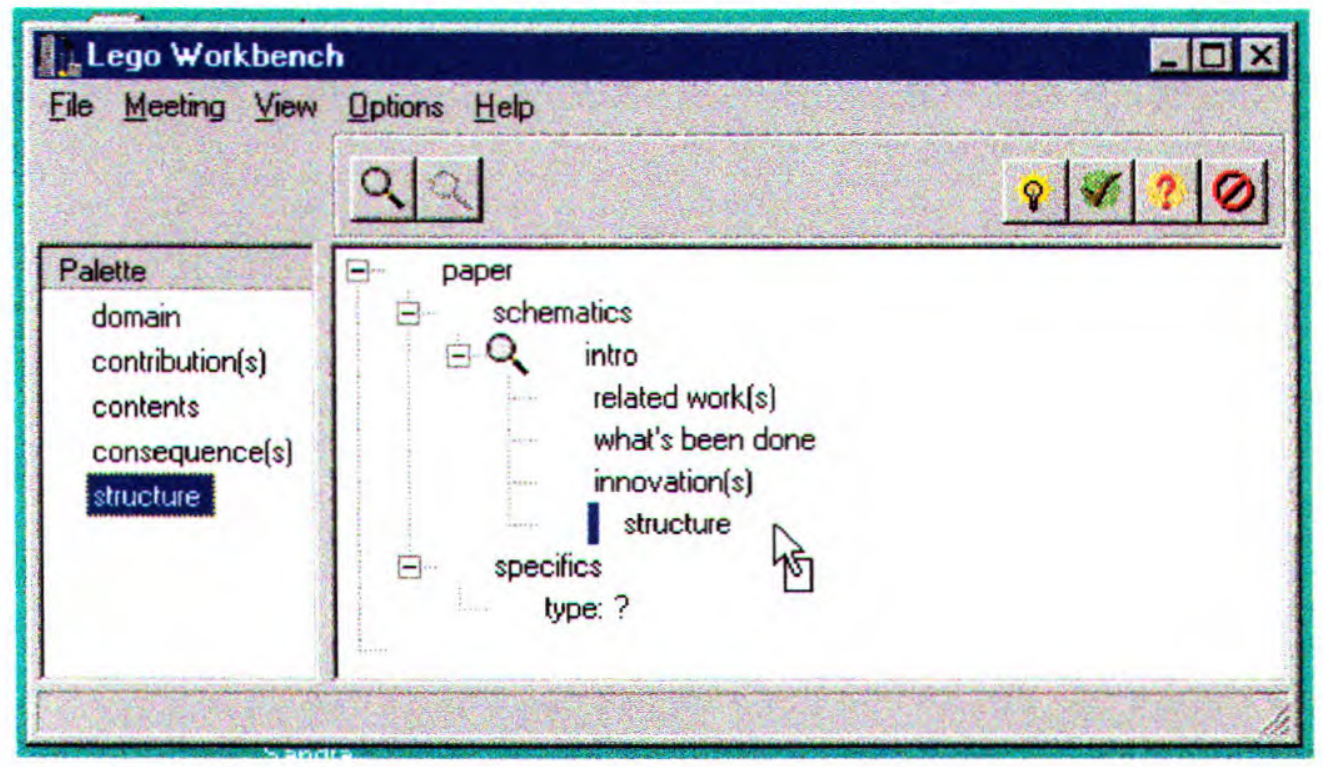

Figura 5.10: Interface Gráfica do Lego Workbench

A concepção de um ambiente como Lego Workbench é um ponto importante para o projeto, visto que um dos objetivos deste não é testar a memória ou a persistência do usuário final, mas levá-lo a expressar sua vontade com naturalidade num código que o computador possa interpretar com facilidade. A seguir, apresentamos uma discussão, em sua maior parte, orientada 
ao projeto de interfaces. Tentou-se apresentar as diversas características da interface resultante de uma forma evolutiva, numa seqüência de figuras não necessariamente igual à que foi desenvolvida no ciclo de vida do projeto, mas que permita maior clareza na apresentação de justificativas.

Na tarefa de codificação numa linguagem de árvore, dois são os pontos que representam a maior carga de dificuldade para o usuário comum:

a) sintaxe: apesar de serem tarefas muito familiares, a construção e, em especial, a manutenção de uma árvore podem se tornar árduas e sujeitas a alta probabilidade de erro caso o autor esteja trabalhando num ambiente puramente textual. $O$ mínimo que se pode conceber em direção a um ambiente de composição mais confortável é algo como podemos observar na Figura 5.11, onde as relações de descendência entre nós e de ordem entre irmãos são representadas por meio de uma estrutura gráfica.

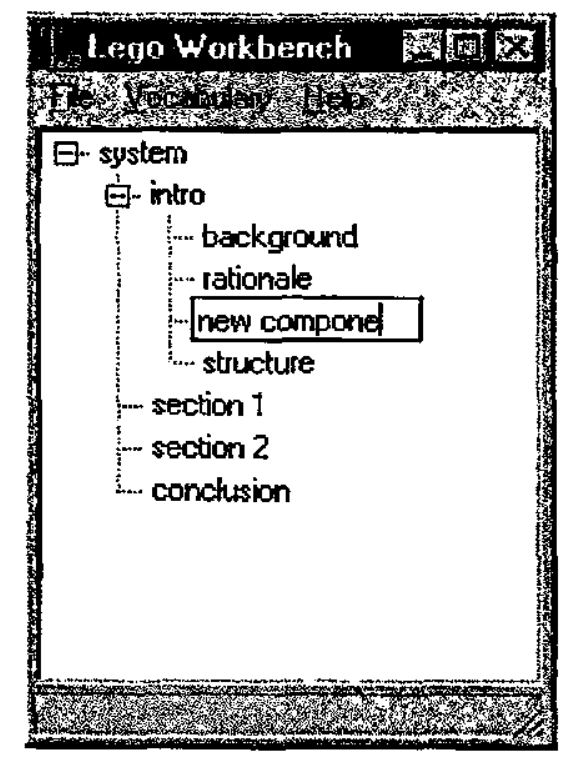

Figura 5.11: Apoio Gráfico à Construção de Árvores

b) vocabulário/semântica: sem dúvida, a carga cognitiva representada pela aquisição de um novo vocabulário e seu uso correto (compreensão da semântica) é bastante grande, tanto para o usuário novato quanto para o experiente. Estes, num ambiente como o apresentado na Figura 5.11, não recebem qualquer auxílio nesse sentido, sendo obrigados a memorizar cada um dos possíveis vocábulos. Isso pode ser evitado caso o vocabulário fique presente na forma de uma palette - uma lista cujos elementos (vocábulos) o usuário pode arrastar para a área 
de composição (vide Figura 5.12). Além disso, é desejável que se possa especificar uma ordem, pelo menos inicial, para a apresentação dos elementos da palette, de forma a agrupar os vocábulos segundo algum critério que favoreça seu uso ou a memorização de seu significado.

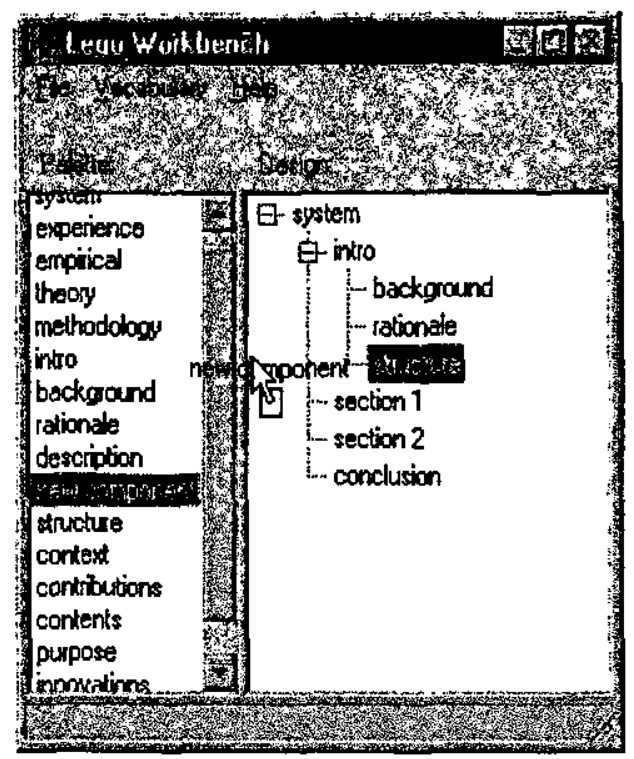

Figura 5.12: Aliviando a Memória com a Adição de uma Palette

Neste momento, percebe-se que somente o estabelecimento de uma ordem na palette não parece ajudar muito, pois os vocábulos podem ser muitos, talvez não sendo possível a apresentação de todos simultaneamente, o que acarreta o uso um tanto incômodo da barra de rolagem, e a necessidade de memorização dos itens não visíveis em um dado momento. Dois mecanismos foram concebidos para abordar o problema, podendo ser considerados como diferentes formas de agrupar vocábulos em conjuntos significativos:

- A palette dinâmica: na especificação de um vocabulário de árvore, é muito freqüente que alguns vocábulos só façam sentido quando inseridos como filhos de um vocábulopai em específico. Quando isso valer, é interessante que aqueles só se tornem disponiveis na palette quando no refinamento deste estiver se concentrando o usuário. Para isso, no entanto, faz-se necessário que o usuário explicite para onde está voltada a sua atenção a cada momento, o que pode ser realizado com a introdução da operação de focalização. A Figura 5.13 ilustra o funcionamento desse mecanismo: no primeiro screemdump de tela (à esquerda) o elemento schematics foi focalizado (clicase sobre o botão que representa uma lupa e em seguida sobre o vocábulo a ser 
focalizado). No próximo screemdump de tela (à direita), o componente intro foi inserido e, na última das telas (abaixo) o componente intro foi focalizado, momento em que os componentes da estrutura esquemática podem ser inseridos.

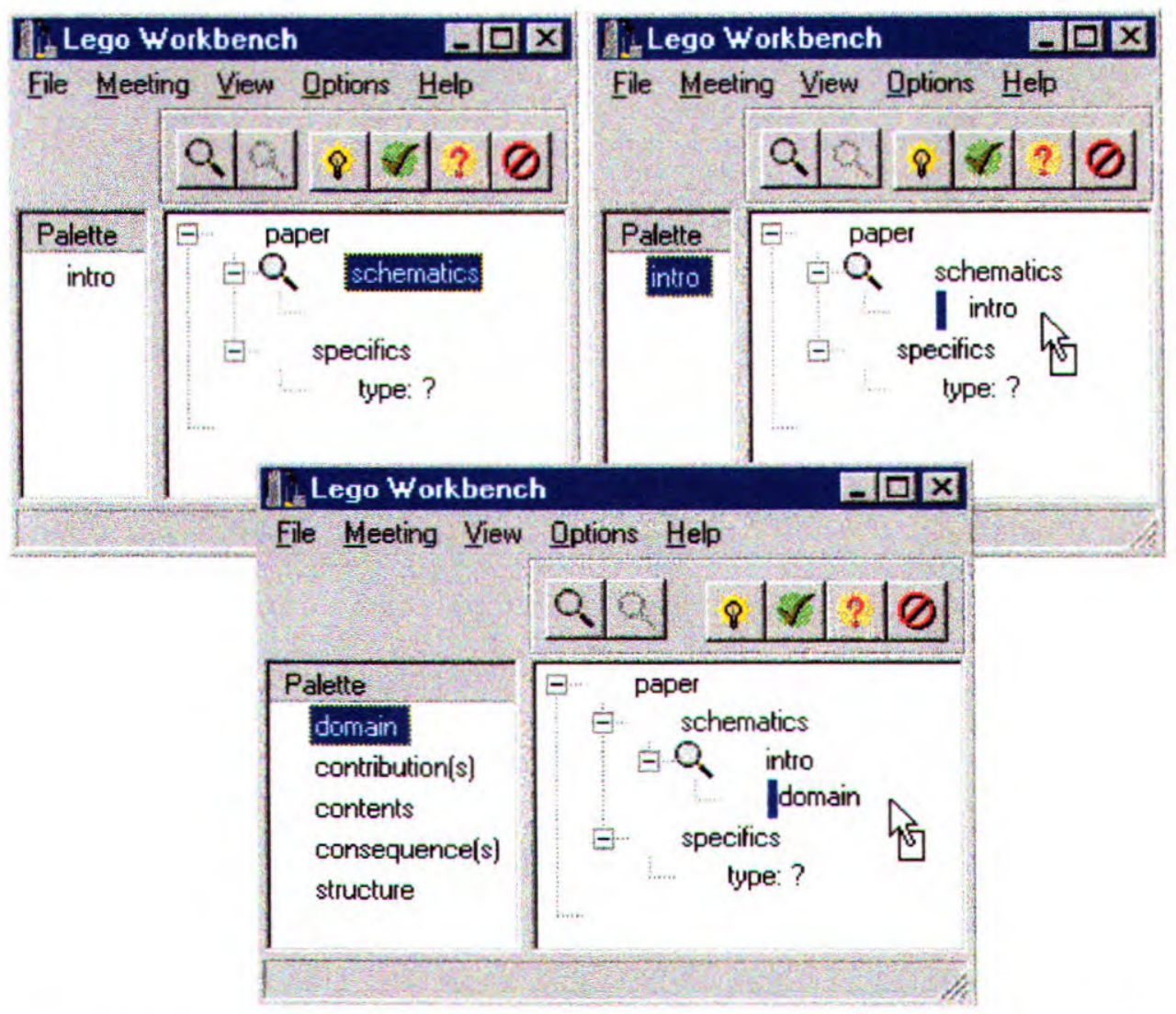

Figura 5.13: Três Momentos da Palette Dinâmica (Sensível a Contexto) em Ação

- Vocábulos abstratos: é possível ainda que, mesmo com o uso de uma palette dinâmica, o número de vocábulos disponíveis em dado momento seja grande. Nesse caso, se pelo menos alguns itens puderem ser agrupados em conjuntos devido a algum tipo de semelhança natural, é aplicável a idéia de vocábulos abstratos. Um vocábulo abstrato, quando focalizado ou inserido, requisita sua substituição por um dos elementos de uma palette auxiliar especifica (chamada de palette de substitutos do vocábulo em questão). A Figura 5.14 e a Figura 5.15 ilustram o funcionamento desse mecanismo. Na Figura 5.14, a focalização em "type:?" desencadeou o surgimento da palette de substitutos com os tipos possiveis de artigos. Na Figura 5.15, o componente "contents" foi inserido, 
momento em que a palette de substitutos com os outros componentes pôde ser visualizada para que um deles fosse selecionado.
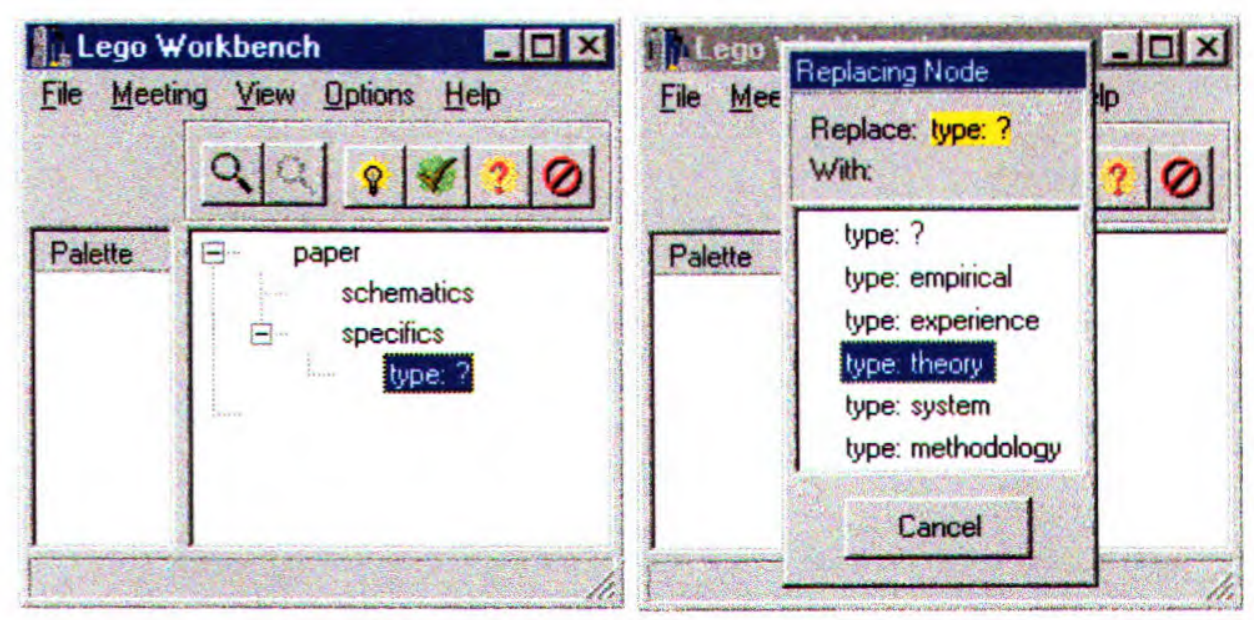

Figura 5.14: Seqüência da Substituição de um Vocábulo Abstrato Quando de sua focalização (Theory é um tipo de Type)

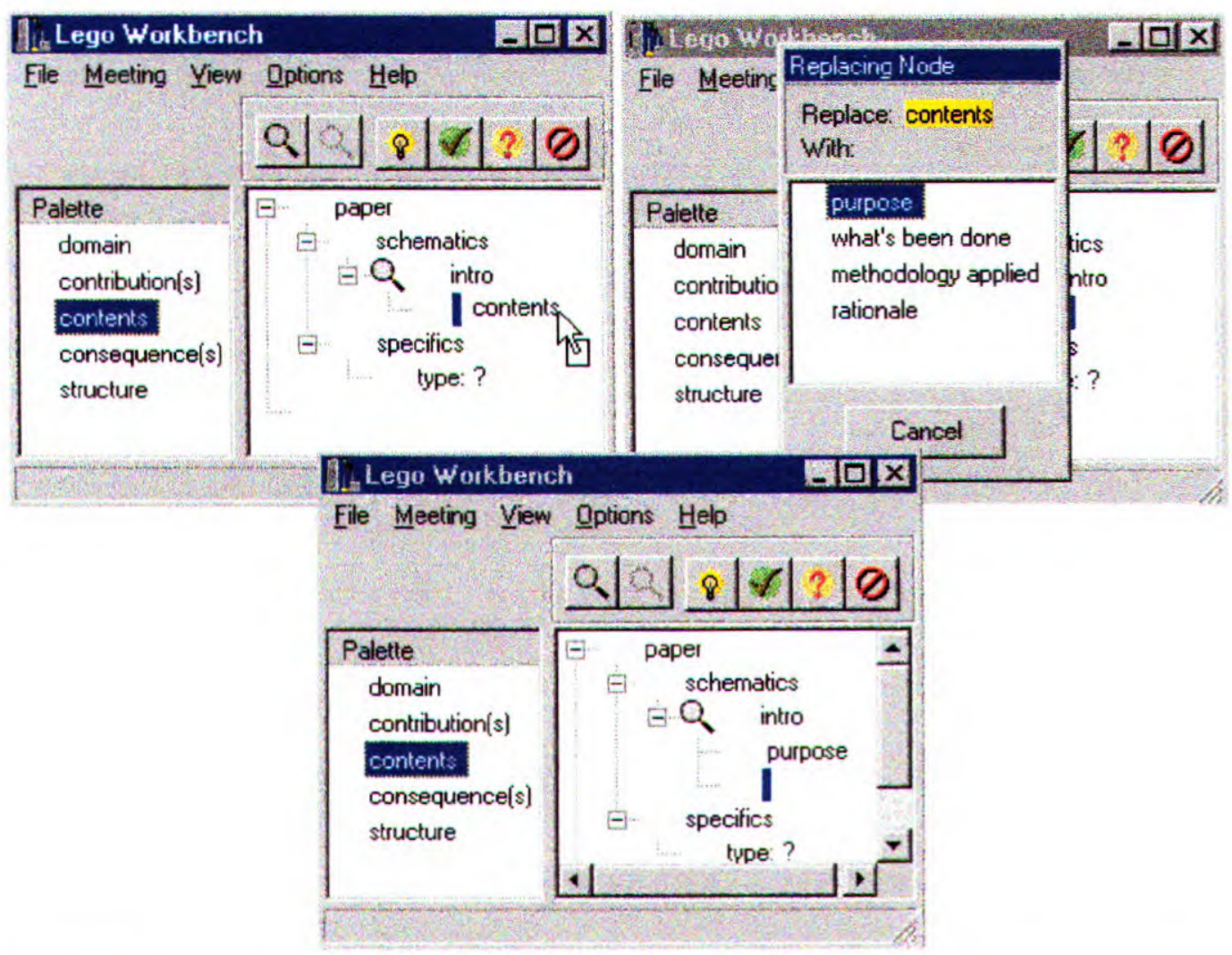

Figura 5.15: Seqüência da Substituição de um Vocábulo Abstrato Quando de sua Inserção 
O usuário de Lego Workbench tem acesso às anotações referentes ao componente correntemente selecionado por meio da janela auxiliar Peer Annotations, como se pode observar na Figura 5.16. Essas anotações podem ser feitas, tanto pelo crítico artificial, quanto por colaboradores humanos. Além disso, tenta-se chamar a atenção do usuário para a existência de uma ou mais anotações não lidas, por meio da apresentação de ícones ao lado dos componentes a que se referem às anotações em questão, o que é exemplificado na mesma figura.

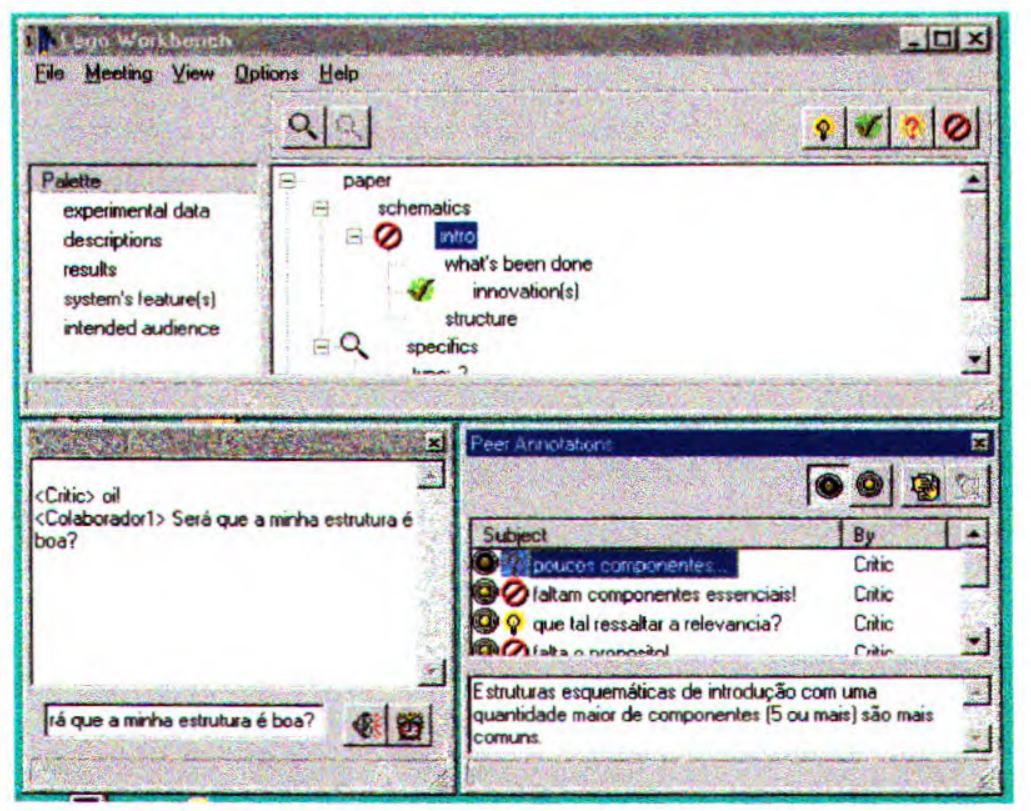

Figura 5.16: Lego Workbench: Ênfase em Anotações de Revisão

Para que um colaborador humano possa emitir uma crítica na forma de anotação de revisão, basta que selecione um dos quatro botões posicionados no canto superior direito da janela de Lego Workbench e clique sobre o componente/vocábulo que deseja críticar. Estes botões estão relacionados às formas de crítica, e podem assim ser definidos:

- 8 Representa uma crítica do tipo New!. Este tipo de crítica significa idéia e está diretamente relacionada à forma de crítica Sugestões Diretas e Instruções;

- $\forall \mid$ Crítica do tipo Good!. Indica uma crítica positiva e representa a forma de crítica Elogios;

- 3 Crítica do tipo Hum.... É a indicação de que o produto pode ser melhorado. Representa a forma de crítica Sugestões Impessoais para Melhorias e Críticas 


\section{Indiretas.}

- 8 Crítica do tipo Bad!. Este ícone significa que o produto apresentado possui sérios problemas e deve ser reestruturado; está associado á forma de crítica Críticas Diretas.

Além de anotações de revisão, Lego Workbench suporta também notificações. Para o colaborador a chegada de uma notificação representa inevitavelmente a interrupção de suas atividades correntes (caracterizando uma crítica intrusiva), como exemplificado na Figura 5.17.

O colaborador pode ainda tomar parte de discussões por meio da janela auxiliar Discussion Room, que funciona à maneira de um "Chat" convencional. Como exemplo, na Figura 5.17 visualizamos a tentativa de comunicação de um colaborador com os demais.

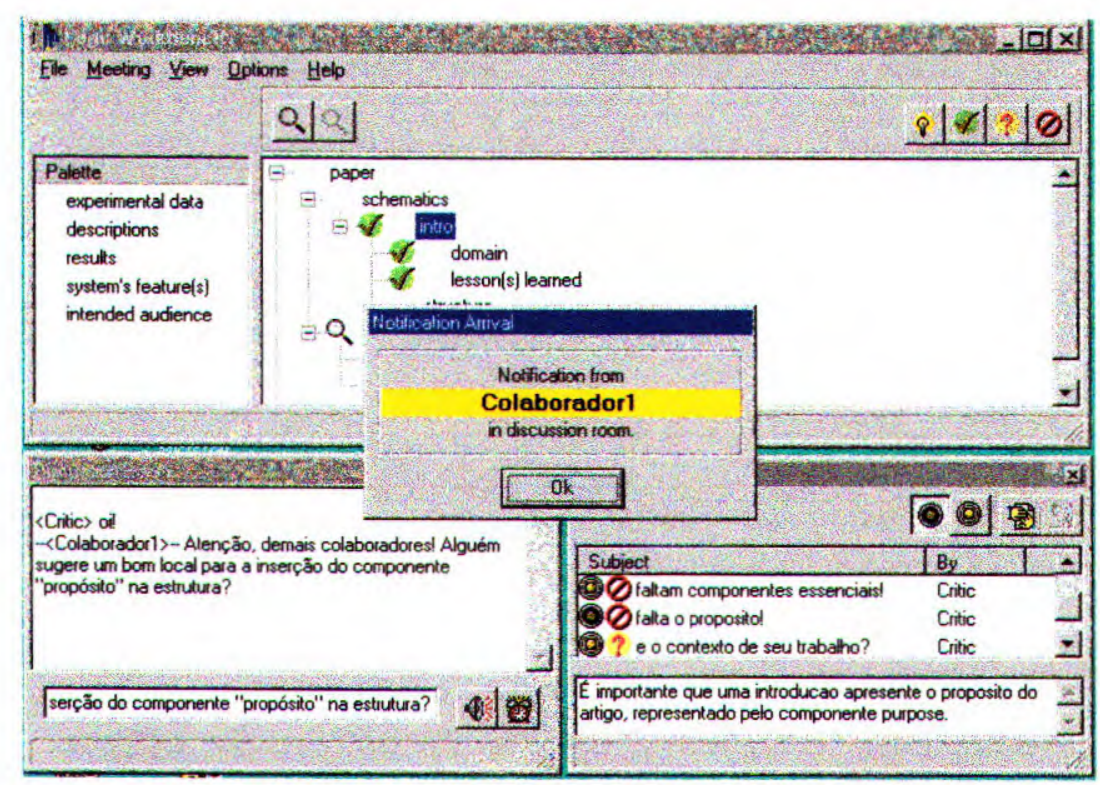

Figura 5.17: Lego Workbench: Ênfase em Notificações

\subsubsection{Lego Prolog Agent}

Lego Prolog Agent é o módulo que, ao ser executado, carrega um programa Prolog compilado num servidor de lógica embutido (AMZI! Logic Server) e, em seguida, conecta-se a uma seção com a ferramenta de crítica. A partir desse momento, passa a executar, no servidor de lógica, predicados especiais, chamados operadores passivos ou eventos, correspondentes às 
mensagens que recebe de Lego Meeting Server. A execução de um evento não só concorre para a manutenção automática da representação interna da árvore em desenvolvimento quanto chama a totalidade dos predicados de reação que se aplicam ao evento em questão. A condição de prova de um predicado de reação, por sua vez, pode conter chamadas a predicados especiais, chamados operadores ativos, que desencadeiam a emissão de mensagens de Lego Prolog Agent aos seus colaboradores. Os operadores ativos disponíveis cobrem toda sorte de ações que um agente qualquer pode realizar num projeto Lego.

\subsection{Predicados de reação e eventos}

A partir dos seguintes fatos:

a) Sempre que há um evento (operador passivo) Ev a ser efetivado por Lego Prolog Agent, tudo transcorre como se a meta efetivar (Ev, Autor) fosse provada dadas as seguintes definições (Autor é uma string contendo o identificador do autor da mensagem que desencadeou o evento em questão):

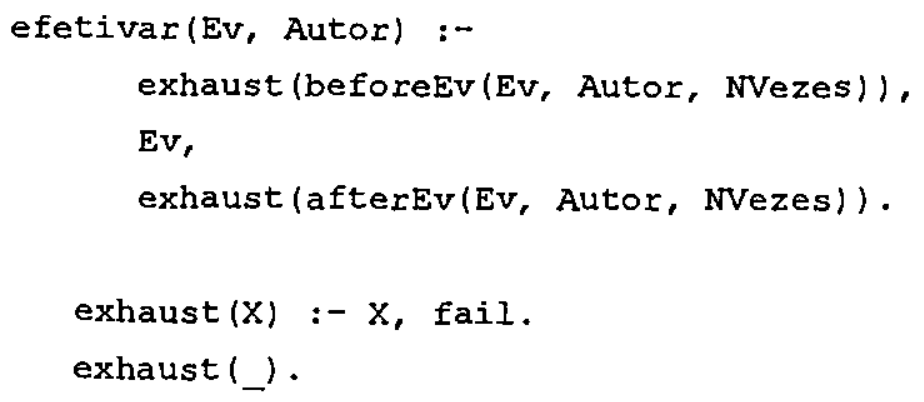

b) Todo predicado beforeEv/3 ou afterEv/3 que se prova verdadeiro e cujo argumento NVezes tiver sido instanciado como justonce é abolido.

pode-se resumir a tarefa do programador do comportamento de Lego Prolog Agent como a criação de predicados beforel/2, beforeN/2, after1/2 e afterN/2 adequados, ditos de reação. Vale lembrar que, a princípio, qualquer predicado tem acesso irrestrito ao estado atual da árvore em desenvolvimento. No entanto, essa estrutura de dados dinâmica só deve ser modificada diretamente pelos operadores passivos, os demais predicados (incluindo os de reação) devendo faze-lo indiretamente, com o uso dos operadores ativos. 
Torna-se importante, portanto, conhecer os possiveis eventos a serem efetivados, que são apresentados, juntamente com seus respectivos significados, na Tabela 5.3.

Tabela 5.3: Predicados e Eventos de Lego Prolog Agent

\begin{tabular}{|c|c|c|}
\hline Evento & Significado (ou ação do autor) & Obs.: \\
\hline PinitDesign & Inicializa o projeto (ocorre uma vez por projeto) & 1 \\
\hline PnewNode(Class, Id) & $\begin{array}{l}\text { Cria um novo nó, isolado, de classe Class (átomo) } \\
\text { e identificado unicamente por Id (inteiro positivo) }\end{array}$ & 1 \\
\hline PdelNode (ByeId) & Exclui a sub-árvore com raiz em Bye Id & 1 \\
\hline $\begin{array}{l}\text { PFirstchildMove (Moving } \\
\text { Id, ParentId) }\end{array}$ & $\begin{array}{l}\text { Move a sub-árvore com raiz em MovingId, } \\
\text { inserindo-a como primeira sub-árvore de ParentId }\end{array}$ & 1 \\
\hline $\begin{array}{l}\text { PNextSibMove (MovingId, } \\
\text { PrevSibId) }\end{array}$ & $\begin{array}{l}\text { Move a sub-árvore com raiz em MovingId, } \\
\text { inserindo-a como sub-árvore seguinte a PrevsibId }\end{array}$ & 1 \\
\hline $\begin{array}{l}\text { PReplaceMove (Moving } \overline{I d}, \\
\text { ByeId) }\end{array}$ & $\begin{array}{l}\text { Move a sub-árvore com raiz em Moving Id de forma } \\
\text { a substituir a sub-árvore com raiz em ByeId, que é } \\
\text { destruida }\end{array}$ & 1 \\
\hline $\begin{array}{l}\text { PAnnot (Annotid, } \\
\text { AnnotType, } \\
\text { TargetId, } \\
\text { Subject, } \\
\text { Text) }\end{array}$ & $\begin{array}{l}\text { Cria uma anotação sobre o no TargetId com as } \\
\text { seguintes características: } \\
\text { - identificada unicamente por AnnotId; } \\
\text { - de tipo AnnotType, que assume um dos } \\
\text { seguintes valores: new, good, bad, hum; } \\
\text { - de assunto Subject e texto Text, ambos } \\
\text { strings. }\end{array}$ & 2 \\
\hline $\begin{array}{c}\text { PDelAnnot (TargetI, } \\
\text { AnnotId) }\end{array}$ & $\begin{array}{l}\text { Apaga a anotação AnnotId, feita sobre o nó } \\
\text { TargetId. }\end{array}$ & 2 \\
\hline BSpeak (Speech) & Emite a fala Speech (string) na sala de discussões & 2 \\
\hline Pnotif(Notif) & $\begin{array}{l}\text { Notifica os colaboradores com a mensagem Notif } \\
\text { (string) }\end{array}$ & 2 \\
\hline PChangeFocus (From, To) & $\begin{array}{l}\text { Avisa que está mudando o foco do nó From para o } \\
\text { nó To (um deles pode assumir o valor inválido }-1 \text {, } \\
\text { indicando, respectivamente, que não havia ou passou } \\
\text { a não haver nenhum nó focalizado) }\end{array}$ & 2,3 \\
\hline
\end{tabular}

Onde Obs. significa:

1 - predicados que, uma vez executados, surtem efeitos colaterais, mantendo a representação interna da árvore em desenvolvimento;

2 - predicados sem efeito, representando apenas ações dos colaboradores;

3 - predicado correspondente à ação de focalização realizada por um usuário de Lego.

\subsection{Operadores Ativos}

Como esperado, para cada operador passivo pop existe um operador ativo dual aOp, no sentido de que a execução de aOp por um agente representa informar todos os seus 
colaboradores (inclusive o próprio agente em questão) da intenção de executar pOp. Os operadores ativos disponíveis são os seguintes:

- aInitDesign

- aNewNode (Class)

- aDelNode (ByeId)

- afirstChildMove (MovingId, ParentId)

- aNextSibMove (MovingId, PrevSibId)

- aReplaceMove (MovingId, ByeId)

- aAnnot (AnnotType, TargetId, Subject, Text)

- aDelAnnot (TargetId, AnnotId)

- $\quad$ aspeak (Speech)

- $\operatorname{aNotif(Notif)}$

- aChangeFocus (From, To)

O significado desses operadores pode ser verificado na tabela de significados dos operadores passivos (Tabela 5.3), guardada a devida dualidade.

\subsubsection{Uma Linguagem para Representação de Artigos como Estruturas em Árvore}

Um dos pontos fundamentais do projeto do protótipo foi a definição de uma linguagem para a especificação em alto nível de textos técnicos em inglês. Esta linguagem deveria possuir algumas características que são imprescindíveis a qualquer linguagem, como por exemplo, ela deveria:

- Ser expressiva o suficiente para que pudesse representar os requisitos que um texto deve preencher, tanto em termos de estrutura esquemática e organização quanto de indicação de conteúdo (estrutura de critérios específicos); e

- Ser simples o suficiente para que pudesse ser facilmente dominada por um usuário e interpretada por um computador;

Uma vez obtida a linguagem com essas características, poderíamos então usar o computador para: 
- Criticar o usuário quanto ao próprio uso dessa linguagem e quanto à escolha e ordenação dos componentes da estrutura dual;

- Verificar se os requisitos expressos pelo usuário atingem algum objetivo,

- Recuperar e disponibilizar casos para que estes auxiliem o usuário na escrita de um texto real uma vez atingida uma especificação satisfatória.

Inspirada nos esquemas hierárquicos com que normalmente se planeja um texto (por exemplo, uso de outline), essa linguagem se concretizou, sintaticamente, como uma linguagem de construção de árvores que mantêm uma relação de ordem total entre nós-irmãos.

Quando uma nova seção com a ferramenta de crítica (projeto Lego) é iniciada, a estrutura principal de um artigo é automaticamente gerada pela linguagem e apresentada aos colaboradores (Figura 5.18). O modo como essa estrutura é mostrada reflete a simplicidade e clareza do protótipo.

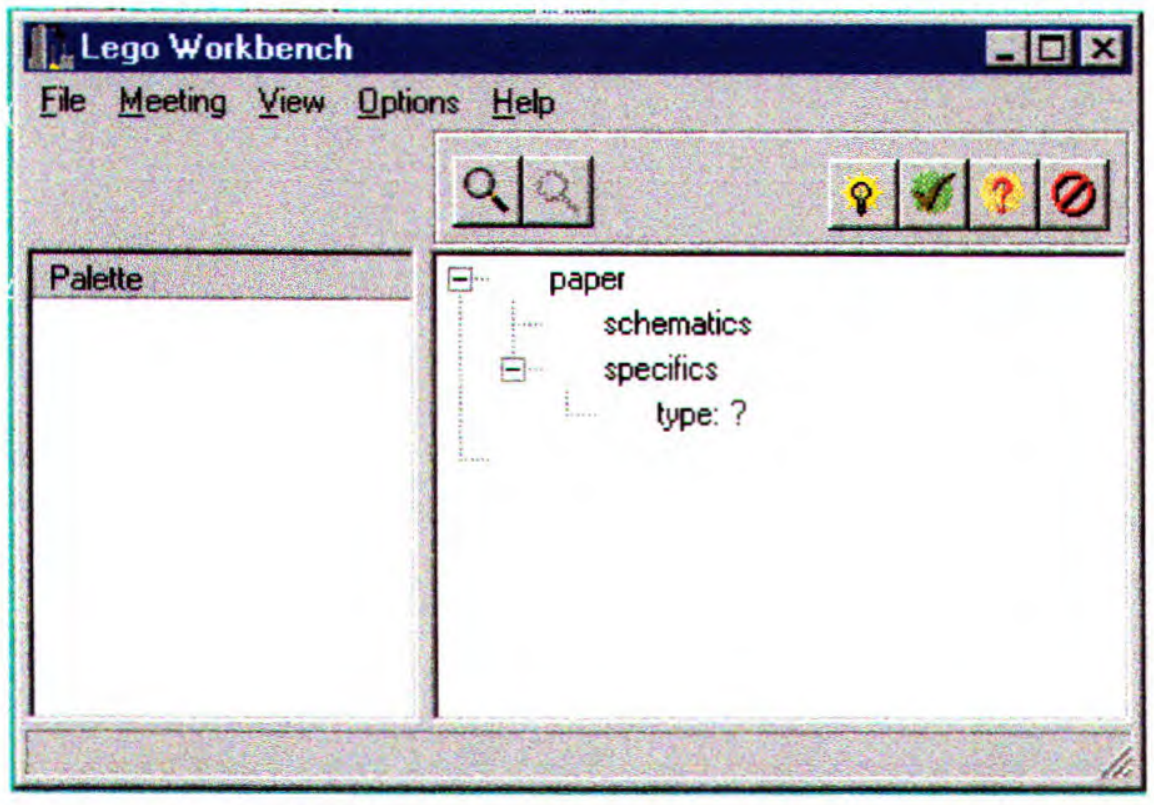

Figura 5.18: Árvore Inicial Montada pela Linguagem

A linguagem implementada se baseia fortemente nas informações das Tabela 5.1 e Tabela 5.2 (Subseção 5.1.2), porém algumas adaptações foram necessárias para que o projeto se tornasse mais simples, tanto em termos de codificação quanto de facilidade de uso e assimilação por parte dos colaboradores. Por exemplo, na Tabela 5.2, o componente Conteúdo apresenta os subcomponentes Propósito, Descrição do que foi feito, Metodologia que foi aplicada e 
Justificativas; em termos de implementação, desconsiderou-se as classes componentes e subcomponentes. No momento da montagem das estruturas, o colaborador trabalha com palettes dinâmicas que surgem quando da escolha de determinados vocábulos (conforme Figura 5.19), as quais disponibilizam outros componentes. Estes vocábulos foram agrupados em palettes na tentativa de organizá-los e não deixá-los totalmente expostos desde o início do projeto. Independentemente dos vocábulos estarem localizados em palettes ou não, os componentes poderão ser inseridos como nós na árvore em apenas um nível, como ilustra a Figura 5.20.

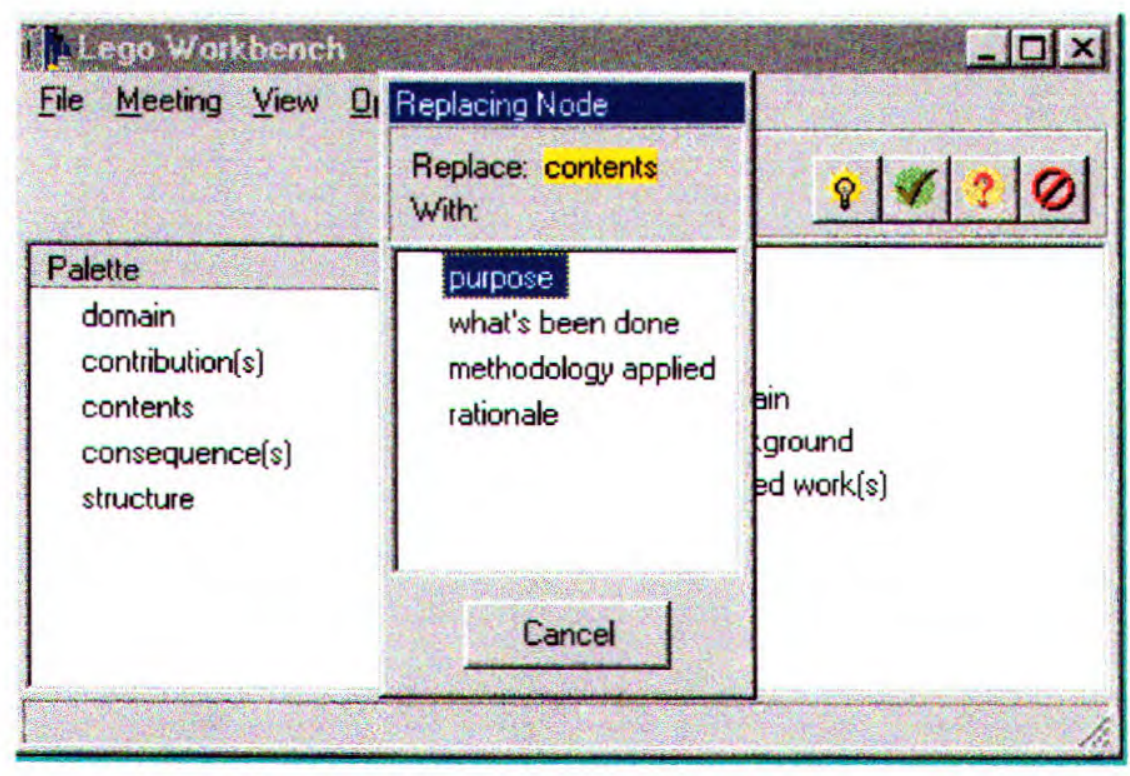

Figura 5.19: A Palette Dinânica

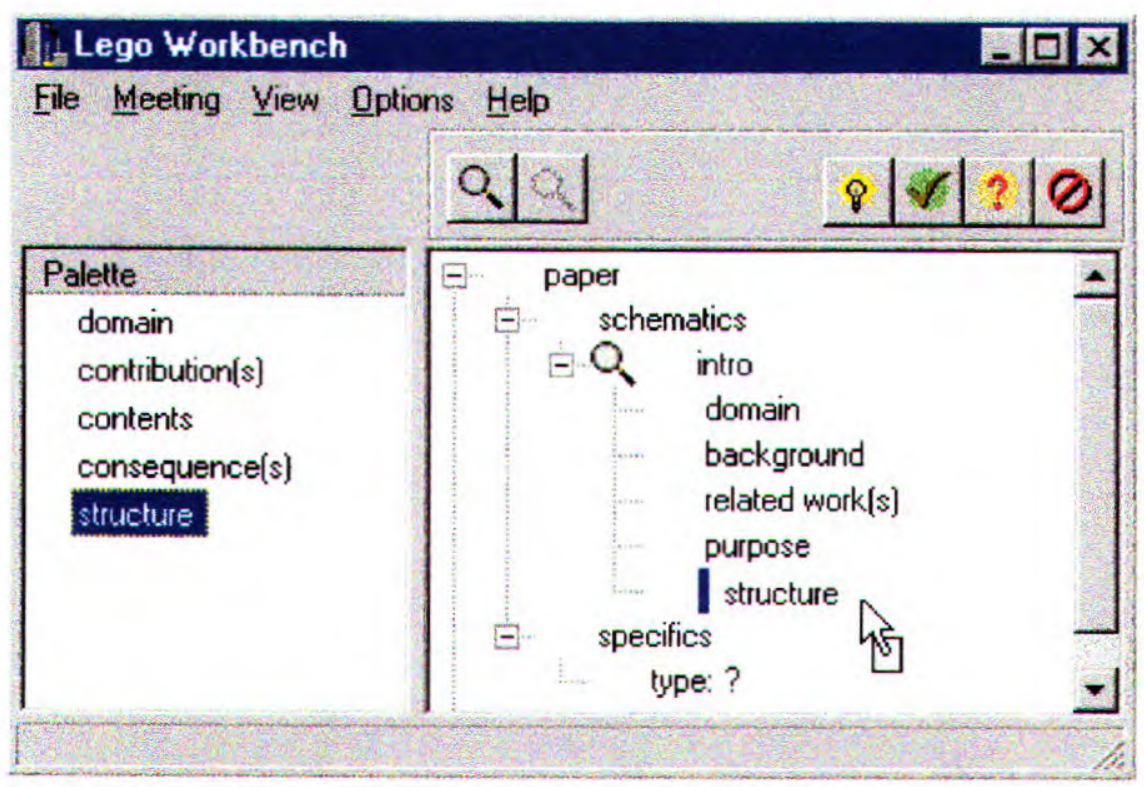

Figura 5.20: Inserção de Nós na Árvore em Apenas um Nível 


\subsubsection{O Agente Gerador de Críticas: O Crítico}

Para que o protótipo da ferramenta de crítica obtenha êxito no seu funcionamento, a definição e a programação do crítico são de vital importância. O crítico constitui-se de um programa Prolog que alimenta o módulo Lego Prolog Agent, que, desta forma pode colaborar na construção de estruturas de introduçðes de artigos.

De um modo mais ilustrativo, se voltarmos a analisar a Figura 5.3, que trata do modelo computacional para ferramentas de crítica para a escrita técnica, concluímos que o crítico compreende o reconhecedor de objetivos, o analisador analitico, o analisador diferencial, o conhecimento utilizado por estes analisadores e as estratégias utilizadas na apresentação das críticas.

Esta subseção está organizada com enfoque nos módulos agentes do crítico, ou seja, os analisadores diferencial e analítico e o reconhecedor de objetivos. Ao longo da discussão de cada uma dessas "personalidades" do crítico, o conhecimento utilizado e as estratégias de crítica irão sendo apresentados conforme se fizerem necessárias. $O$ conhecimento utilizado no protótipo da ferramenta de crítica foi representado de três formas diferentes: casos, regras heurísticas/guidelines e estruturas (esquemática e de critérios especificos). O reconhecedor de objetivos trabalha com o conhecimento das estruturas enquanto que $o$ analisador diferencial trabalha com os casos e o analítico com as regras heurísticas/guidelines. Estes dois últimos são apresentados com detalhes nas Subseções 5.4.3.1 e 5.4.3.2, respectivamente. Outros pontos a serem ressaltados são: (a) quais os critérios utilizados para a emissão de criticas e, (b) de uma forma geral, como o sistema irá proceder durante o processo de estruturação da introdução e busca e recuperação de casos semelhantes ao produto do usuário.

\subsubsection{Analisador Diferencial}

A função básica do analisador diferencial é comparar o produto apresentado com os casos armazenados na base.

Para a obtenção da base de casos, que se constitui no conhecimento utilizado por este analisador, inicialmente fez-se necessário classificar os artigos de acordo com os tipos possiveis e, na seqüência, realizar uma análise para a identificar os componentes da estrutura dual de cada um deles. Em seguida, os casos foram codificados em Prolog levando-se em consideração a estrutura 
dual. A Figura 5.21 ilustra um desses casos.

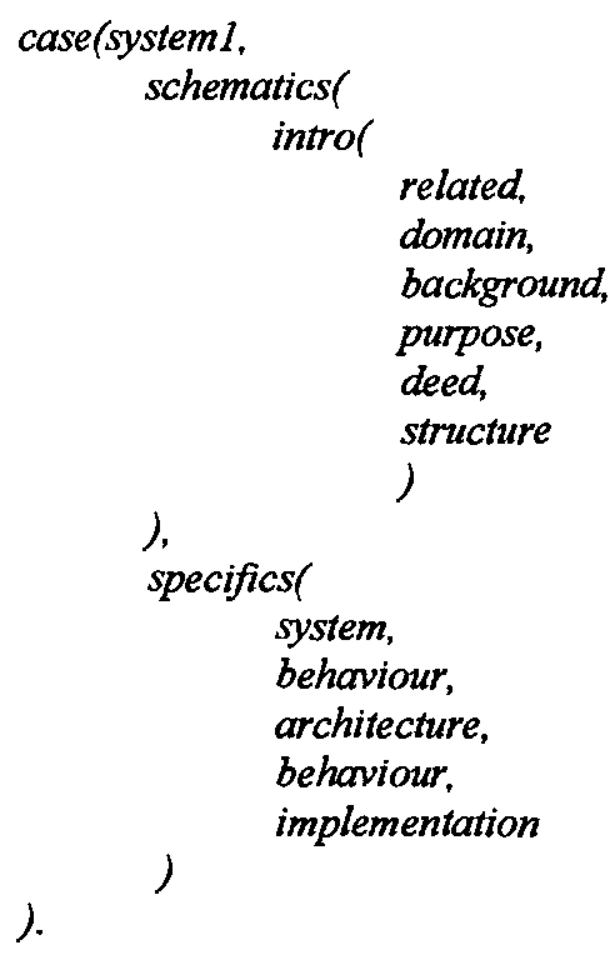

Figura 5.21: Um Caso Codificado em Prolog

$O$ texto do caso ilustrado acima pode ser visualizado também:

- Na Figura 5.2, onde está anotado com os componentes da estrutura dual;

- Na Figura 5.4, onde está anotado em SGML (para apresentação no Panorama PRO) com relação à estrutura de componentes esquemáticos;

- Na Figura 5.6, onde está anotado em SGML (para apresentação no Panorama PRO) com relação à estrutura de critérios específicos; $\mathrm{e}$

- Na Figura 5.8, que representa a forma como o caso é mostrado no browser Panorama PRO quando é recuperado.

As introduções de artigos que constituem a base de casos do protótipo foram anotadas de acordo com gramáticas livre de contexto (uma para a estrutura de componentes esquemáticos e outra para a estrutura de critérios especificos), que foram criadas para possibilitar a visualização 
das introduções no browser Panorama PRO, durante o processo de utilização da ferramenta de crítica, quando da emissão de críticas que indicam a recuperação de casos.

As críticas apresentadas por este analisador dizem respeito ao grau de similaridade entre os casos comparados (o produzido e os da base).

$\mathrm{O}$ analisador diferencial funciona de modo passivo e é acionado pelo colaborador, através da emissão de uma crítica do tipo "Hum..." com subject "example", momento em que compara a estrutura apresentada com os casos da base e disponibiliza links para a visualização dos casos mais similares.

Para que este analisador chegue ao final do processo de comparações e recupere casos semelhantes para serem disponibilizados ao colaborador, vários critérios são utilizados; dessa forma, ele pode trazer os melhores casos com relação aos vários aspectos porém, para a busca do melhor caso, vários critérios de busca podem ser ativados ao mesmo tempo. Estes critérios podem ser caracterizados em três níveis:

1. Nível baixo (protocritérios): não são critérios de busca propriamente dito, mas operadores de diferença usados na definição dos demais critérios. Especificamente, os protocritérios não operam sobre pares de casos, mas pares de florestas (conjunto de árvores), considerando apenas as raízes (nós no primeiro nível). Foi necessária a implementação de dois desses operadores de baixo nível, ordDelta e setDelta, cada qual tratando de um aspecto distinto:

- Elementos em comum, sem contar ordem ou repetições: nesse caso, define-se o grau de dissimilaridade $D$ entre duas florestas $F 1$ e $F 2$ da seguinte forma:

$D(F 1, F 2)=1-(\#(\operatorname{raizes}(F 1) \cap \operatorname{raizes}(F 2)) / \#(\operatorname{raizes}(F 1) \cup \operatorname{raizes}(F 2)))$,

onde $\operatorname{raizes}(F)$ é uma função que calcula o conjunto das raizes em $F$, sem repetição. $\mathrm{O}$ predicado setDelta(F1+, F2+, D-) é a expressão em Prolog para essa definição de $D(F 1, F 2)$. Por exemplo:

$D(\mathrm{X}, \mathrm{Y})=0, \mathrm{X}=\mathrm{Y}$.

$D([[\mathrm{a}],[\mathrm{b}],[\mathrm{c}],[\mathrm{d}]],[[\mathrm{b}],[\mathrm{d}],[\mathrm{c}],[\mathrm{a}]])=0$

$D([[\mathrm{a}],[\mathrm{b}],[\mathrm{c}],[\mathrm{d}]],[[\mathrm{x}],[\mathrm{b}],[\mathrm{x}],[\mathrm{a}],[\mathrm{c}]])=0,,4^{(*)}$

$D([[\mathrm{a}],[\mathrm{b}],[\mathrm{c}],[\mathrm{d}]],[[\mathrm{x}],[\mathrm{x}],[\mathrm{x}],[\mathrm{x}],[\mathrm{x}],[\mathrm{d}],[\mathrm{x}]])=0,8$

$D([[\mathrm{a}],[\mathrm{b}],[\mathrm{c}],[\mathrm{d}]],[[\mathrm{x}],[\mathrm{x}],[\mathrm{x}],[\mathrm{x}],[\mathrm{x}],[\mathrm{x}]])=1$

Por exemplo, para o caso acima que está marcado com um ${ }^{(*)}$,os cálculos foram os seguintes: 
$D(F 1, F 2)=1-((a, b, c, d) \cap(x, b, a, c) /(a, b, c, d) \cup(x, b, c, d))$

$\mathrm{D}(\mathrm{F} 1, \mathrm{~F} 2)=1-((\mathrm{a}, \mathrm{b}, \mathrm{c}) /(\mathrm{a}, \mathrm{b}, \mathrm{c}, \mathrm{d}, \mathrm{x}))$

isso traduzido em valores:

$\mathrm{D}(\mathrm{F} 1, \mathrm{~F} 2)=1-(3 / 5)$

$\mathrm{D}(\mathrm{F} 1, \mathrm{~F} 2)=1-0,6$

$\mathrm{D}(\mathrm{F} 1, \mathrm{~F} 2)=0,4$

- A seqüência em que as raízes aparecem, contando repetições: nesse caso, define-se $D(F 1$, $F 2$ ) como o número mínimo de elementos que devem ser ignorados em $F 1$ de forma a obter uma sequência de raízes que possa ser também obtida se um certo número de elementos for ignorado em F2. Por exemplo:

$D(\mathrm{X}, \mathrm{Y})=0, \mathrm{X}=\mathrm{Y}$.

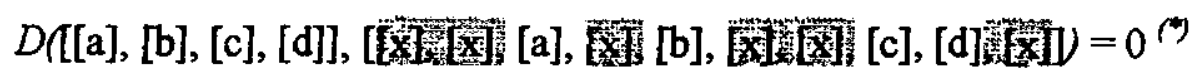

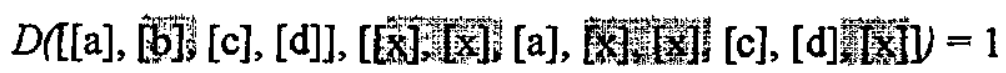

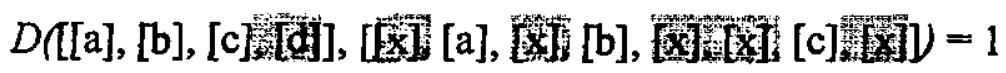

$D([\mathrm{a}],[\mathrm{b}] \mathrm{k}[\mathrm{c}][\mathrm{d}]],[[\mathrm{a}],[\mathrm{b}] \mathrm{y}=2$

O predicado ordDelta (E1t, F2t, D-) é a expressão em Prolog para uma versão levemente modificada dessa definição de $D(F 1, F 2)$ :

$$
D^{\prime}(F 1, F 2)=\min (D(F 1, F 2),(\#(F 1) / 2+1)) /(\#(F 1) / 2+1)
$$

pois uma implementação direta de $D(F 1, F 2)$ seria por demais custosa.

Por exemplo, para o caso acima, marcado com um ${ }^{(*)}$, os cálculos seriam:.

$$
\begin{gathered}
\min (0,4 / 2+1) /(4 / 2+1) \\
0 / 3=0
\end{gathered}
$$

onde " $m i n "$ significa o valor mínimo.

2. Nível Médio (critérios básicos): os critérios básicos foram assim denominados por motivos de (a) implementação, uma vez que são definidos exclusivamente a partir dos protocritérios, e (b) função, quantificando a diferença entre dois artigos quanto a um único aspecto. Os critérios básicos implementados são os seguintes: 
- spc/set: compara os componentes específicos de estruturas como conjunto, sem considerar o tipo do artigo, consistindo na aplicação do protocritério setDelta entre as estruturas de critérios específicos da construção do usuário e os casos;

- spc/setSameType: compara os componentes específicos de estruturas como conjunto, dando ao tipo do artigo um peso muito alto, de forma que tudo se processa como se a busca por esse critério só cobrisse os artigos de mesmo tipo. Seu resultado é igual ao de $\mathrm{spc} / \mathrm{set}$, se os dois artigos comparados tiverem o mesmo tipo ou um deles não tiver tipo definido, ou 1 , caso contrário;

- sch/set: compara os componentes esquemáticos de estruturas como conjunto, sem se preocupar com ordem ou repetição, consistindo na aplicação do protocritério set Delta entre as estruturas esquemáticas da construção do usuário e os casos;

- sch/ord: compara os componentes esquemáticos de estruturas considerando a ordem em que aparecem e repetições, consistindo na aplicação do protocritério ordDelta entre as estruturas esquemáticas da construção do usuário e os casos;

3. Nível Alto (critérios derivados): os critérios derivados resultam da composição (cálculo de média ou outras expressões matemáticas e lógicas) de dois ou mais criténos básicos para tentar avaliar a diferença com relação a mais de um aspecto simultaneamente. Esses critérios derivados são:

- sch/set_ord: tenta considerar ordem e conjunto de componentes de forma conjunta, tendo sido, para isso, definido como $\max (s c h / s e t, s c h / o r d)$;

- sumUp: tenta considerar as duas estruturas de forma conjunta, levando em conta ordem na parte esquemática, tendo sido, para isso, definido como max (sch/set_ord, spc/set);

- sumUpNoOrder: considera as duas estruturas, sem contar ordem na parte esquemática, definido como $\max (\mathrm{spc} / \mathrm{set}$, sch/set).

Com base nas diferenças (ou conhecimento) encontradas em decorrência do processo de comparações, uma critica torna-se disponível ao colaborador, indicando os nomes dos casos mais semelhantes ao apresentado, em relação aos diversos critérios. Estes nomes são apresentados na forma de links, e ao serem selecionados, podem ser visualizados no browser SGML. 


\subsubsection{Analisador Analitico}

O conhecimento que permite ao analisador analítico emitir criticas são regras heurísticas/guidelines. Pelo fato da escrita técnica se constituir em um domínio não prescritivo, existe a necessidade da extração de tais regras, para que elas possam auxiliar os usuários no desenvolvimento do processo da escrita.

Para a extração das regras heurísticas/guidelines, além de nos basearmos nos erros típicos relatados por revisores de submissões em conferências CHI já apresentados anteriormente (Subseção 3.3.1.3, Tabela 3.1), também nos baseamos no CHI'96 Guide to Successful Papers Submission. Através de uma análise mais detalhada, acrescentamos mais alguns itens já citados na Tabela 3.1, tais como:

- O autor não indica o que é realmente novo e significativo no seu trabalho, ou o que é diferente em relação aos trabalhos já existentes.

- O autor não indica a utilidade e a relevância do trabalho para a comunidade $\mathrm{CHI}$.

- É necessário que o autor valide as suas idéias e objetivos através de dados apropriados, de análises ou argumentos. No caso de análise de dados, uma metodologia adequada deve ser selecionada e corretamente aplicada para sustentar o trabalho. $\mathrm{O}$ autor deve prover dados suficientes e/ou argumentos bem estruturados, explicar o que da análise, e como, foi feito, citar trabalhos relacionados e abordar tópicos importantes em um nível apropriado de detalhes.

- Caso o autor se proponha a descrever uma nova metodologia, deve ser também incluída alguma avaliação da sua utilidade para as pessoas, mesmo que seja apenas uma indicação dos seus beneficios.

Baseados na análise dos artigos, também descobrimos que:

- O componente domínio (domain) aparece em praticamente todos os artigos;

- O componente background aparece em todos os artigos; e

- O componente propósito (purpose) aparece em todos os artigos,

e dessa forma, concluímos que esses são componentes que devem necessariamente aparecer em uma introdução de artigo, pois são componentes de extrema relevância.

Tomando por base essas anotaçōes e também aquelas feitas por revisores de conferências, pudemos extrair regras heurísticas/gutidelines. Algumas delas são: 
- Se não aparecem justificativas

Então a hipótese não foi validada.

- Se não aparecem trabalhos relacionados ou background

Então o autor não está comparando e contrastando o seu trabalho com a literatura.

- Se não aparecem lições aprendidas ou inovações

Então o trabalho não esboça conclusões, ou seja, simplesmente fornece informações do contexto e discussões sobre a importância do tópico.

- Se não aparecem justificativas

Então o autor apresenta afirmações sem fundamentá-las e as conclusões vão além dos resultados do trabalho.

- Se não aparece o propósito do trabalho

Então o autor não está ressaltando a importância do seu trabalho.

- Se não aparecem o domínio e as lições aprendidas

Então o autor não indica a relevância e a utilidade do trabalho para a comunidade $\mathrm{CHI}$, respectivamente.

- Se não aparecem domínio, background e propósito

Então faltam as partes mais importantes e necessárias da estrutura de um artigo.

- Se o autor ainda não trabalhou com os componentes da estrutura de critérios específicos

Então ele não tem condições de escolher o tipo de artigo.

- Se a estrutura proposta não apresenta componentes esquemáticos repetidos

Então irá caracterizar uma estrutura de Introdução simples.

- Se a estrutura proposta apresenta uma quantidade pequena de componentes (menor ou igual a 4, por exemplo)

Então esta estrutura não é muito comum.

Em seguida, procuramos expressá-las, de acordo com a classificação de críticas de Kukulska-Hulme (1997), na forma como seriam apresentadas aos colaboradores. Por exemplo, algumas delas foram escritas da seguinte forma:

- Eu sugiro que seja acrescentado o componente Rationale para que as afirmações sejam fundamentadas e as conclusões não ultrapassem os resultados do trabalho.

- A citação de Related Work(s)/Background são essenciais para comparar e contrastar o seu trabalho com a literatura atual. 
- O componente Lesson(s) Learned/Innovation(s) deve aparecer para esboçar conclusões.

- É importante que uma introdução apresente o propósito do artigo, representado pelo componente "purpose".

- Bom! Com a citação de Related Work(s)/Background, você está corretamente comparando e contrastando o seu trabalho com a literatura atual.

$\mathrm{Na}$ seqüência, essas regras heurísticas/guidelines foram codificadas, para constituírem as regras heurísticas/guidelines utilizadas pelo crítico analítico. Para cada uma das regras heurísticas/guidelines que identificam faita de componentes (podendo ser apresentada com uma das duas formas de críticas — diretas ou indiretas - ou duas formas de sugestões impessoais para melhorias ou diretas e instruções), também foi codificada a regra heuristica positiva, na forma de elogios. A seguir pode ser visualizado um exemplo do modo como essas regras heurísticas/guidelines foram codificadas:

([purpose], bad, \$falta o propósitol\$,

SÉ importante que uma introdução apresente o propósito do artigo, representado pelo componente "purpose".\$)

Onde os respectivos elementos em Prolog são:

([componentes enfocados], tipo da crítica, título da crítica, mensagem da crítica)

No processo de estruturação de uma introdução de artigo, sempre que o colaborador mudar o foco de trabalho, de schematics para specifics, ou vice-versa, este analisador, baseado nas regras heurísticas/guidelines, irá emitir críticas, com relação à falta de componentes essenciais, quantidade pequena de componentes, componentes iguais na seqüência, etc. Essas críticas poderão ser lidas pelo usuário na janela auxiliar Peer Annotations.

\subsection{Consideraçôes Finais}

Neste capítulo abordamos as decisões de projeto para a construção do protótipo da ferramenta de ensino da escrita técnica em inglês, direcionada à seção introdutória de artigos científicos. Foram 
detalhados todos os passos do desenvolvimento, desde a coleta e análise do corpus, até a construção do protótipo. Dentre as fases abordadas, ênfase maior deve ser atribuída ao modelo computacional para a construção de ferramentas de crítica para a escrita técnica (abordado na Subseção 5.2), pois, este modelo pode ser utilizado como base para a construção de outros sistemas de crítica que possuam enfoque semelhante ao deste trabalho. A descrição do protótipo construído, bem como a do analisador analítico e do diferencial, também se constituem de etapas extremamente importantes para que o leitor/pesquisador compreenda um pouco mais sobre o funcionamento do protótipo. 


\section{Avaliação do Protótipo da Ferramenta de Crítica}

$\mathrm{N}$

o capítulo anterior descremos os passos executados para a construção do protótipo da ferramenta de crítica. Neste capítulo, nos voltamos para uma análise crítica da arquitetura e do funcionamento desse protótipo, respondendo a duas questões: uma relativa à operacionalidade (ele funciona?) e outra relativa à praticidade (ele é prático?). .

Para responder a questão operacional, avaliamos a efetividade da ferramenta em ensinar um usuário a produzir melhores estruturas para um determinado tipo de artigo de uma comunidade. Ela é julgada através de três simulações de supostas utilizaçőes do protótipo por usuários com diferentes níveis de conhecimento da escrita técnica em inglês (detalhadas na Subseção 6.1). Os níveis dos usuários foram: principiante, intermediário e especialista. As ações esperadas por usuários nestas classes foram retiradas de uma classificação para enquadrar textos técnicos em inglês escritos por não-nativos, desenvolvida durante o pós-doutoramento da orientadora deste projeto de mestrado (disponível no Apêndice A). O conjunto de críticas ativado pelo protótipo e a estrutura resultante da seção de cada uma das três simulações, foram avaliados 
quanto à capacidade do protótipo em elevar em pelo menos um o nivel de conhecimento dos usuários participantes, sendo que, para o usuário especialista o protótipo não o deveria fazer descer de nível, isto é, ele não deveria nem atrapalhar a confeç̧ão da estrutura de Introdução deste usuário, nem confundi-lo. Tanto a simulação quanto a análise estão detalhadas nas próximas subseções. Para que o leitor possa compreender com maior clareza as operações realizadas durante as simulações é recomendável uma prévia leitura do Apêndice B.

Para responder a questão prática, analisamos a estendibilidade, personalização, portabilidade e custo de implementação (abordados nas Subseções 6.2.1, 6.2.2, 6.2.3 e 6.2.4, respectivamente).

\subsection{Operacionalidade}

Esta subseção visa ilustrar processos de interação entre o protótipo da ferramenta de crítica e usuários com diferentes niveis de conhecimento em relação à escrita técnica de artigos em inglês. As figuras visualizadas se constituem de screendumps da interface do protótipo desenvolvido $\mathrm{e}$ são utilizadas para ilustrar o seu funcionamento.

\subsubsection{Interação Entre um Usuário Inexperiente e o Protótipo}

De acordo com a classificação apresentada no Apêndice $A$, os textos produzidos por usuários inexperientes normalmente não possuem componentes essenciais da estrutura esquemática (como por exemplo: background, revisão de literatura e propósito), além de se apresentarem pobres em termos de organização e coerência.

No apêndice $B$, mostramos como o protótipo deve ser inicializado para uma sessão com um ou mais usuários. Assim, com o protótipo da ferramenta previamente inicializado, o usuário inicia o processo de seleção e inserção de componentes esquemáticos, ou seja, começa a montagem da sua estrutura de introdução de artigo.

Visto que este usuário é inexperiente no dominio da escrita técnica, supõe-se que os componentes esquemáticos por ele selecionados não sejam suficientes para caracterizar uma boa estrutura, ao contrário, a sua estrutura de componentes esquemáticos irá se caracterizar pela falta de componentes essenciais e por não apresentar uma boa ordem. Um exemplo de estrutura com essas características pode ser visualizado na Figura 6.1. A partir do momento em que o usuário 
transfere o foco para um outro componente ("specifics", por exemplo) a ferramenta disponibiliza críticas à estrutura. Um exemplo dessas críticas é ilustrado na Figura 6.2.

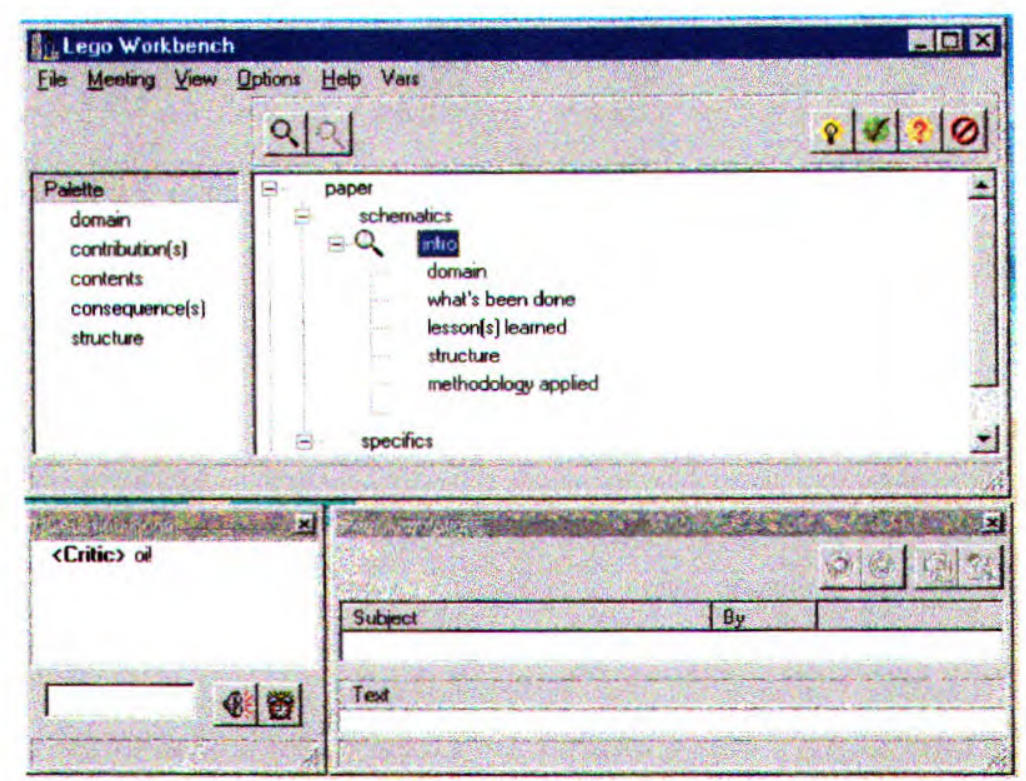

Figura 6.1: Uma Estrutura Inicial Proposta por um Usuário Inexperiente no Domínio da Escrita Técnica

A Figura 6.2 mostra todas as críticas que foram emitidas com relação ao componente "Intro", ou seja, com relação à introdução do artigo como um todo (perceba que "Intro" aparece num tom de cinza claro, o que indica que as críticas que estão sendo visualizadas em Peer Annotations dizem respeito a este componente). Esta observação se faz necessária porque, como também pode ser visualizado na Figura 6.2, foram também emitidas críticas na forma de elogios para os componentes "domain" e "lesson(s) learned". Para acessar essas críticas basta clicar sobre cada um desses componentes e depois sobre o subject da crítica na janela Peer Annotations. 


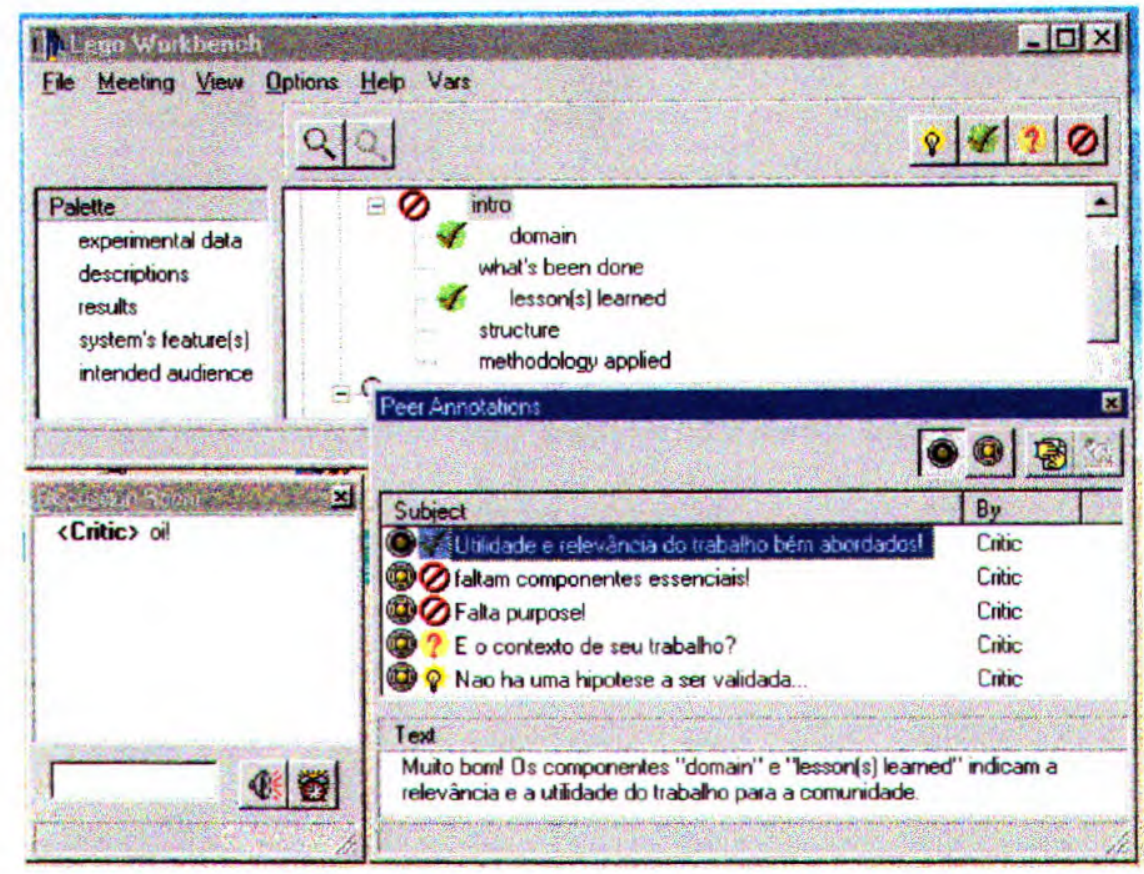

Figura 6.2: Visualização das Críticas Emitidas pelo Protótipo a um Usuário Inexperiente no Domínio da Escrita Técnica

As críticas que aparecem na Figura 6.2 podem ser melhor visualizadas na Tabela 6.1 (críticas relacionadas ao componente "Intro") e Tabela 6.2 (críticas relacionadas aos componentes "domain" e "lesson(s) learned", respectivamente).

Tabela 6.1: Caracterização das Críticas Emitidas a um Usuário Inexperiente no Domínio da Escrita Técnica - Componente "Intro"

\begin{tabular}{|l|l|l|l|}
\hline Subject & Tipo & Forma de Crítica & Texto da Crítica \\
\hline $\begin{array}{l}\text { Utilidade e } \\
\text { relevância do } \\
\text { trabalho bem } \\
\text { abordados! }\end{array}$ & Good! & Crítica Positiva & $\begin{array}{l}\text { Muito bom! Os componentes "domain" e "lesson(s) } \\
\text { learned" indicam a relevância e a utilidade do trabalho } \\
\text { para comunidade. }\end{array}$ \\
\hline $\begin{array}{l}\text { Faltam componentes } \\
\text { essenciais! }\end{array}$ & Bad! & Crítica Direta & $\begin{array}{l}\text { Os componentes "domain", "background" e "purpose" } \\
\text { são os mais importantes e necessários em uma } \\
\text { introdução. }\end{array}$ \\
\hline Falta "purpose"! & Bad! & Crítica Direta & $\begin{array}{l}\text { Falta o componente "purpose", e este é essencial em uma } \\
\text { introdução de artigo. }\end{array}$ \\
\hline $\begin{array}{l}\text { E o contexto de seu } \\
\text { trabalho? }\end{array}$ & Hum... & Crítica Indireta & $\begin{array}{l}\text { A citação de "related work(s)/background" são essenciais } \\
\text { para comparar e contrastar o seu trabalho com a literatura } \\
\text { atual. }\end{array}$ \\
\hline $\begin{array}{l}\text { Não há uma hipótese } \\
\text { a ser validada... }\end{array}$ & New! & $\begin{array}{l}\text { Sugestão Direta e e } \\
\text { Instrução }\end{array}$ & $\begin{array}{l}\text { Eu sugiro que seja acrescentado o componente } \\
\text { "rationale" para que as afirmações sejam fundamentadas. }\end{array}$ \\
\hline
\end{tabular}


Tabela 6.2: Caracterização das Críticas Emitidas a um Usuário Inexperiente no Domínio da Escrita Técnica - Componentes "domain" e "lesson(s) learned"

\begin{tabular}{|l|l|l|l|}
\hline Subject & Tipo & Forma de Crítica & Texto da Crítica \\
\hline $\begin{array}{l}\text { Componentes } \\
\text { importantes e úteis } \\
\text { foram abordados... }\end{array}$ & Good! & Elogio & $\begin{array}{l}\text { Excelente! Os componentes "domain/background/ } \\
\text { purpose" são os mais importantes de uma introdução. }\end{array}$ \\
\hline $\begin{array}{l}\text { Trabalho bem } \\
\text { concluido! }\end{array}$ & Good! & Elogio & $\begin{array}{l}\text { Parabéns! A escolha dos componentes "lesson(s) } \\
\text { learned/innovations" lhe permitirá relatar conclusões } \\
\text { sobre o seu trabalho. }\end{array}$ \\
\hline
\end{tabular}

Após ler as críticas emitidas pelo protótipo, o usuário passa a ter conhecimento de quais componentes são essenciais na montagem de uma estrutura. A partir de então, ele pode realizar uma série de alterações na estrutura inicial, ou seja, pode excluir e inserir componentes. Ele pode, também, alterar a ordem dos componentes, embora uma crítica sobre as organizações mais comuns encontradas na base vai aparecer somente na ativação da crítica passiva, onde são recuperados os casos mais semelhantes ao caso proposto (veja Figura 6.4). Um exemplo de como a estrutura anterior pode ficar após sofrer alterações pelo usuário, supondo-se que ele tenha aceitado a terceira, a quarta e a quinta crítica (conforme ordem da Tabela 6.1), é mostrado na Figura 6.3, já com as novas críticas emitidas pelo protótipo.

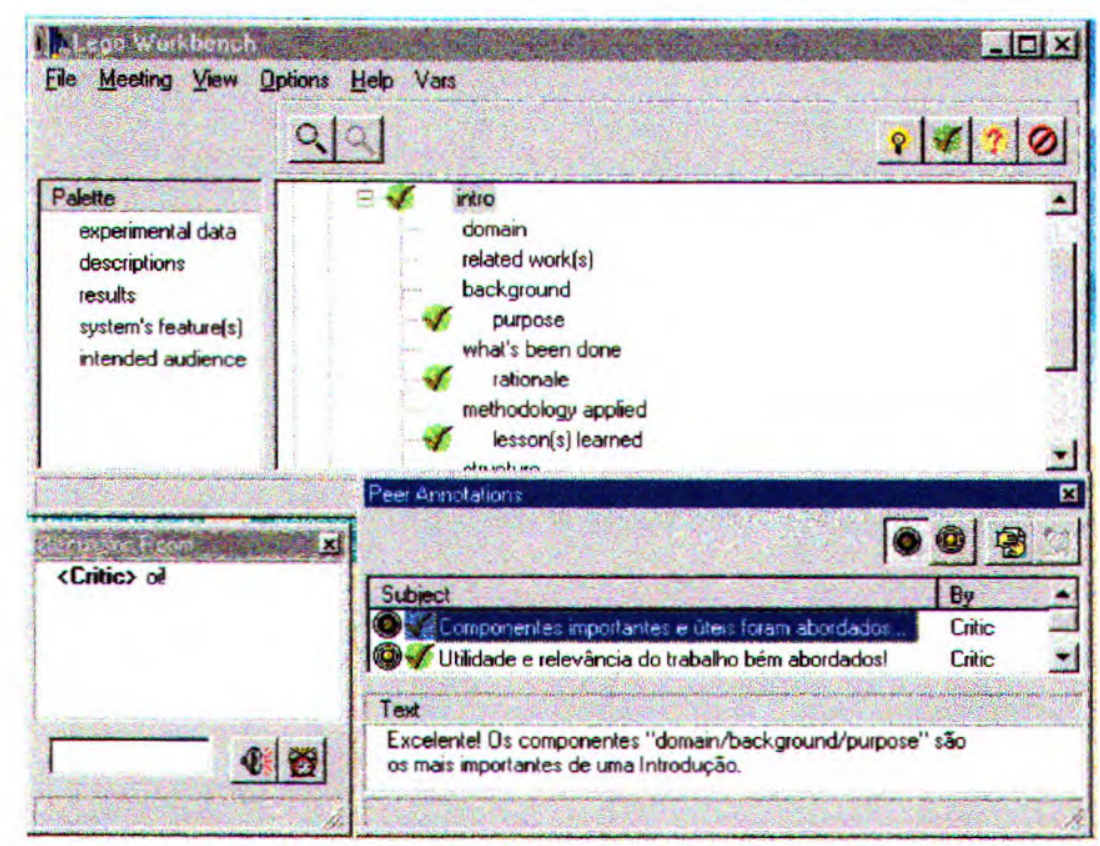

Figura 6.3: Novas Críticas Emitidas pelo Protótipo em Resposta a Alterações Realizadas por um Usuário Inexperiente no Domínio da Escrita Técnica 
As críticas que aparecem na Figura 6.3 podem ser visualizadas na Tabela 6.3 (críticas relacionadas ao componente "Intro") e na Tabela 6.4 (críticas relacionadas aos componentes "purpose", "rationale" e "lesson(s) learned", respectivamente) de modo mais completo.

Tabela 6.3: Caracterização das Novas Críticas Emitidas a um Usuário Inexperiente no Domínio da Escrita Técnica - Componente "Intro"

\begin{tabular}{|l|l|l|l|}
\hline Subject & Tipo & Forma de Crítica & Texto da Crítica \\
\hline $\begin{array}{l}\text { Componentes } \\
\text { importantes e úteis } \\
\text { foram abordados! }\end{array}$ & Good! & Elogio & $\begin{array}{l}\text { Excelentel Os componentes "domain/backgroundl } \\
\text { purpose" săo os mais importantes de uma introduçăo. }\end{array}$ \\
\hline $\begin{array}{l}\text { Utilidade e relevância } \\
\text { do trabalho bem } \\
\text { abordados! }\end{array}$ & Good! & Elogio & $\begin{array}{l}\text { Muito bom! Os componentes “domain" e "lesson(s) } \\
\text { leamed" indicam a relevância e a utilidade do trabalho } \\
\text { para a comunidade. }\end{array}$ \\
\hline $\begin{array}{l}\text { Trabalho } \\
\text { contextualizadol }\end{array}$ & Good! & Elogio & $\begin{array}{l}\text { Bom! Com a escolha dos componentes "related work(s) } \\
\text { lbackground" vocè está corretamente comparando e } \\
\text { contrastando o seu trabalho com a literatura atual. }\end{array}$ \\
\hline
\end{tabular}

Tabela 6.4: Caracterização das Novas Críticas Emitidas a um Usuário Inexperiente no Domínio da Escrita Técnica - Componentes "purpose", "rationale" e "lesson(s) learned"

\begin{tabular}{|l|l|l|l|}
\hline Subject & Tipo & Forma de Crítica & Texto da Crítica \\
\hline "Purpose" é essencial... & Good! & Elogio & $\begin{array}{l}\text { Otimo! "Purpose" é um dos componentes mais } \\
\text { importantes de uma introdução. Com ele, você pode } \\
\text { ressaltar a importancia do seu trabalho! }\end{array}$ \\
\hline $\begin{array}{l}\text { Trabalho bem } \\
\text { fundamentado! }\end{array}$ & Good! & Elogio & $\begin{array}{l}\text { Ótimo! Com o componente "rationale" vocè está } \\
\text { fundamentando as afirmaçôes e consequitentemente } \\
\text { validando a hipótese! }\end{array}$ \\
\hline $\begin{array}{l}\text { Trabalho bem } \\
\text { concluído! }\end{array}$ & Good! & Elogio & $\begin{array}{l}\text { Parabéns! A escolha do componente "lesson(s) leamedl } \\
\text { innovations" the permitirá relatar conclusóes sobre o } \\
\text { seu trabalho. }\end{array}$ \\
\hline
\end{tabular}

Neste momento podemos perceber a existência de componentes essenciais que não haviam aparecido na estrutura inicial. Desta forma, notamos que as críticas transmitiram um conhecimento adicional para o usuário, que agora pode ser classificado como um usuário com nível de conhecimento intermediário. Geralmente, um usuário com nível de conhecimento intermediário monta sua estrutura sem se esquecer de componentes essenciais como revisão de literatura, background e propósito do artigo. Caracterizam-se ainda por apenas anexarem/listarem componentes opcionais em vez de os integrarem na estrutura.

O usuário e o protótipo trabalham de forma iterativa. Os ciclos podem ocorrer quantas vezes o usuário desejar ou achar necessário para atingir o seu objetivo. No nosso exemplo de simulação não repetiremos muitas vezes esse ciclo para não tornar o texto por demais repetitivo. 
Após a leitura das novas críticas, o usuário pode novamente voltar às alterações na sua estrutura de introdução de artigo, no intuito de otimizá-la. Assim, se necessário, novos componentes podem ser inseridos, alguns podem ser excluídos e a ordem deles pode ser alterada, até o momento em que as críticas podem ser visualizadas na forma de elogios (como ilustra a Figura 6.3). É importante notar que não há críticas relacionadas à ordem. $O$ usuário pode, entretanto, verificar se a ordem de sua estrutura está boa através do pedido de recuperação de casos. Neste caso haverá uma recuperação dos casos similares com relação à ordem (veja Figura 6.4). Quando uma estrutura chega a um ponto refinado com relação à componentes e ordem (ocasião em que recebe um score alto neste critério), significa que o usuário que a elaborou possui bom nível de experiência no domínio, ou seja, além de selecionar componentes essenciais, optou também por bons componentes opcionais e os posicionou em uma ordem coerente.

Para que o protótipo recupere os casos mais semelhantes (com relação à estrutura esquemática, específica ou ambas) e os disponibilize para visualização no browser Panorama PRO, o usuário deve primeiramente clicar sobre o botão Hum... e em seguida sobre o componente "paper" (para recuperar os melhores casos considerando todos os critérios relativos à parte esquemática e específica)", sobre o componente "Intro" ou "schematics" (para recuperar os melhores casos seguindo os critérios relativos à parte esquemática) ou sobre o componente "specifics" (para recuperar casos seguindo os critérios relativos à parte específica); na janela Annotation Editor que surgirá, o usuário deve escrever example no subject, e então ganhará a janela Peer Annotations, que contém estatísticas e hyperlinks de acesso aos casos recuperados (Figura 6.4).

Caso o usuário tenha dúvida com relação ao melhor posicionamento de um componente na estrutura, ele pode solicitar, ao protótipo, exemplos de casos nos quais aquele componente está presente. Para isso, basta que o usuário proceda da mesma forma como foi descrito no parágrafo anterior, porém, em vez de clicar sobre o componente paper//ntro/schematics/specifics, ele deverá clicar sobre o componente no qual possui a dúvida. Assim, o usuário irá visualizar os hyperlinks de acesso aos vários casos onde aquele componente está presente, podendo com isso verificar a ordem dele nos exemplos recuperados, além de poder associá-lo à presença de outros (por exemplo, related work(s) e background são componentes que estão intimamente ligados).

\footnotetext{
${ }^{7}$ Estes critérios (e os demais citados nesta subseção) foram abordados na Subseção 5.4.3.1.
} 


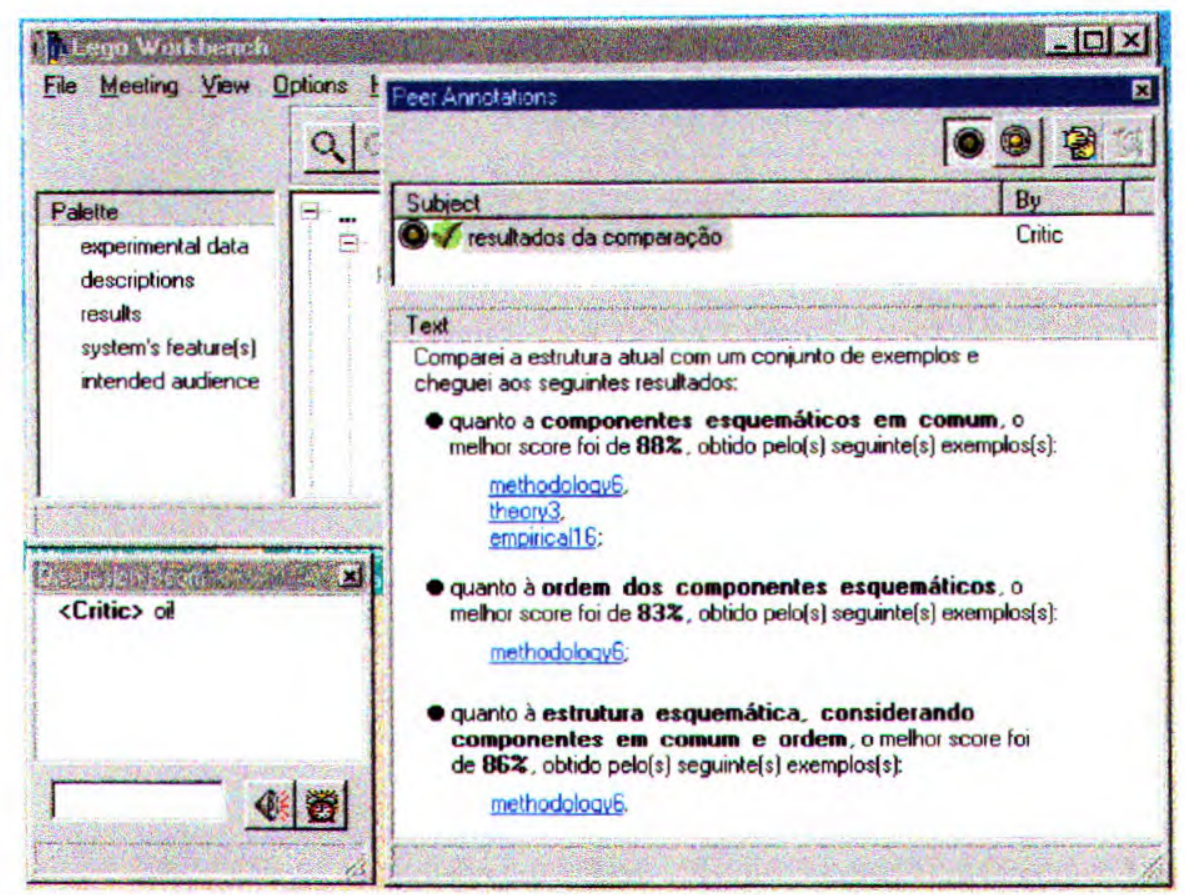

Figura 6.4: Crítica Sobre Resultados da Comparação do Caso Estruturado com os Casos da Base de Casos (Usuário Inexperiente no Domínio da Escrita Técnica)

Note que os nomes dos casos estão sob a forma de hyperlinks que, quando selecionados, executam o software Panorama PRO, que apresenta os casos anotados. Para alternar entre o caso anotado com os componentes esquemáticos e o caso anotado com os componentes específicos, e vice-versa, existe, no início do arquivo, um hyperlink com esta função. As figuras 6.5 e 6.6 ilustram o caso metodology6, escolhido para visualização por ser o que possui o maior índice de similaridade com relação aos critérios utilizados para a parte esquemática (indicado na Figura $6.4)$. 


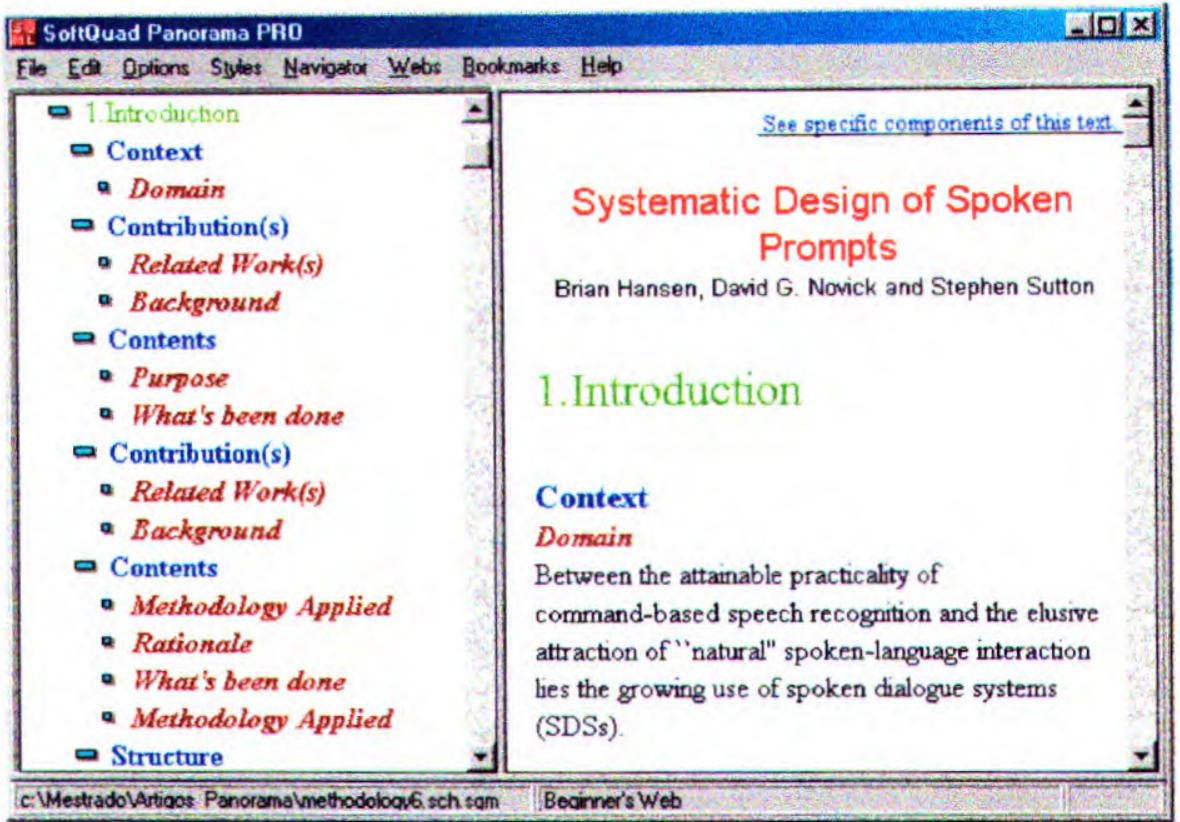

Figura 6.5: Caso Recuperado pelo Panorama PRO Mostrando a Estrutura de Componentes Esquemáticos (Usuário Inexperiente no Domínio da Escrita Técnica)

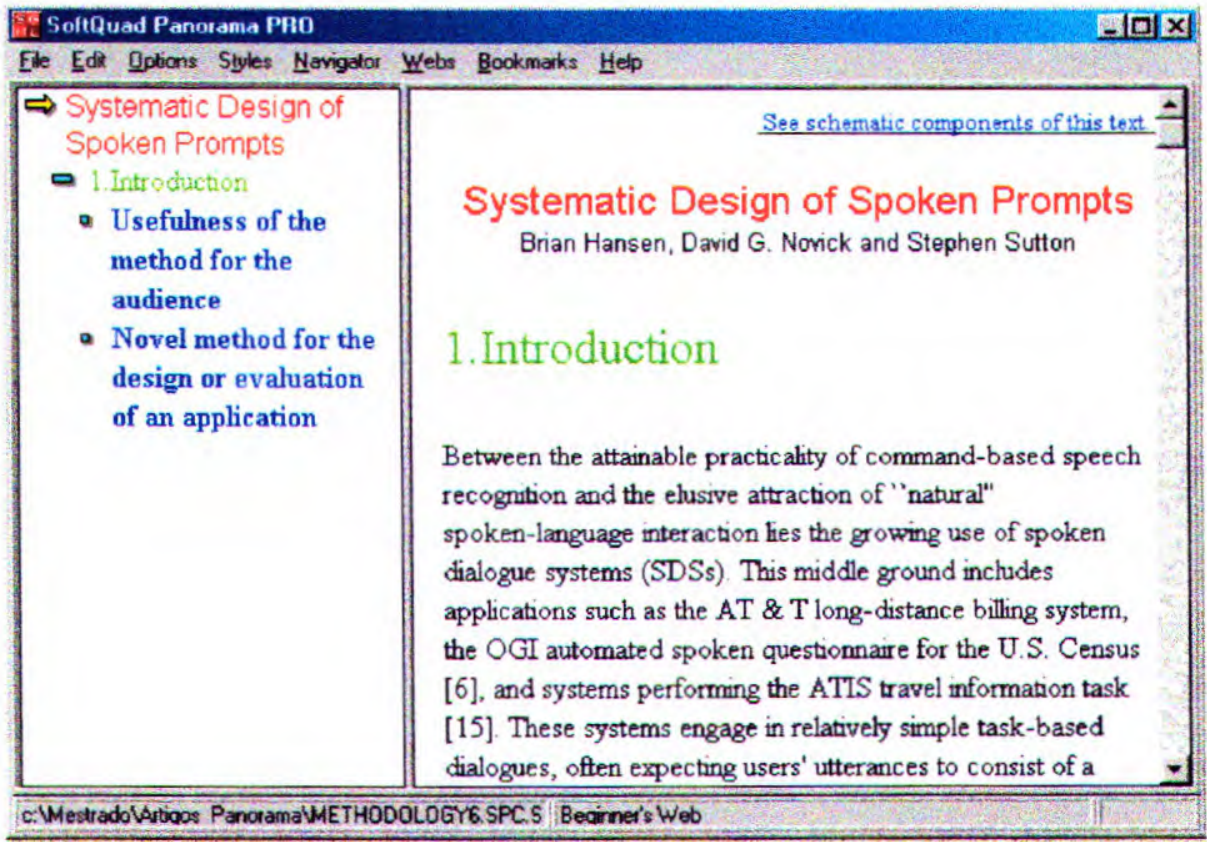

Figura 6.6: Mesmo Caso da Figura 6.5, porém Mostrando a Estrutura de Componentes Específicos (Usuário Inexperiente no Domínio da Escrita Técnį̣a) 


\subsubsection{Interação Entre um Usuário de Nível Intermediário e o Protótipo}

Seguindo a classificação apresentada no Apêndice A, os textos produzidos por usuários com nível de conhecimento médio no domínio da escrita técnica normalmente apresentam componentes essenciais da estrutura esquemática (como por exemplo: background, related wok(s) e purpose) e apresentam também componentes opcionais, porém a ordem em que eles são encaixados na estrutura nem sempre é a melhor.

De acordo com os conhecimentos desse tipo de usuário, podemos perceber, conforme ilustra a Figura 6.7, a inserção de componentes essenciais e também de componentes opcionais. Outra característica marcante desse tipo de usuário, e que pode ser visualizada com clareza, é a inserção de uma quantidade razoável de componentes, porém há uma falta aparente de coerência com relação à organização destes componentes.

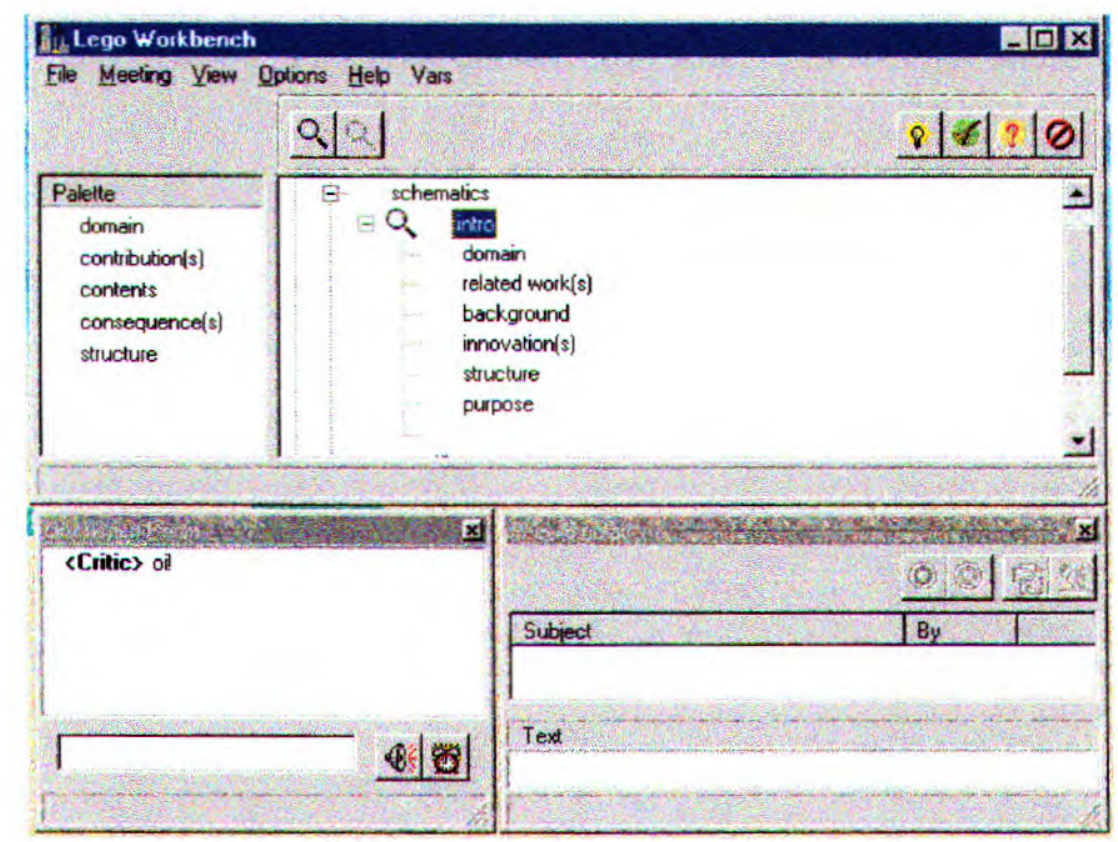

Figura 6.7: Uma Estrutura Inicial Proposta por um Usuário com Nível Médio de Experiência no Domínio da Escrita Técnica

Quando ocorre a mudança de foco, as críticas com relação à estrutura esquemática tornam-se disponíveis. A princípio, são proferidas algumas críticas (elogios e sugestões) relacionadas ao componente "Intro" (Figura 6.8) e alguns elogios referentes a componentes que foram corretamente inseridos na estrutura que está sendo elaborada (conforme Figura 6.8, indicação de elogios relacionados aos componentes "domain", "innovation(s)" e "purpose"). 


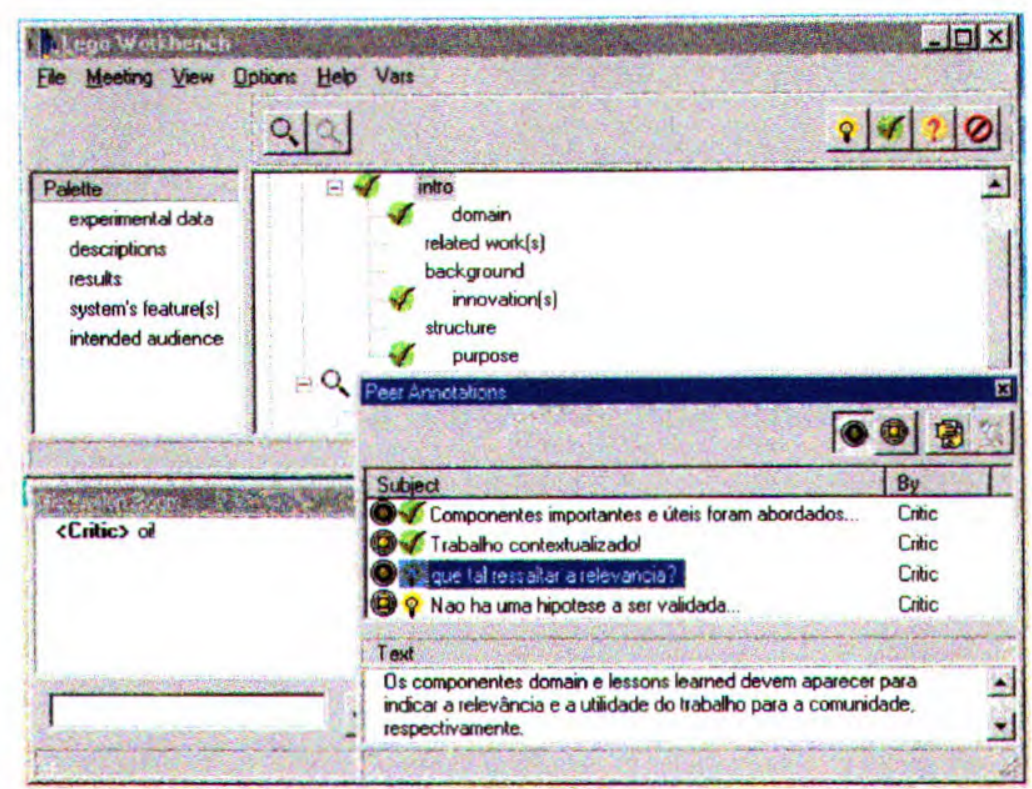

Figura 6.8: Visualização das Críticas Emitidas pelo Protótipo a um Usuário com Nível Médio de Experiência no Domínio da Escrita Técnica

As críticas relacionadas ao componente "Intro" podem ser visualizadas de modo mais completo na Tabela 6.5, enquanto que os elogios que aparecem nos demais componentes ("domain", "innovation(s)" e "purpose") podem ser visualizadas, respectivamente, na Tabela 6.6.

Tabela 6.5: Caracterização das Críticas Emitidas a um Usuário com Nível Médio de Experiência no Domínio da Escrita Técnica - Componente "Intro"

\begin{tabular}{|l|l|l|l|}
\hline Subject & Tipo & Forma de Crítica & Texto da Crítica \\
\hline $\begin{array}{l}\text { Componentes } \\
\text { importantes e úteis } \\
\text { foram abordados... }\end{array}$ & Good! & Elogio & $\begin{array}{l}\text { Excelente! Os componentes "domain/background/ purpose" } \\
\text { são os mais importantes de uma Introdução. }\end{array}$ \\
\hline $\begin{array}{l}\text { Trabalho } \\
\text { contextualizado! }\end{array}$ & Good! & Elogio & $\begin{array}{l}\text { Bom! Com a escolha dos componentes "related work(s)/ } \\
\text { background" você está corretamente comparando e } \\
\text { contrastando o seu trabalho com a literatura atual. }\end{array}$ \\
\hline $\begin{array}{l}\text { Que tal ressaltar a } \\
\text { relevância? }\end{array}$ & New! & $\begin{array}{l}\text { Sugestão Direta e e } \\
\text { Instrução }\end{array}$ & $\begin{array}{l}\text { Os componentes "domain" e "lesson(s) learned" devem } \\
\text { aparecer para indicar a relevância e a utilidade do trabalho para } \\
\text { a comunidade, respectivamente. }\end{array}$ \\
\hline $\begin{array}{l}\text { Não há uma hipótese } \\
\text { a ser validada... }\end{array}$ & New! & $\begin{array}{l}\text { Sugestão Direta e e } \\
\text { Instrução }\end{array}$ & $\begin{array}{l}\text { Eu sugiro que seja acrescentado o componente "rationale" para } \\
\text { que as afirmações sejam fundamentadas. }\end{array}$ \\
\hline
\end{tabular}


Tabela 6.6: Caracterização das Críticas Emitidas a um Usuário com Nível Médio de Experiência no Domínio da Escrita Técnica - Componentes "domain", "innovation(s)" e "purpose"

\begin{tabular}{|l|l|l|l|}
\hline Subject & Tipo & Forma de Crítica & Texto da Crítica \\
\hline $\begin{array}{l}\text { Utilidade e relevância } \\
\text { do trabalho bem } \\
\text { abordados... }\end{array}$ & Good! & Elogio & $\begin{array}{l}\text { Muito bom! Os componentes "domain" e "lesson(s) learned" } \\
\text { indicam a relevância e a utilidade do trabalho para a comunidade. }\end{array}$ \\
\hline $\begin{array}{l}\text { Trabalho bem } \\
\text { concluido! }\end{array}$ & Good! & Elogio & $\begin{array}{l}\text { Parabéns! A escolha do componente "lesson }(s) \text { learned/ } \\
\text { innovations" lhe permitirá relatar conclusões sobre o seu } \\
\text { trabalho. }\end{array}$ \\
\hline $\begin{array}{l}\text { "Purpose" é } \\
\text { essencial... }\end{array}$ & Good! & $\begin{array}{l}\text { Ótimo! "Purpose" é um dos componentes mais importantes de } \\
\text { uma introdução. Com ele, você pode ressaltar a importância do } \\
\text { seu trabalho! }\end{array}$ \\
\hline
\end{tabular}

Considerando as críticas que foram emitidas pelo protótipo, o usuário irá novamente focalizar specifics e irá realizar alterações na estrutura. Supondo que ele não aceite a sugestão de inserção do componente "lesson(s) learned" (terceira crítica da tabela 6.5), pelo fato de já ter inserido o componente "innovation(s)", e aceite somente a sugestão de inserção do componente "rationale" (quarta crítica da Tabela 6.5). Quando o foco for mudado novamente, as mesmas críticas poderão ser visualizadas, com exceção da quarta crítica da Tabela 6.5 ("Não há uma hipótese a ser validada..."). O usuário resolve então solicitar ao protótipo a recuperação de casos; o resultado pode ser visualizado na Figura 6.9.

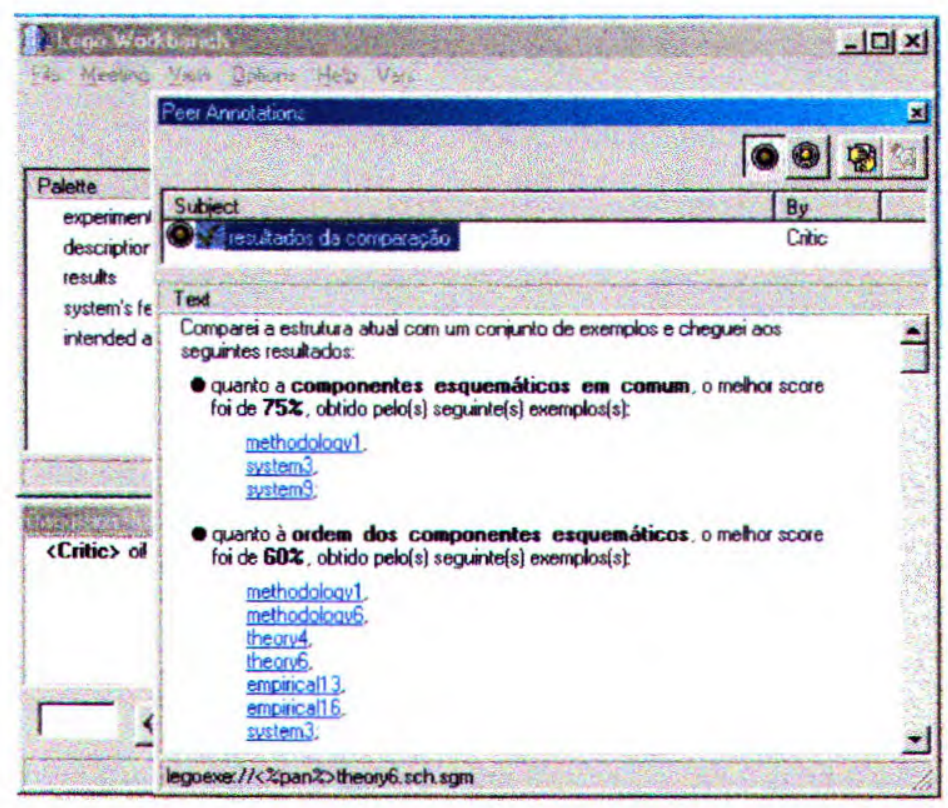

Figura 6.9: Crítica Sobre Resultados da Primeira Comparação do Caso Proposto com os Casos da Base de Casos (Usuário com Nível Médio de Conhecimento no Domínio da Escrita Técnica) 
A paritr da visualização dos casos recuperados, o usuário nota que alguns componentes se repetem nas estruturas. Baseado nesta descoberta, ele tenta a inserção de um segundo componente "related work(s)" após o componente "background" já existente, porém, em vez de posicionar o ponteiro para inserção abaixo de "background", ele posicionou o ponteiro sobre "background", tentado assim, inserir "related work(s)" abaixo do "related work(s)" já existente, o que culminou com a crítica intrusiva, cuja mensagem pode ser visualizada na Figura 6.10.

Para dar continuidade ao seu trabalho, o usuário lê a crítica e prossegue nas suas inserções. Quando insere o segundo componente "related work(s)" em um local permitido, uma nova crítica é disponibilizada com o intuito de ensinar recursos de aprimoramento da estrutura para o usuário (Figura 6.11).

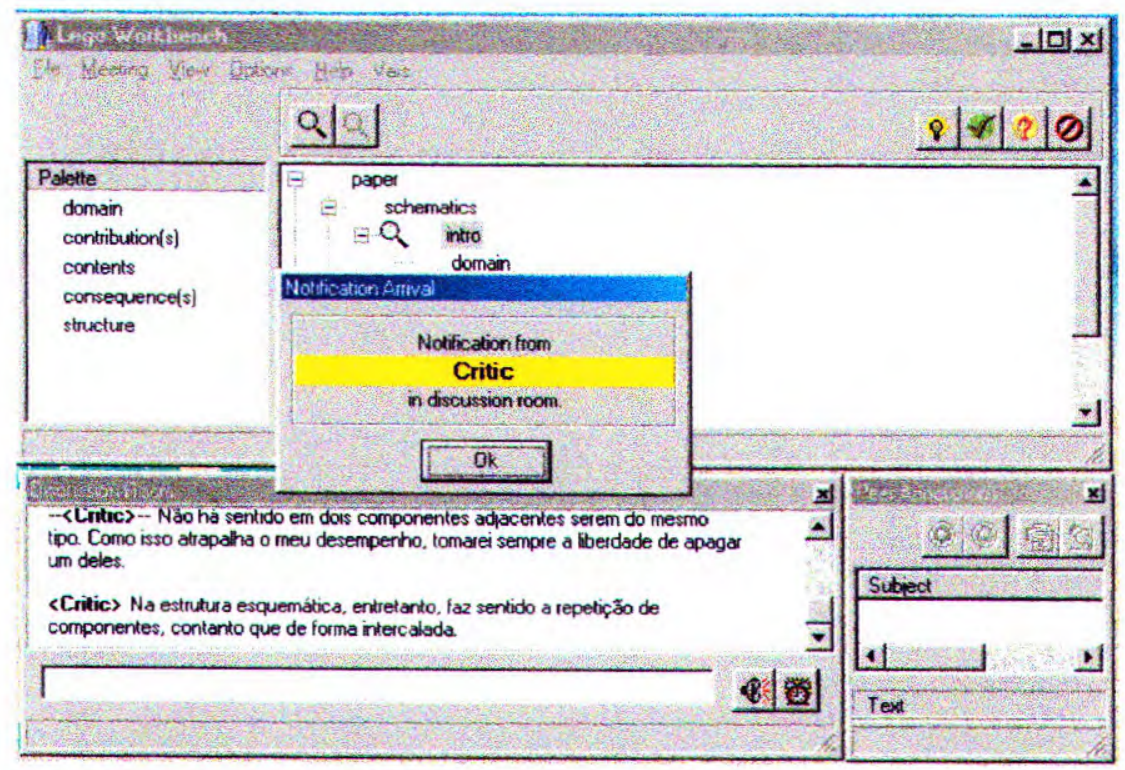

Figura 6.10: Crítica Intrusiva Emitida a um Usuário com Nível Médio de Experiência no Domínio da Escrita Técnica em Resposta a uma Ação Incorreta 


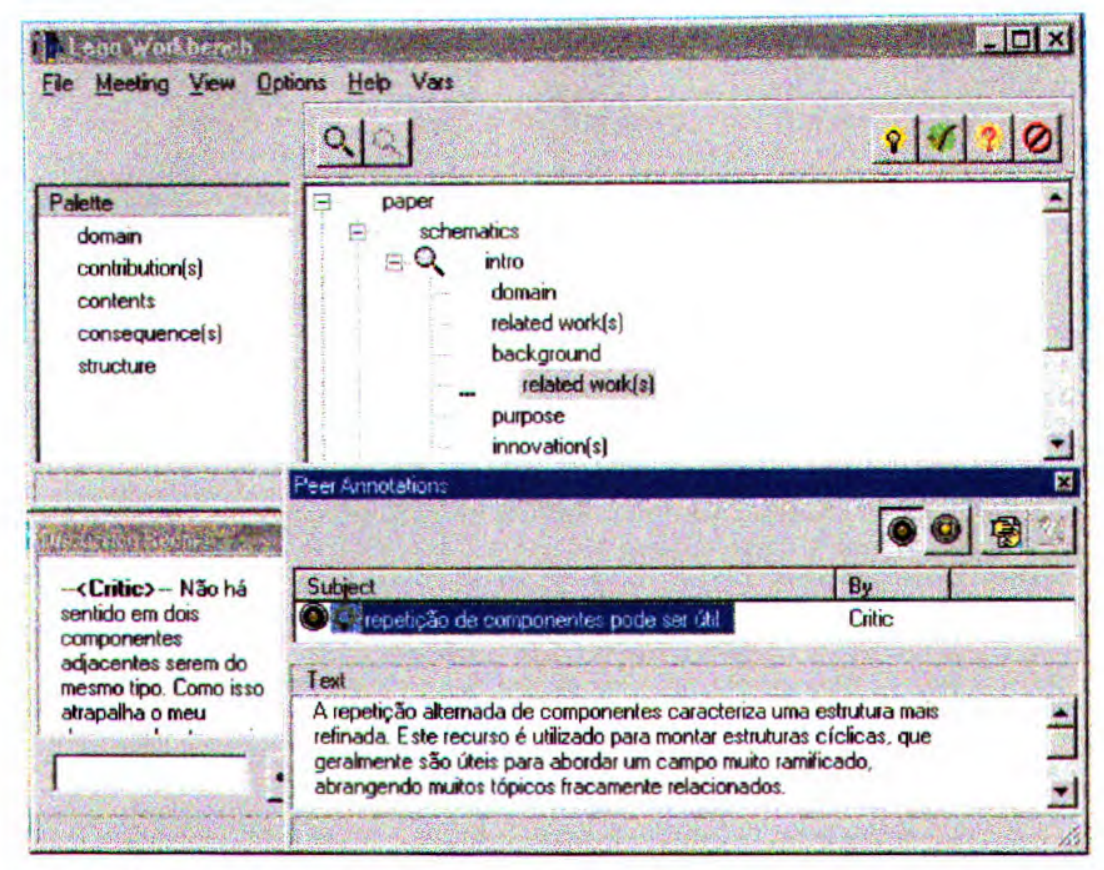

Figura 6.11: Crítica na Forma de Instrução Emitida a um Usuário com Nível Médio de Experiência no Domínio da Escrita Técnica

De posse da estrutura alterada, o usuário muda o foco e recebe novas críticas. Essas críticas são: uma na forma de elogio, e duas na forma de sugestão direta e instrução, conforme pode ser visualizado na Figura 6.12. A leitura do elogio contribui para que o usuário fixe conceitos; no caso específico desta simulação, as sugestões emitidas na iteração dizem respeito à falta do componente (i) "lesson(s) learned", sugestão essa que já havia sido emitida anteriormente, momento em que o usuário abriu mão da inserção deste componente pelo fato de já ter inserido o componente "innovation(s)", e do componente (ii) "rationale", sugerido para que as afirmações sejam fundamentadas.

Com a estrutura esquematizada, o usuário solicita, novamente, ao protótipo a recuperação de casos semelhantes na base de casos. Em seguida visualiza no Peer Annotations as estatísticas e os hyperlinks para os casos mais semelhantes e pode então acessá-los (Figura 6.13). 


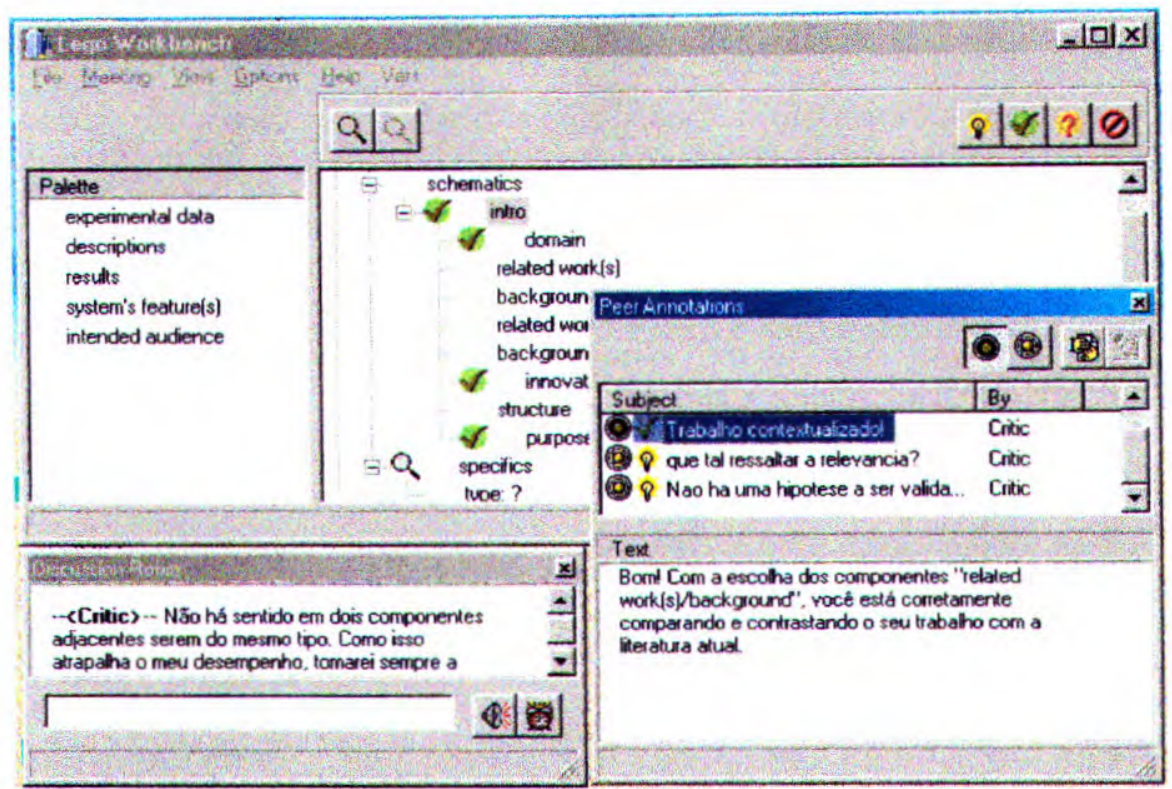

Figura 6.12: Novas Críticas Emitidas pelo Protótipo a um Usuário com Nível Médio de Experiência no Domínio da Escrita Técnica

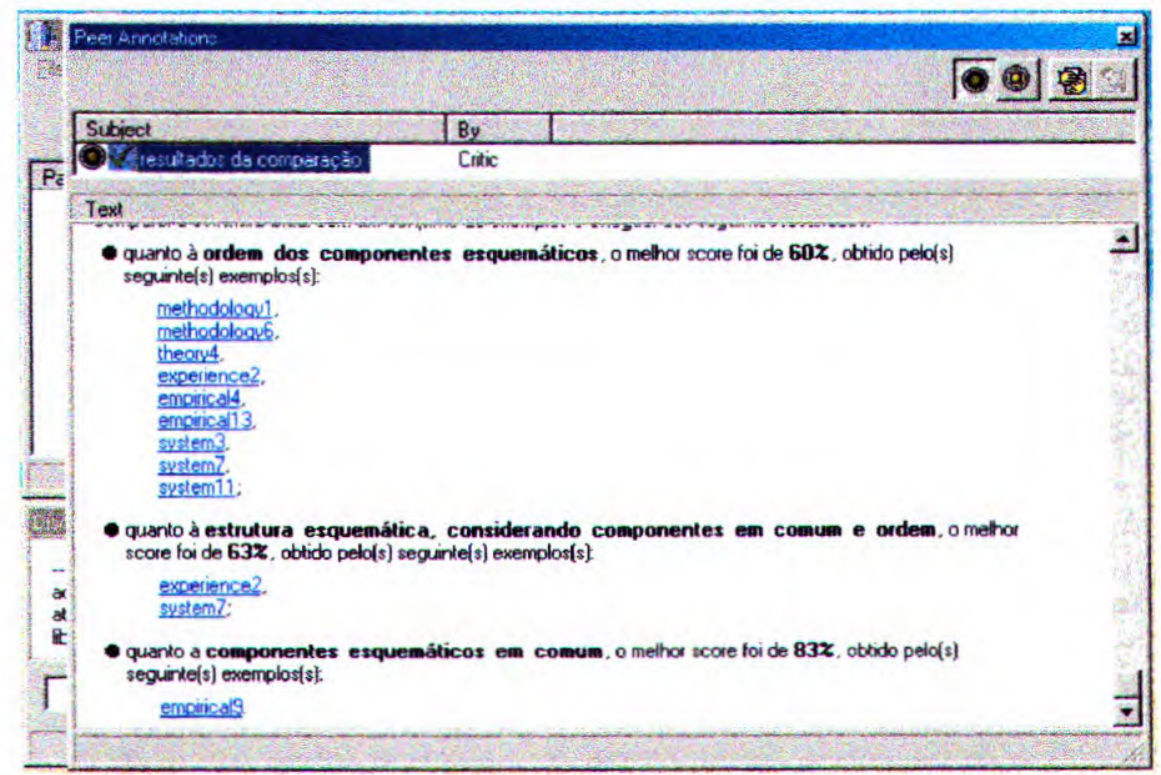

Figura 6.13: Casos Recuperados pelo Panorama PRO em Resposta a uma Estrutura Proposta por um Usuário com Nível Médio de Experiência no Domínio da Escrita Técnica

Como podemos perceber, as estatísticas resultantes da comparação entre o caso proposto e os casos da base, indicam níveis médios de semelhança, tanto em relação somente à ordem dos componentes esquemáticos quanto a componentes esquemáticos em comum e ordem. Porém, com relação a componentes esquemáticos em comum, sem levar em consideração a ordem, as estatísticas indicam níveis maiores de semelhanças. Então, o usuário analisa os vários casos 
recuperados e percebe que, se com relação a componentes esquemáticos em comum o score obtido foi de $83 \%$, o que deve ser melhorada é a ordem em que esses componentes devem ser dispostos; assim, ele altera a ordem do componente "purpose" (conforme Figura 6.14), porque, nos casos recuperados pelo protótipo, raramente este componente aparece como o último da estrutura. Com a estrutura novamente alterada, após nova solicitação para comparação e recuperação de casos, as estatísticas obtidas são melhores que as anteriores tanto em relação à ordem dos componentes esquemáticos ( $80 \%$ é o score atual, contra $60 \%$ da iteração anterior), quanto a elementos em comum e ordem ( $71 \%$ é o score atual, contra $63 \%$ da iteração anterior); em relação a componentes esquemáticos em comum o score foi de $83 \%$, ou seja, manteve-se igual à iteração anterior.

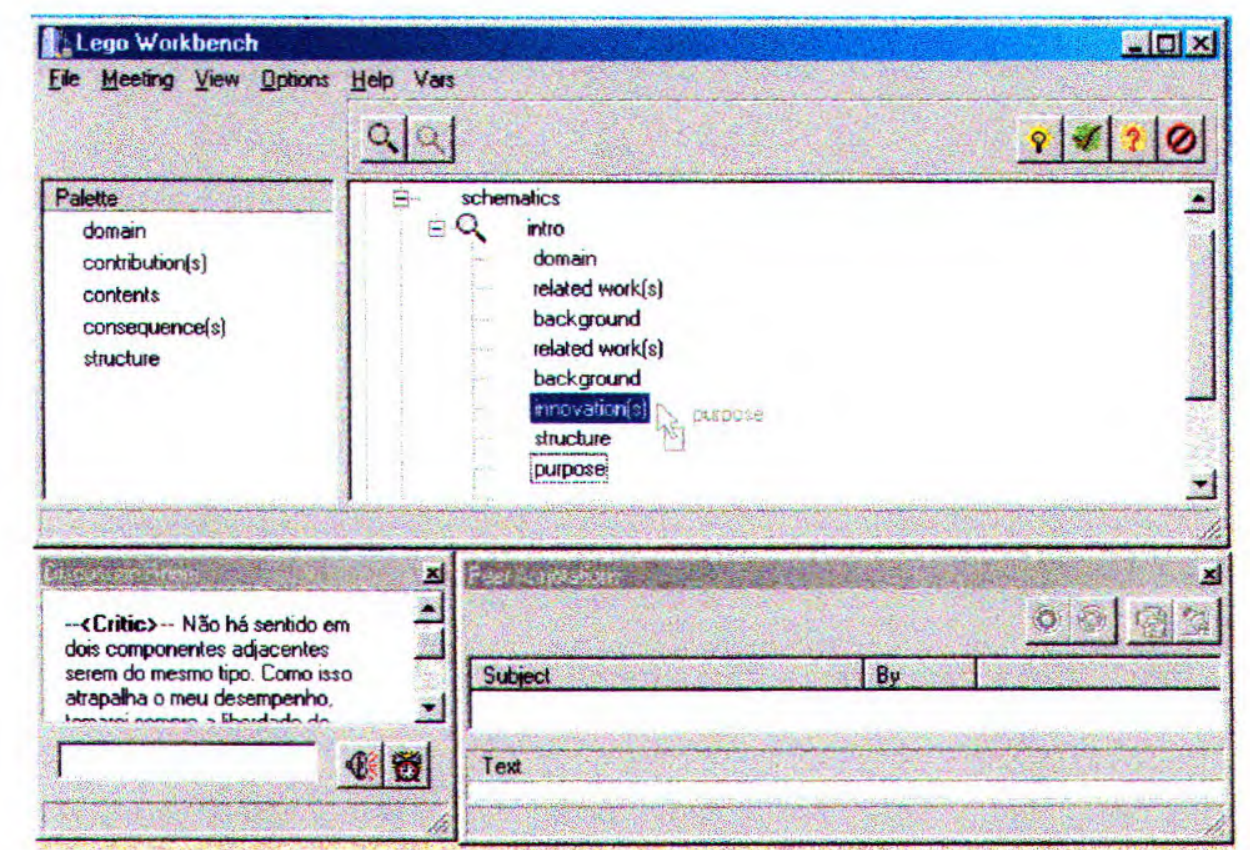

Figura 6.14: Alteração da Ordem de Componentes da Estrutura Esquemática Realizada por um Usuário com Nível Médio de Experiência no Domínio da Escrita Técnica

Assim concluímos que, tanto as críticas, quanto a visualização dos casos recuperados transmitiram um conhecimento adicional para o usuário, que agora pode ser classificado como um usuário com nível de conhecimento avançado. 


\subsubsection{Interação Entre um Usuário com Nível de Conhecimento Avançado e o Protótipo}

Pela classificação de usuário experiente apresentada no Apêndice A, o usuário esquematizará uma ótima estrutura de introdução de artigo, visto que ele conseguirá se expressar muito claramente com relação à escolha de componentes essenciais e também de componentes opcionais e, além disso, conseguirá integrá-los de forma bastante coerente.

Como exemplo de simulação entre um usuário experiente e o protótipo da ferramenta de crítica, podemos imaginar uma situação semelhante à demonstrada na Figura 6.15, onde já podem ser visualizadas, além da estrutura proposta, as críticas emitidas pelo protótipo em relação à estrutura. Como pode ser visto, apenas elogios foram atribuídos a este esquema, visto que apresenta um ótimo conjunto de componentes em uma ordem muito boa, além de apresentar a repetição de componentes, o que caracteriza uma estrutura muito bem elaborada. É interessante notar que a ferramenta não está preparada para fazer críticas (não há guidelines) quanto à ordem. Porém, como comentado na subseção anterior o resultado do pedido de recuperação de casos, e a visualização dos mesmos, fornece informações úteis para se melhorar a ordem dos componentes.

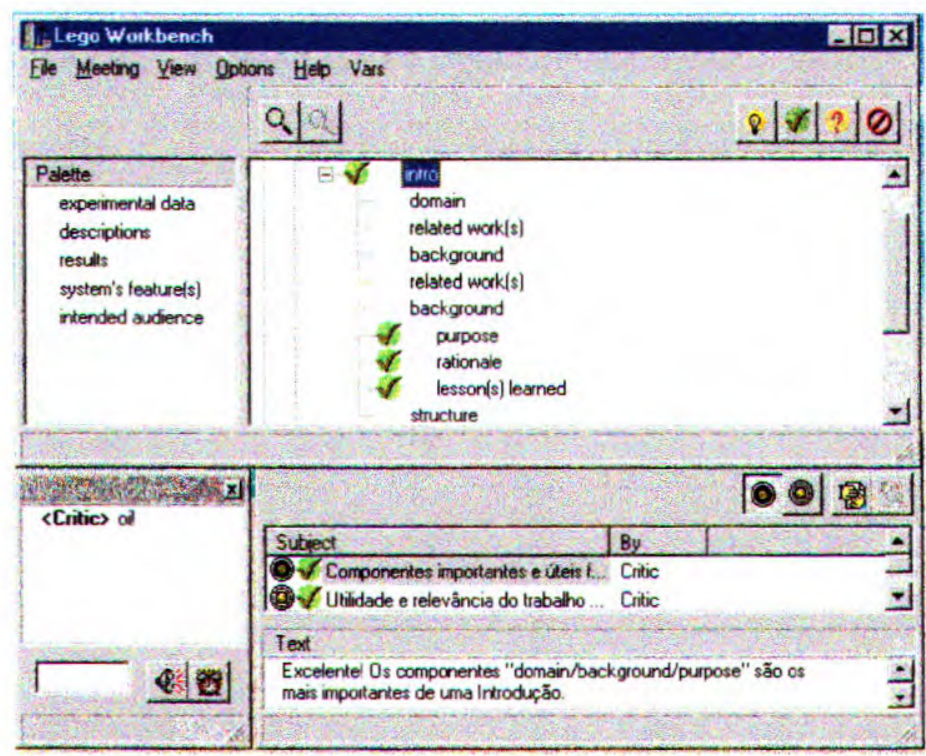

Figura 6.15: Uma Estrutura Inicial Proposta por um Usuário Experiente no Domínio da Escrita Técnica e as Críticas Emitidas pelo Protótipo

Como a estrutura só recebeu elogios, o usuário solicita, então, ao protótipo a recuperação de casos semelhantes. Neste exemplo de simulação, os casos recuperados se constituem de ótimos exemplos, pois as estatísticas foram muito boas (Figura 6.16) e consequentemente a visualização 
desses casos irá propiciar ao usuário o acúmulo de experiência com relação às variações possiveis na estrutura, utilizando os mesmos componentes ou substituindo alguns componentes opcionais por outros.

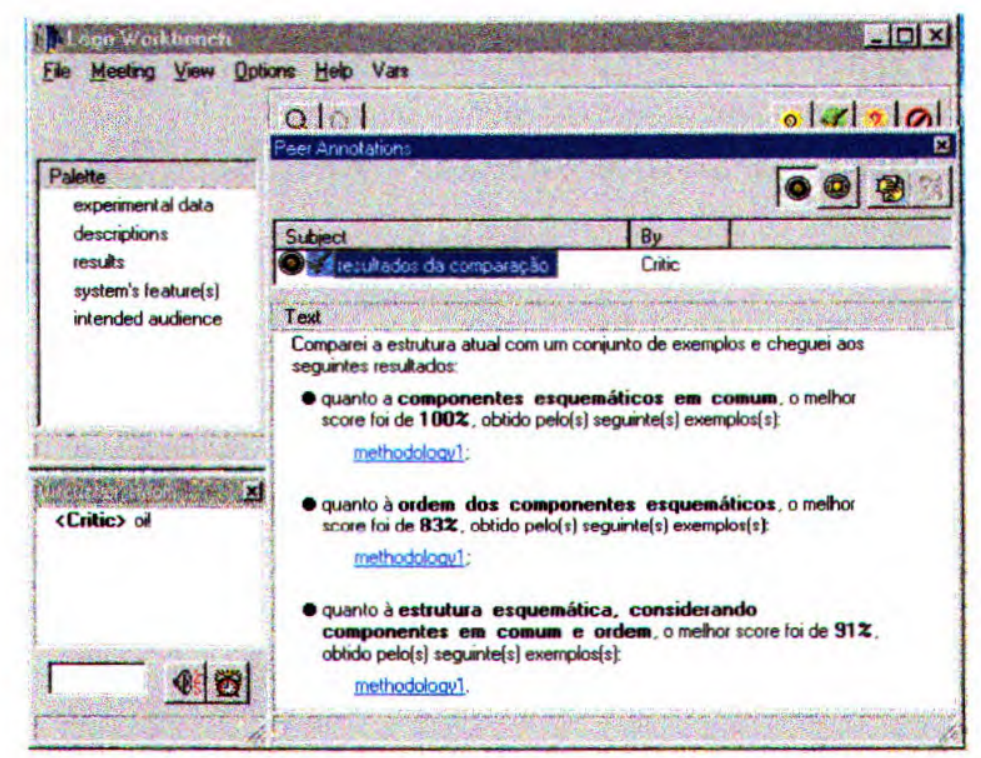

Figura 6.16: Crítica Sobre Resultados da Comparação Emitida pelo Protótipo a um Usuário Experiente no Domínio da Escrita Técnica

\subsection{Praticidade}

\subsubsection{Estendibilidade de Guidelines, Casos e Estruturas de Novas Seções ou de Novos Tipos de Artigos}

Para que o protótipo construído alcance os seus objetivos - emissão de críticas efetivas ${ }^{8}$ sobre um produto apresentado/modificado pelo usuário -, ele precisa possuir conhecimento sobre o domínio. Este conhecimento é formado pelas estruturas de seções de artigos, por um conjunto de guidelines/regras para geração de estruturas adequadas, e uma base de casos, isto é, exemplos de textos de uma seção. Incrementar o número de guidelines é totalmente possível, uma vez que estas foram criadas a partir de instruções obtidas da chamada de trabalhos da conferência CHI'96 e vieram de críticas dos avaliadores (referees) de conferências anteriores. Assim, poderiamos trabalhar com um corpus de avaliações de artigos e inserir os comentários dos avaliadores.

\footnotetext{
${ }^{8}$ Críticas que produzem um efeito real.
} 
Também, em grande parte, as guidelines utilizadas no protótipo foram deduzidas através da análise do corpus e, sem dúvida, se esse processo for realizado por terceiros, certamente novas guidelines serão apontadas. Exemplos de guidelines podem ser visualizados na Subseção 5.4.3.2. Se o número de casos for grande pode-se também aplicar algoritmos de aprendizado de máquina para que se induza novas regras.

Quanto aos casos, novos representantes também podem ser adicionados aos já existentes na base, desde que sejam classificados e anotados de acordo com as convenções estabelecidas e utilizadas para os demais. Exemplos de como os casos foram anotados e codificados podem ser vistos nas Subseções 5.3 e 5.4.3.1, respectivamente.

No tocante a seções, o protótipo atual disponibiliza somente o conhecimento sobre a estrutura da seção introdutória de artigos. Conseqüentemente, a pallete da estrutura de componentes esquemáticos possui apenas um filho - "Intro". Caso o protótipo necessite ser adaptado para trabalhar com outras seções de um artigo, como abstracts ou conclusões, esta pallete deve ser acrescida dos componentes apropriados.

Para estender o conhecimento do protótipo para um novo tipo de artigo como, por exemplo, "Design Briefings", como aparece na chamada de trabalhos da CHI'98 (ver WWW: http://www.acm.org/sigchi/chi98/call/papers.html), precisamos levantar os componentes $\mathrm{e}$ subcomponentes da chamada de trabalhos, analisar, anotar textos de Introduções exemplificando este tipo de artigo e estender as regras heurísticas/guidelines para criticar também este novo tipo de artigo.

\subsubsection{Personalização}

Uma das preocupações durante o desenvolvimento do protótipo da ferramenta de crítica foi a necessidade/facilidade de personalização para outras comunidades que possuíssem características diferentes da atual. Algumas características foram levadas em consideração no ato da construção/implementação para facilitar a adaptação. Por exemplo, caso o protótipo necessite ser adaptado para ser utilizado por uma comunidade multidisciplinar, onde as introduções se caracterizam pela ocorrência de ciclicidade de componentes (principalmente related works e background), o protótipo atual está totalmente apto para atender esta necessidade.

Supondo também uma outra situação, onde exista a necessidade de estruturação da introdução de um short paper, que se caracteriza como um tipo artigo que possui uma introdução 
sucinta, ou de um poster, onde devem aparecer apenas componentes significativos e essenciais, 0 protótipo também pode ser reutilizado sem a necessidade de maiores mudanças em seu código. Somente as críticas devem ser adaptadas para que não sejam feitas criticas com relação à faita de componentes repetidos ou a estruturas com uma quantidade pequena de componentes.

\subsubsection{Portabilidade para uma Nova Comunidade de Pesquisa}

Como sabemos, para a chamada de trabalhos da CHI'96, os tipos de artigos permitidos são empirical, experience, theory, system, opinion e methodology. Pensando na possibilidade de reuso do protótipo implementado para uma nova comunidade, realizamos um processo de pesquisa nas chamadas para artigos de algumas conferências da área de Inteligência Artificial, e dentre outras, selecionamos três delas para estabelecermos um mapeamento entre os tipos de artigos aceitos nestas e os da CH''96. As conferências selecionadas foram:

- A Fifteenth National Conference on Artificial Intelligence - AAAI 98 (http://www.aaai.org:80/Conferences/National/1998/aaai98-call.html), que é uma conferência que aceita artigos nas várias subáreas da Inteligência Artificial. Através da sua chamada de artigos constatamos que são aceitos artigos dos tipos: theoretical, empirical experimental results. Após um mapeamento com os aceitos pela CHI'96, podemos dizer que correspondem, respectivamente a: theory, empirical e experience;

- A Ninth International Conference on Artificial Intelligence in Education -AI-ED 99 - (http://ai-ed99.univ-lemans.fr/scientific/scientific.html). Esta é uma conferência que aceita somente artigos específicos de Inteligência Artificial aplicada à educação. Em sua chamada para artigos pudemos detectar a aceitação dos seguintes tipos: research papers, survey papers, theme papers e work in progress. De acordo com as características de cada tipo, mapeando com os tipos aceitos na CHI'96, concluímos que o primeiro tipo (research papers) abrange os cinco tipos da $\mathrm{CHI}$ implementados no protótipo; theme papers apresenta as mesmas características que opinion papers (da CHI'96); survey papers são artigos de revisão literária que apresentam um resumo coerente e crítico dos resultados e problemas principais em uma área; e work in progress caracteriza-se como um tipo de artigo que visa descrever pesquisas realizadas por alunos de pós-graduação e pesquisadores novatos; $\mathrm{e}$ 
- A Third International Conference on Case-Based Reasoning - ICCBR 99 (http://www.iccbr.org/iccbr99/), conferência esta destinada especificamente a artigos que abordem a utilização da abordagem de RBC. Esta conferência aceita dois tipos de artigos: research papers e application papers. Mapeados com os da CHI'96, o primeiro corresponde os tipos theory, empirical, experience e methodology, e o segundo corresponde ao tipo system.

Para concluirmos tais afirmações a respeito da equivalência dos tipos de artigos aceitos por outras conferências com os da CHI'96, realizamos uma comparação da estrutura de componentes específicos dos artigos da CHI'96, com algumas características desejáveis para cada tipo de artigo de cada uma dessas conferências, as quais foram mencionadas na sua própria call for papers.

Caso a chamada para artigos de uma conferência não especifique, ou dê margens a dúvidas sobre as características desejáveis para cada tipo de artigo, e havendo a necessidade dessa classificação, uma pessoa especializada em determinada área de pesquisa tem condições, através da análise do corpus, de identificar os componentes que caracterizam os diversos tipos de artigos. Há a necessidade de se treinar este analista, entretanto, para que consiga segmentar e rotular textos de acordo com uma classificação.

Com relação aos componentes esquemáticos, podemos afirmar que a elaboração de uma estrutura para classificação não é uma tarefa extremamente dificil, visto que os componentes que a constituem são bastante conhecidos e muito bem aceitos.

Em termos de adaptação do protótipo construído neste trabalho para uma nova comunidade de pesquisa, além da substituição da base de casos e das regras heurísticas/guidelines relacionadas à nova comunidade, em termos de programação, é necessário a concepção de uma linguagem (em árvore) para a especificação dos objetivos do usuário (componentes, subcomponentes), caso a estrutura dual não seja mantida, além de adaptações no arquivo de vocabulário - relativo à interface - e no arquivo onde é especificado o comportamento do crítico (que no protótipo da ferramenta de crítica denomina-se Soul.xpl); quanto mais diferir o comportamento atual daquele pretendido para a nova comunidade, maiores as modificações que deverão ser feitas sobre ele. Entretanto, caso o (i) apoio geral ao uso da linguagem (não repetição de componentes consecutivos, por exemplo), (ii) os tipo de regras heurísticas/guidelines (shoulContainl, shouldContainAll etc), (iii) a estrutura dual, (iv) a noção de tipo de artigo, (v) os 
critérios de busca e sua semântica e (vi) as formas de acionamento do crítico se mantenham, as modificações previstas são mínimas.

No arquivo de vocabulário está definido o vocabulário utilizado pelo protótipo da ferramenta de crítica, ou seja, quais os tipos de estruturas que podem ser trabalhadas (schematics ou specifics) e os componentes de cada uma delas, além dos possíveis tipos de artigos.

Quanto ao tipo de artigo, se esta noção não se mantiver na nova comunidade (visto que a codificação reserva um espaço bem definido para esse elemento - o primeiro filho de schematics), uma saída simples é fixar um único tipo de artigo para todos os exemplos.

Quanto à comunicação inter-agentes (Lego Middleware) não existe a necessidade de mudanças, visto que a estrutura disponivel para comunicação é independente da comunidade de pesquisa.

\subsubsection{Custo de Implementação}

As possibilidades de estender as regras heurísticas/guidelines, casos e estruturas de novas seções ou de novos tipos de artigos são totalmente viáveis, assim como a adaptação da ferramenta para uma nova comunidade de pesquisa. Em contrapartida, o custo de implementação de uma ferramenta similar à desenvolvida é bastante alto. Essa característica se deve principalmente à análise e anotação do corpus, codificação do conhecimento e preparação do corpus para ser apresentado aos colaboradores no momento oportuno. $\mathrm{O}$ tempo gasto e a habilidade necessária por um ser humano na realização destas tarefas são relativamente grandes e são responsáveis pelo alto custo da implementação. A metodologia utilizada para a construção do conhecimento utilizado em ferramentas de crítica foi descrita na Seção 5.3; algumas daquelas etapas (análise a anotação do corpus, por exemplo) são mais detalhadamente descritas na Tabela 6.1. O tempo estimado para a realização dos seis passos da Tabela 6.1 é de aproximadamente um dia para cada artigo do corpus. Estas etapas se caracterizam como bastante morosas porque, como já comentado, são de extrema importância para a eficiência do protótipo, uma vez que resultam no conhecimento utilizado pelo mesmo.

Entretanto, existe o trabalho de Sardinha (1997) sobre identificação automática de segmentos de textos escritos que merece ser estudado e avaliado para esta nossa tarefa de análise e anotação. 
Tabela 6.7: Passos Realizados para a Análise e Anotação do Corpus

\begin{tabular}{|ll|}
\hline 1. & Classificação do corpus coletado em um dos seis tipos de artigos aceitos na CHI'96 \\
\hline 2. & Identificação de componentes da estrutura esquemática \\
\hline 3. & Identificação de componentes da estrutura de critérios específicos \\
\hline 4. & Codificação do artigo em caso \\
\hline 5. & Extração e codificação de regras heuristicas/guidelines baseadas nos artigos do corpus \\
\hline 6. & Preparação dos textos dos artigos que contém a estrutura dual anotada para serem visualizados com \\
& um software de apresentação \\
\hline
\end{tabular}

\subsection{Consideraçóes Finais}

Neste capítulo abordamos a avaliação do protótipo da ferramenta de crítica, procurando - responder duas questões: “o protótipo realmente funciona?", e “o sistema é prático?". Procuramos responder a primeira questão através de três simulações da utilização da ferramenta. Utilizando uma classificação para textos de usuários proposta pela orientadora deste trabalho de mestrado, onde os usuários (e consequentemente a estrutura produzida por eles) são classificados em grupos, de acordo com o nível de conhecimento em determinado domínio (vide Apêndice A). Dessa classificação utilizamos apenas três classes: experiente, com nível médio de conhecimento e inexperiente no domínio. Essas simulações nos levaram a concluir que, o protótipo da ferramenta de crítica pode transmitir conhecimentos ao usuário, tanto através da exibição de críticas, quanto por disponibilizar a recuperação de casos para que o usuário os visualize.

Para a segunda pergunta, abordamos quatro critérios: (i) Estendibilidade de Guidelines, Casos e Estruturas de Novas Seções ou de Novos Tipos de Artigos; (ii) Personalização; (iii) Portabilidade para uma Nova Comunidade de Pesquisa; e (iv) Custo de Implementação. A resposta às três primeiras perguntas é "sim, é possível estender o conhecimento do sistema, personalizá-lo para outros propósitos e portá-lo para outra comunidade, porém o custo de implementação ainda é alto". O passo importante dado por este trabalho é que muito do conhecimento presente na ferramenta particular pode ser reutilizado, diminuindo o custo da implementação para outros propósitos. 


\section{Conclusão}

este trabalho abordamos o desenvolvimento de uma ferramenta de crítica destinada ao
ensino da escrita técnica em. inglês, mais especificamente da seção introdutória de
artigos. Essa ferramenta é direcionada a usuários com alguma experiência no domínio da escrita técnica, porém ainda possuem problemas de coesão e interferências da língua materna.

As atividades principais da pesquisa foram a construção do protótipo, seguindo o modelo computacional para ferramentas de crítica da escrita técnica em inglês, visto no Capitulo 5 , e a avaliação deste protótipo, descrita no Capítulo 6 .

\subsection{Contribuiçôes}

Para a concretização deste trabalho, várias etapas foram necessárias. Inicialmente, foi realizada uma ampla revisão de literatura sobre sistemas tutores inteligentes e ambientes de aprendizado colaborativo, a escrita técnica em inglês como língua estrangeira, e a abordagem de criticas. 
O corpus foi então selecionado, coletado e classificado de acordo com os diversos tipos de artigos da CHI'96. Em seguida, cada artigo do corpus foi anotado de acordo com os componentes da estrutura esquemática e da estrutura de critérios específicos, isto é, de acordo com a estrutura dual, e codificado em Prolog para, em conjunto, constituírem a base de casos do protótipo (e consequentemente o conhecimento utilizado pelo analisador diferencial). A base de casos anotados com a estrutura dual, se constitui, assim, na primeira contribuição deste trabalho de mestrado.

A chamada de trabalhos da conferência CHI' 96 contribuiu como fonte para a extração de regras heurísticas (ou guidelines), as quais constituíram o conhecimento do analisador analítico.

Com base no processo de critica proposto por Fischer et al. (1991), estruturamos um modelo computacional para a construção de ferramentas de crítica para a escrita técnica. Com relação ao processo proposto por aquele autor, o modelo atual difere em alguns módulos. Este modelo é a nossa segunda contribuição, e uma das principais, visto que é um modelo genérico, que pode ser utilizado para o desenvolvimento de sistemas de crítica direcionados a outros domínios relacionados ou outras comunidades.

Além da especificação de um modelo computacional para a construção de ferramentas de crítica, trabalhamos também na elaboração de uma metodologia para a construção do conhecimento que a ferramenta de crítica irá utilizar. Essa metodologia consiste de tarefas que o usuário deve executar para a definição e implementação do conhecimento que será utilizado pelo protótipo. Esta é a nossa terceira contribuição.

Posteriormente realizou-se a especificação da arquitetura e a implementação do protótipo. Essas duas tarefas foram amplamente abordadas, pois é neste momento que a proposta do trabalho de mestrado realmente se concretiza. A especificação da arquitetura e a implementação do protótipo se caracterizam como a nossa quarta contribuição.

Finalmente, a nossa quinta e última contribuição consiste na avaliação do protótipo implementado. Ele foi avaliado de acordo com os critérios de operacionalidade e praticidade. A questão da operacionalidade foi avaliada através da análise da interação de usuários com diferentes graus de competência da escrita técnica em inglês. O resultado da avaliação da operacionalidade é que o protótipo pode transmitir conhecimento aos usuários das três classes avaliadas, fazendo com que eles consigam produzir estruturas mais adequadas ao propósito pretendido. Para a questão da praticidade, a estendibilidade, portabilidade, personalização, e custo de implementação foram estudados. Os resultados dos três primeiros critérios é positiva, 
enquanto que a do último é que o custo de implementação ainda é aito. Porém, muito do conhecimento já implementado para o protótipo pode ser reutilizado.

\subsection{Limitaçôes}

Como sabemos, a ferramenta de crítica trabalha com uma estrutura dual: a de componentes esquemáticos e a de componentes específicos. No que diz respeito à estrutura de componentes específicos, nenhum mecanismo foi implementado no sentido verificar a necessidade de certos componentes. Com relação a esta estrutura, cabe ainda ao usuário inferir a necessidade de inserção, remoção ou substituição de componentes a partir da visualização e estudo dos casos que foram recuperados.

Os casos anotados também podem servir de base para a extração de regras heurísticas, tanto em relação aos componentes esquemáticos quanto aos componentes específicos se utilizarmos algoritmos de aprendizado de máquina, porém, esta estratégia de obtenção de conhecimento não foi utilizada neste trabalho. Este tipo de abordagem também poderia ser utilizado para investigar regras a respeito de uma possível correlação entre as duas estruturas, por exemplo, sempre que ocorre um determinado elemento na estrutura esquemática deve ocorrer a existência de outro determinado elemento da estrutura de componentes específicos.

Com relação à exibição das críticas, quando o foco é mudado de uma estrutura para outra, podem ser visualizadas a indicação de que existem críticas, através do aparecimento de ícones ao lado dos componentes. Assim, o usuário pode lê-las e, baseado nestas, pode realizar alterações na estrutura. Uma das limitações da ferramenta está no fato de que, quando o usuário mudar novamente o foco, críticas novamente serão exibidas; dentre essas críticas, com certeza algumas serão repetidas com relação àquelas apresentadas primeiramente, principalmente no que diz respeito aos elogios. Talvez este fato faça com que o usuário perca o interesse pela leitura das mesmas.

Quanto à recuperação dos casos, o protótipo possui determinados critérios que são considerados para a recuperação dos casos mais semelhantes ao caso do usuário. Normalmente, se o critério não obtém uma boa pontuação, o protótipo simplesmente não mostra estatísticas sobre ele. Algo poderia ser feito para melhorar esta situação, ou seja, caso o critério não tenha obtido uma boa pontuação, o protótipo poderia mesmo assim mostrá-la, porém sem disponibilizar os hyperlinks para a visualização de casos. Este é um procedimento cuja 
implementação não é complexa, porém foi uma idéia que surgiu quando já não mais havia tempo hábil para alterações no protótipo.

\subsection{Trabalhos Futuros}

Como observado na Subseção 7.2, o crítico diferencial não tira conclusões dos resultados obtidos na comparação da estrutura em construção com os casos da base. Há muito o que se investigar nessa direção; e uma possibilidade especialmente promissora, identificada no decurso do projeto, parece ser 0 uso de regras que explorem, de forma conjunta, os valores mínimos encontrados para o grau de dissimilaridade (um valor por cada critério de cálculo) em um dado momento. Nesse sentido, como ponto de partida, poder-se-iam gerar regras como a seguinte:

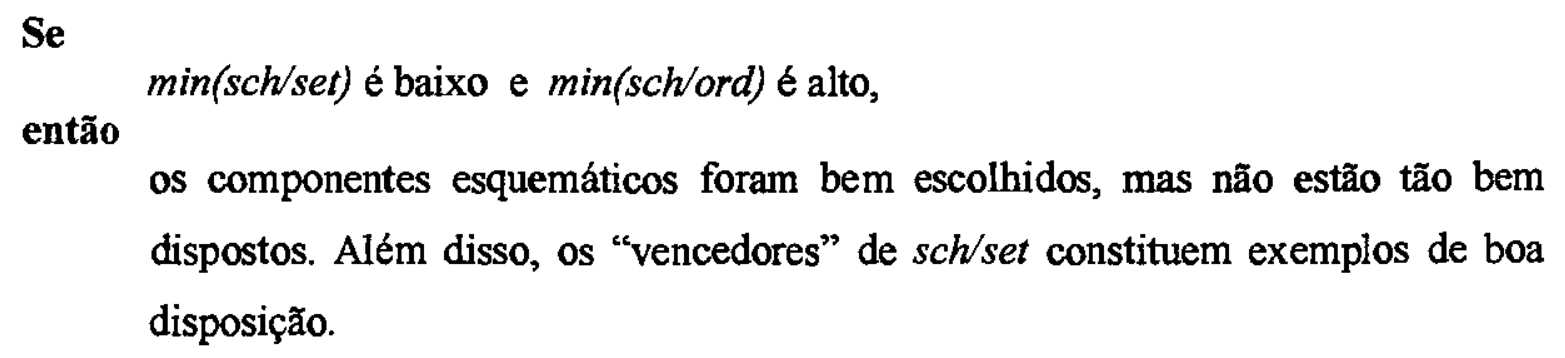

ou seja, regras que recorrem aos critérios atualmente definidos para explicitar apenas o contraste entre os resultados obtidos, notadamente uma classe de conclusð̃es mais óbvias.

Entretanto, quatro parâmetros de especial interesse, que podem fundamentar conclusōes bem menos óbvias, são $\min (\mathrm{sch} / \mathrm{set} A B), \min (\mathrm{sch} / \mathrm{set} B A), \min (\mathrm{spc} / \mathrm{set} A B)$ e $\min (\mathrm{spc} / \mathrm{set} B A)$, onde $X / \operatorname{set} A B$ (ou $X / \operatorname{set} B A$ ) são novos critérios de cálculo de dissimilaridade cujo resultado é a proporção de elementos na construção do usuário (ou num caso da base) que não são encontrados num caso da base (ou na construção do usuário). Ou seja, $X / \operatorname{set} A B$ e $X /$ setBA são medidas para a quantidade de componentes que estão "sobrando" ou na construção do usuário ou num caso da base, respectivamente. A princípio, os resultados desses critérios não deveriam ser apresentados diretamente ao usuário, mas usados em regras como as seguintes:

i. $\quad$ Se

então

$\min (X / \operatorname{set} A B) \downarrow$ e $\min (X / \operatorname{set} B A) \uparrow$,

não há componentes suficientes para caracterizar a estrutura correspondente $\mathrm{a} X$ (esquemática, se $\mathrm{X}=s c h$, ou de critérios específicos, $\mathrm{se} \mathrm{X}=s p c$ ). 
ii. Se

$\min (X / \operatorname{set} A B) \uparrow$ e $\min (X / \operatorname{set} B A) \uparrow$, então

há, na estrutura correspondente a $\mathrm{X}$, componentes demais e desconexos entre si, ou seja, que não funcionam nem como um todo nem se tomados em pequenos grupos. Em resumo, a um só tempo, sobram e faltam componentes.

iii. Se

$$
\text { então } \min (X / \operatorname{set} A B) \uparrow \text { e } \min (X / \operatorname{set} B A) \downarrow \text {, }
$$

há, na estrutura correspondente a $\mathrm{X}$, componentes demais; mas certos grupos funcionais podem ser identificados. Ou seja, os componentes em questão não são de todo desconexos, já que há pelo menos um subconjunto deles que possa ser considerado bem-caracterizado. Em resumo, é provável que apenas sobrem componentes.

Vale observar que a implementação efetiva desse tipo de regras não é trivial, em especial no tocante às expressões lógicas envolvidas (condições das regras). Para isso, algo semelhante a lógica fuzzy parece ser requerido, inclusive para que se possa dar ênfase variável às mensagens a serem geradas. 


\section{Apêndice $\mathbf{A}$}

\section{Rubric for the Research Paper Genre}

Criteria/Features/Basis to analysis:

Needed components of a research paper introduction

Setting

Review of Literature

Statement of Need/Gap

Purpose/Goal/Research Problem

\section{Optional components}

Methodology

Important Results

Justification

Structure of Paper 
Global organization

Language variety, usage and diction

Syntactic errors

\section{Excellent, Clear Competence}

The need for research is motivated (Gap)

The focus is strong/clear, convincing (Purpose)

The literature review is cohesive and specific (Review)

Connections are logical and cohesive

Usage and diction is consistent

Sentence Structure shows variety, but it is not completely syntax-error free

\section{Good, Competence}

Need for research is less apparent

Focus is clear

Literature review is present but general (i.e. not well motivated, not well unified with gap + purpose/research problem)

Connections are present and organization obvious

Optional components present when necessary to the research problem addressed

Language shows some variety and consistency but minor syntactic errors are present

\section{Fair, Minimal Competence}

Need for research is routine

Focus is stated but flat

Lit review presented as a list

Organization OK but connections not strong

Optional components tacked on or underdeveloped

Adequate but inconsistent language usage

Syntactic errors present but meaning is still apparent

\section{Poor, Developing Competence}

Need for research somewhat defined 
Unclear focus

Literature review not thorough

Inadequate organization; lacks cohesive devices

Needed componentes incomplete or reader must infer them from context

Accumulation of syntactic errors obscure meaning

\section{Unreadable, Incompetent}

Need for research not motivated

Focus absent

Literature review not apparent

Poor organization, lack of coherence

One or more needed components (needed components to the research problem) missing Inappropriate sentence structure and usage, and serious syntactic errors 


\section{Apêndice B}

Este apêndice visa esclarecer ao leitor os procedimentos comuns iniciais que todo usuário deve executar para trabalhar com o protótipo da ferramenta de crítica; procuramos também relatar o modo de acessar alguns recursos que a ferramenta disponibiliza.

Para iniciar a execução do protótipo da ferramenta de crítica, o usuário, que pode ser o único ou apenas mais um, dos vários colaboradores possíveis no processo de utilização do protótipo e eventual desenvolvimento de uma estrutura de introdução de artigo, deve informar o seu nick (nome pelo qual ele é identificado pelo crítico e pelos demais possíveis colaboradores). Dessa forma, este colaborador irá visualizar o Lego Workbench (que é a área de trabalho) e eventualmente poderá visualizar o Peer Annotation e o Discussion Room (acessados via menu View de Lego Workbench), conforme Figura B.1. A partir deste momento, o vocabulário do protótipo já foi lido e o processo de design da estrutura de uma introdução pode ser iniciado. Vale ressaltar que a ação de focalizar consiste em clicar com o ponteiro do mouse sobre o botão 
"change focus" $\mathrm{Q}$ e em seguida clicar sobre o componente a ser focalizado. Para retirar o foco de um componente basta clicar sobre o botão "clear focus" ou focalizar outro componente qualquer.

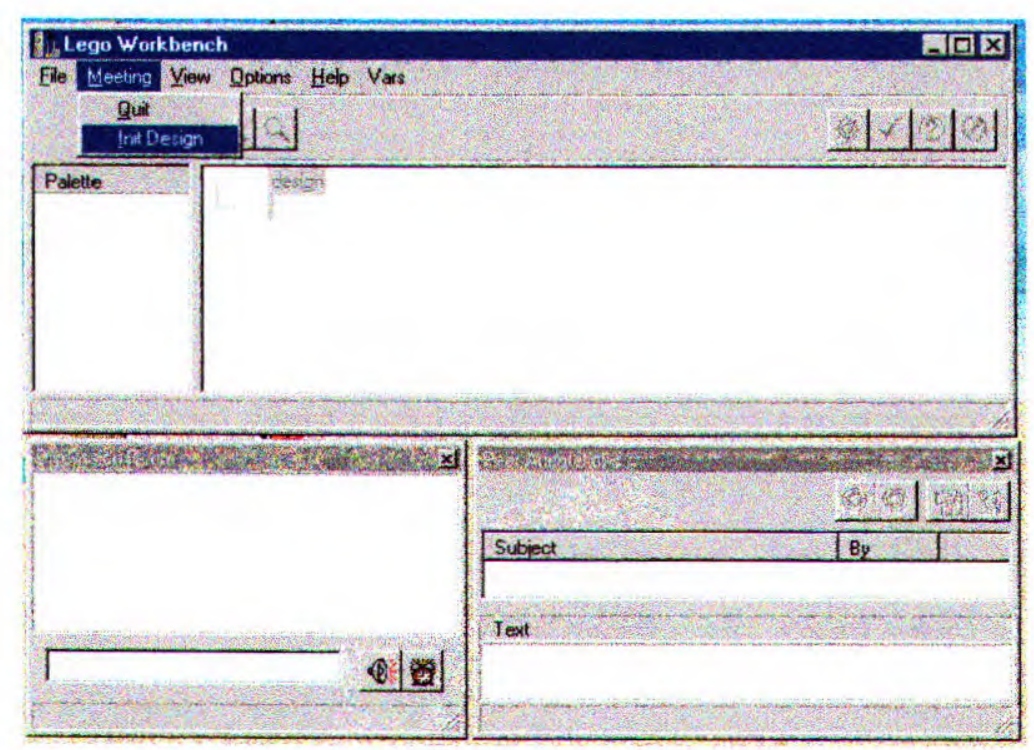

Figura B. 1: Visualização dos Componentes de Comunicação do Protótipo da Ferramenta de Crítica e Início do Design

Durante a utilização do protótipo da ferramenta de crítica, suponhamos que o colaborador inicie definindo o tipo de artigo cuja introdução quer esquematizar, ou seja, ele focaliza em "Type: ?" e define-o como Theory, pois imagina ser esta a classificação ideal para o tipo de artigo que pretende estruturar (Figura B.2). Esse tipo de procedimento não é recomendado, pois geralmente, um usuário sabe melhor o assunto que deseja abordar e quais as características que devem ser enfocadas, do que precisamente qual o tipo de artigo a ser elaborado. O procedimento mais apropriado para um usuário novato na escrita técnica é definir os componentes esquemáticos e, com base nessas informações, o próprio protótipo irá indicar qual o tipo mais provável de artigo para a estrutura elaborada. Como resposta a esse procedimento pouco recomendado, o colaborador recebe uma crítica intrusiva, conforme Figura B.3, alertando-o sobre essa ação. A melhor atitude a ser tomada neste momento é retornar o tipo de artigo como "Type: ?".

Caso vários colaboradores estivessem participando desse processo, todos eles estariam visualizando que o tipo do artigo foi definido por um colaborador e também visualizariam o alerta enviado pelo crítico. Porém, o crítico não é o único agente que pode enviar mensagens; um colaborador também pode enviar mensagens aos demais colaboradores utilizando o Discussion 
Room. O procedimento para o envio de mensagens é o seguinte: o usuário deve posicionar o ponteiro do mouse na parte inferior da janela Discussion Room, escrever a sua mensagem, e em seguida clicar sobre um dos dois botões disponiveis: "just speak" não intrusiva aos demais colaboradores ou "speak and notify" para enviar uma mensagem intrusiva aos demais colaboradores.

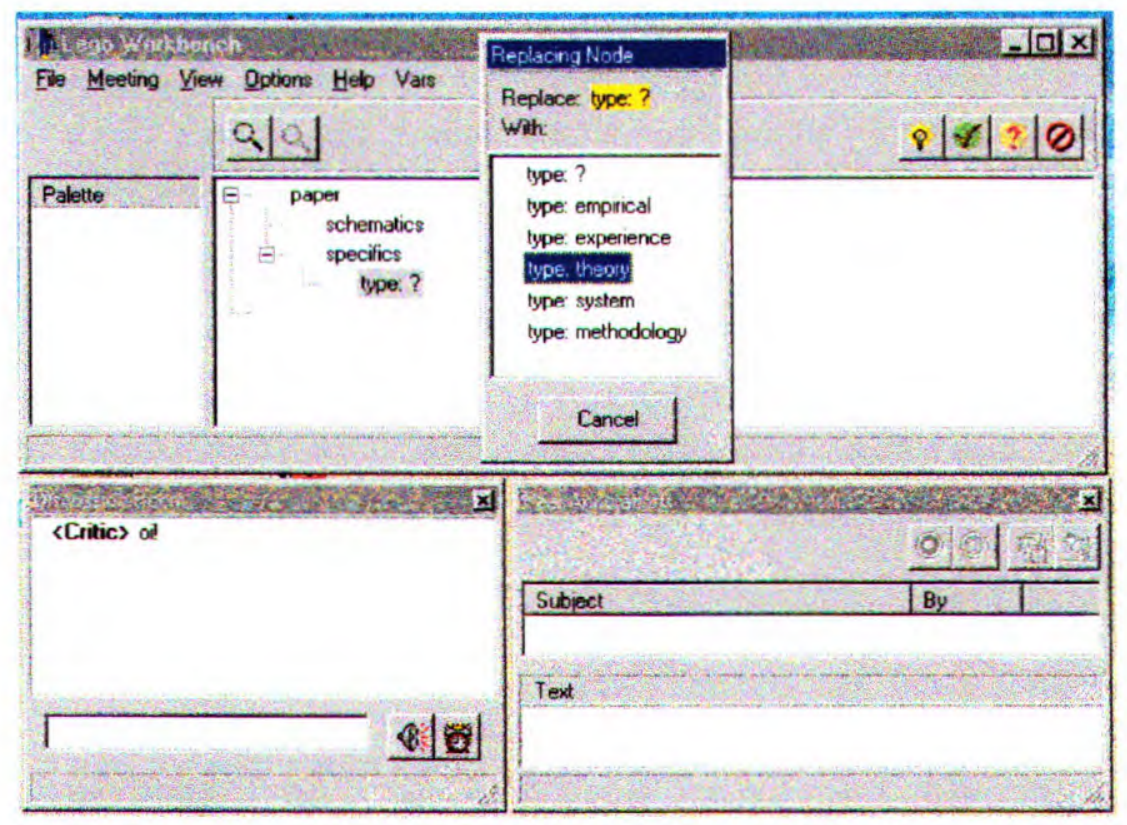

Figura B. 2: Definição Precoce de um Tipo de Artigo

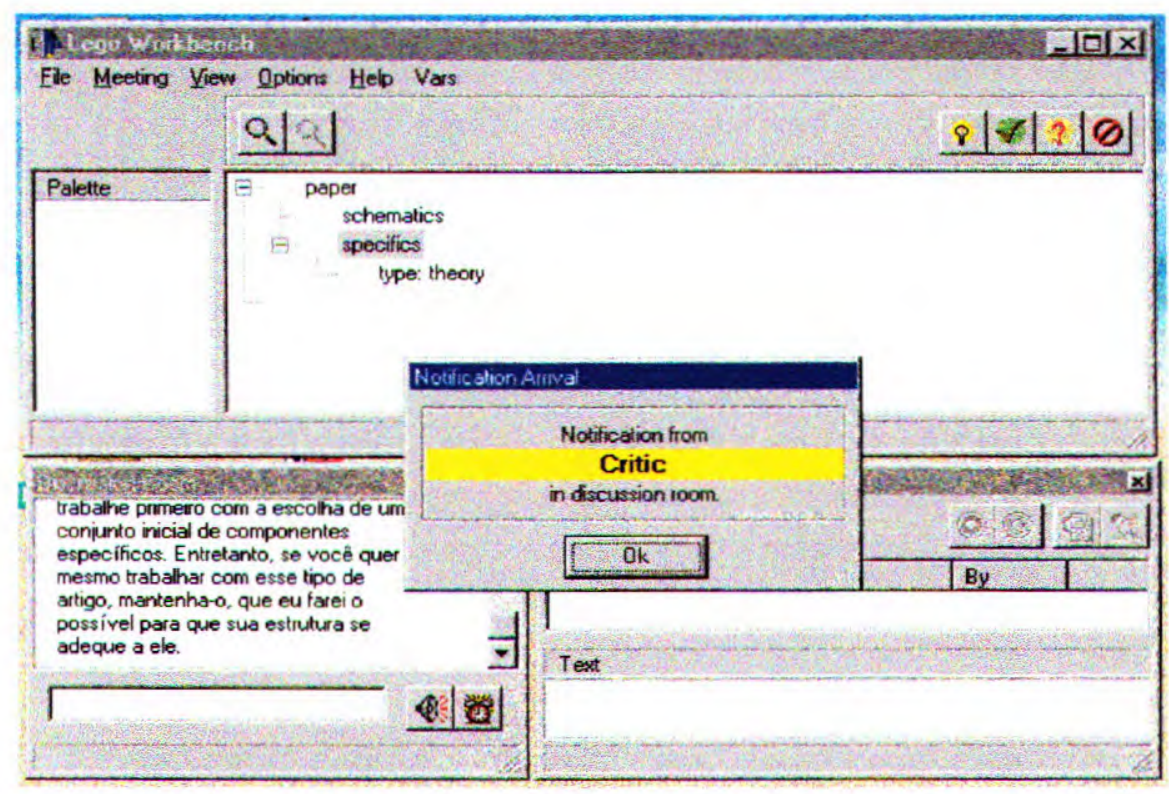

Figura B. 3: Crítica Intrusiva em Resposta a uma Decisão Precoce 
Para definir os componentes esquemáticos da introdução de artigo que será elaborada, o usuário deve focalizar o componente "schematics" e então irá visualizar na pallete o componente "Intro"; este componente deve ser introduzido na área de trabalho de Lego Workbench como componente de "schematics" (Figura B.4). Em seguida, o foco deve ser transferido para "Intro", que desencadeará a visualização dos componentes da estrutura de componentes esquemáticos na pallete (Figura B.5); neste momento o usuário pode começar a inseri-los. O processo de inserção de componentes se restringe a arrastar o componente selecionado na pallete para a área à direita, onde a introdução está sendo estruturada (Figura B.6). Alguns componentes da pallete disponibilizam uma nova lista de componentes; para selecionar componentes dessa lista basta clicar sobre o escolhido, conforme ilustrado na Figura B.7.

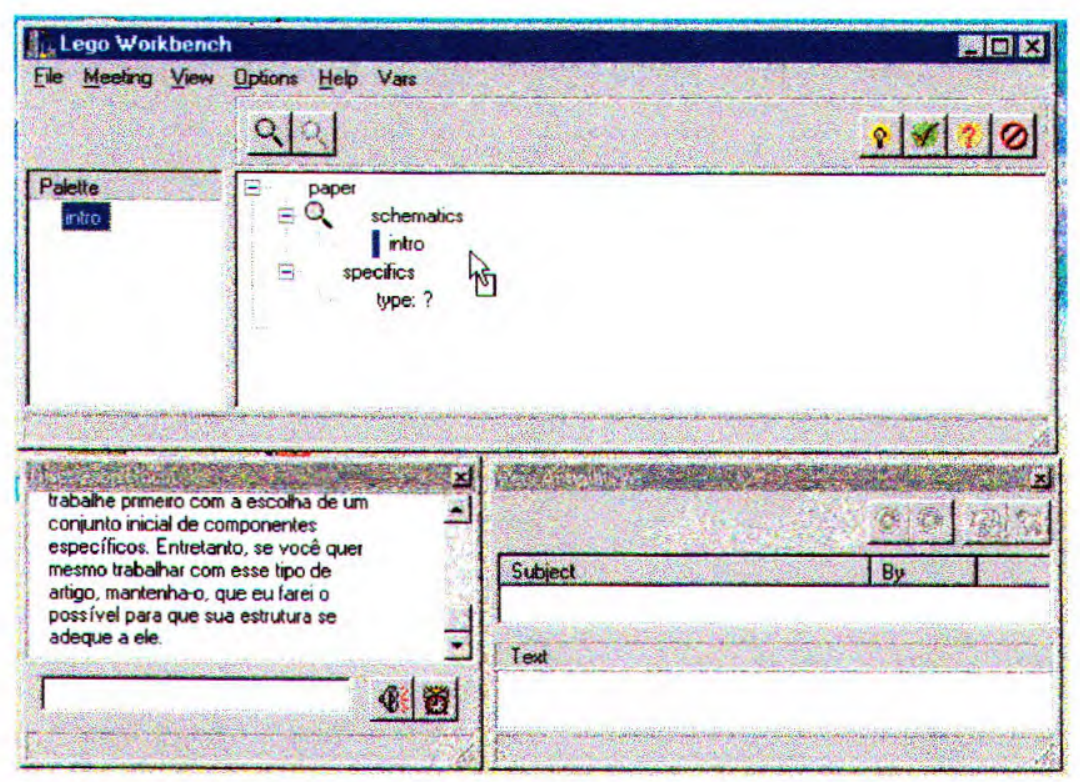

Figura B. 4: Mudança de Foco para Componentes Esquemáticos e Início de Trabalho com Inserção de "Intro" 


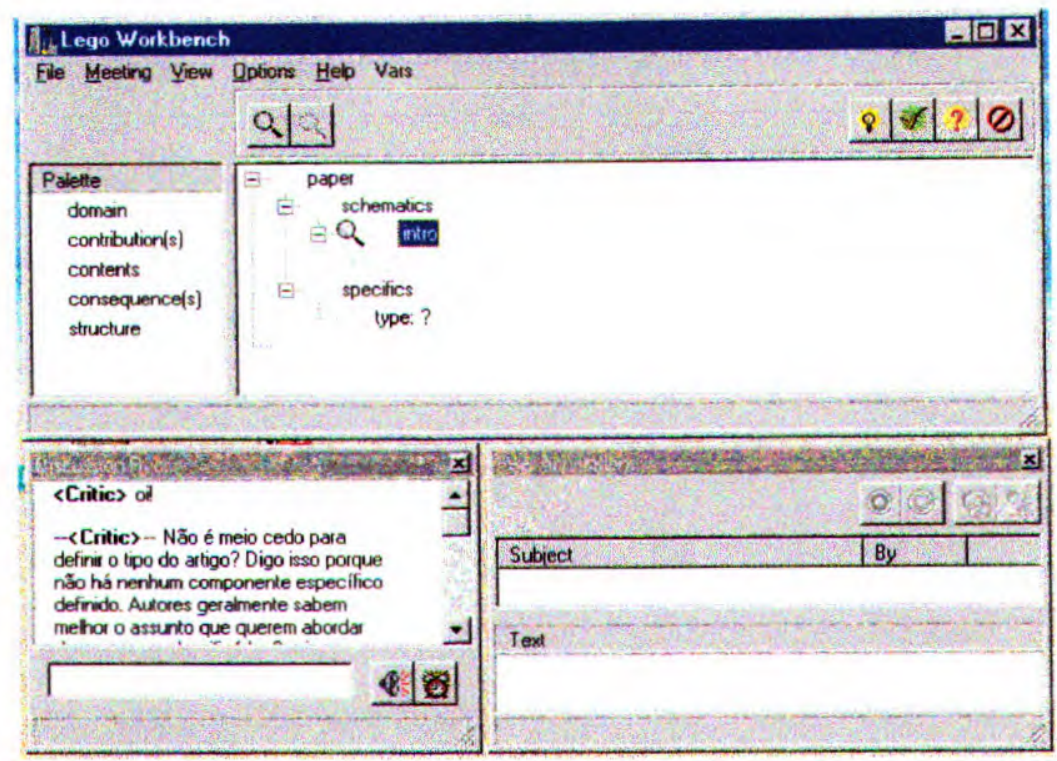

Figura B. 5: Mudança de Foco para "Intro" e Visualização de Componentes Esquemáticos na Pallete

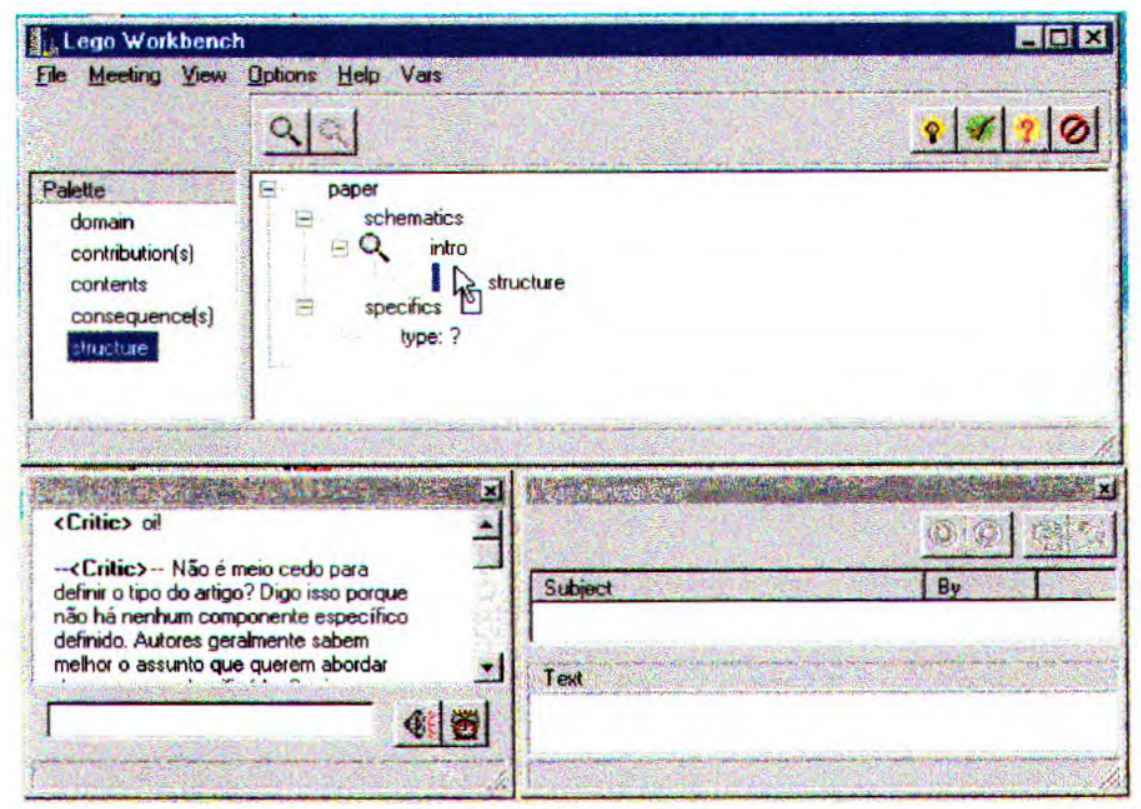

Figura B. 6: Seleção do Componente Esquemático "Structure" 


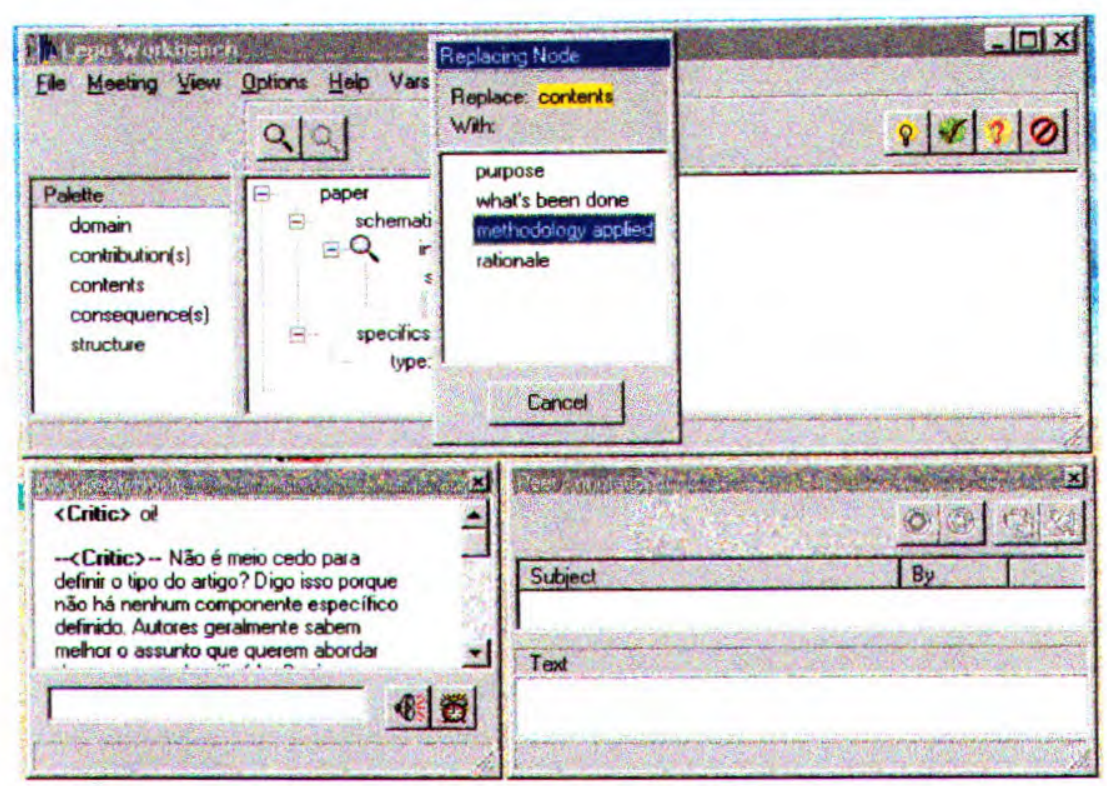

Figura B. 7: Escolha do Componente "Contents", Visualização de Lista de Componentes Esquemáticos e Seleção do Componente "Methodology Applied"

Após a escolha dos componentes que irão formar a estrutura da introdução do artigo, o usuário deve focalizar em "specifics" (irá visualizar na pallete os componentes específicos) e, devido à mudança de foco, recebe as críticas do protótipo quanto aos componentes esquemáticos, como ilustra a Figura B.8.

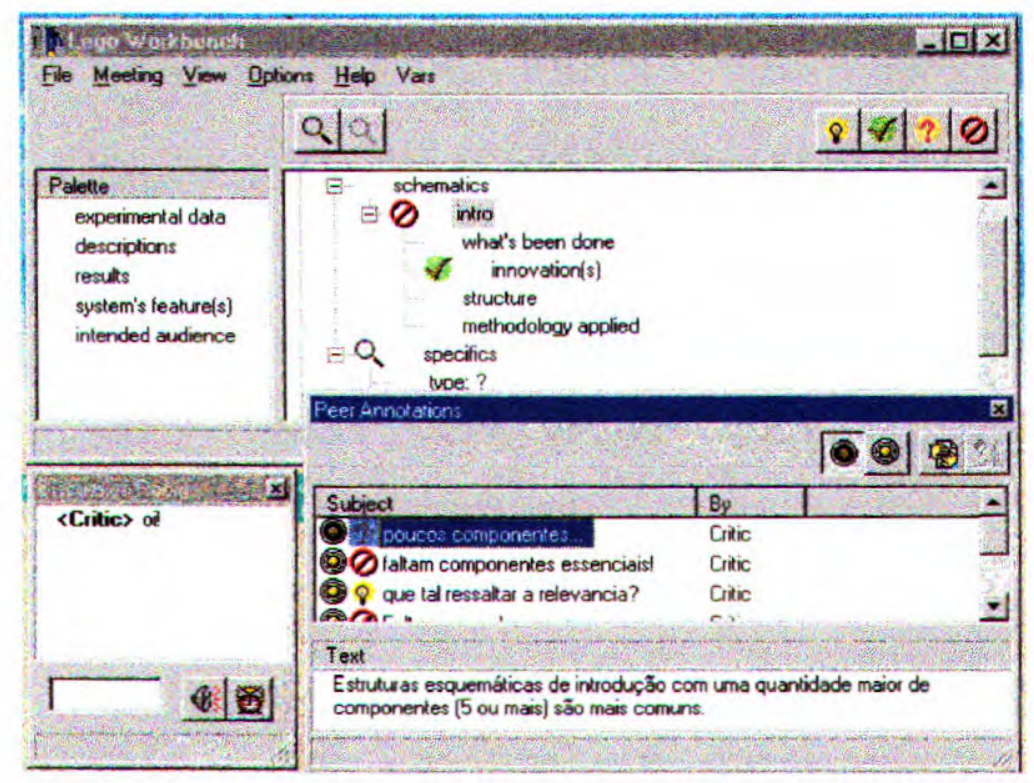

Figura B. 8: Mudança de Foco e Visualização de Críticas 
As críticas exibidas pelo protótipo elogiam o aparecimento de componentes importantes ou alertam o usuário sobre a necessidade de componentes que não aparecem na estrutura e são essenciais para caracterizar determinadas partes que devem existir em uma introdução, como por exemplo, a falta de componentes como o domínio do assunto a ser abordado e o propósito do artigo.

Após a leitura das críticas, elas podem ser excluídas; este processo consiste em selecionar o "subject" da crítica e clicar sobre o botão "hide" 론

Baseado nas críticas, o usuário pode melhorar a estrutura da introdução do artigo (acrescentando, excluindo e alterando a ordem de componentes) ou pode pedir para que o protótipo encontre e recupere os casos armazenados que mais se assemelham ao caso proposto.

Neste exemplo de utilização da ferramenta, digamos que o usuário queira visualizar os casos mais semelhantes; então ele deve clicar sobre o botão "Hum..." ? $\mid$ e em seguida sobre o componente "paper" de Lego Workbench; na janela Annotation Editor que surgirá, no espaço para o "subject", o usuário deve digitar "example" e clicar sobre o botão OK, conforme ilustra a Figura B.9. Como resposta, receberá do protótipo uma crítica com o "subject" "maus resultados da comparação", onde informa que, nesse caso, não existem exemplos armazenados na base de casos com similaridade significativa em relação ao apresentado (Figura B.10).

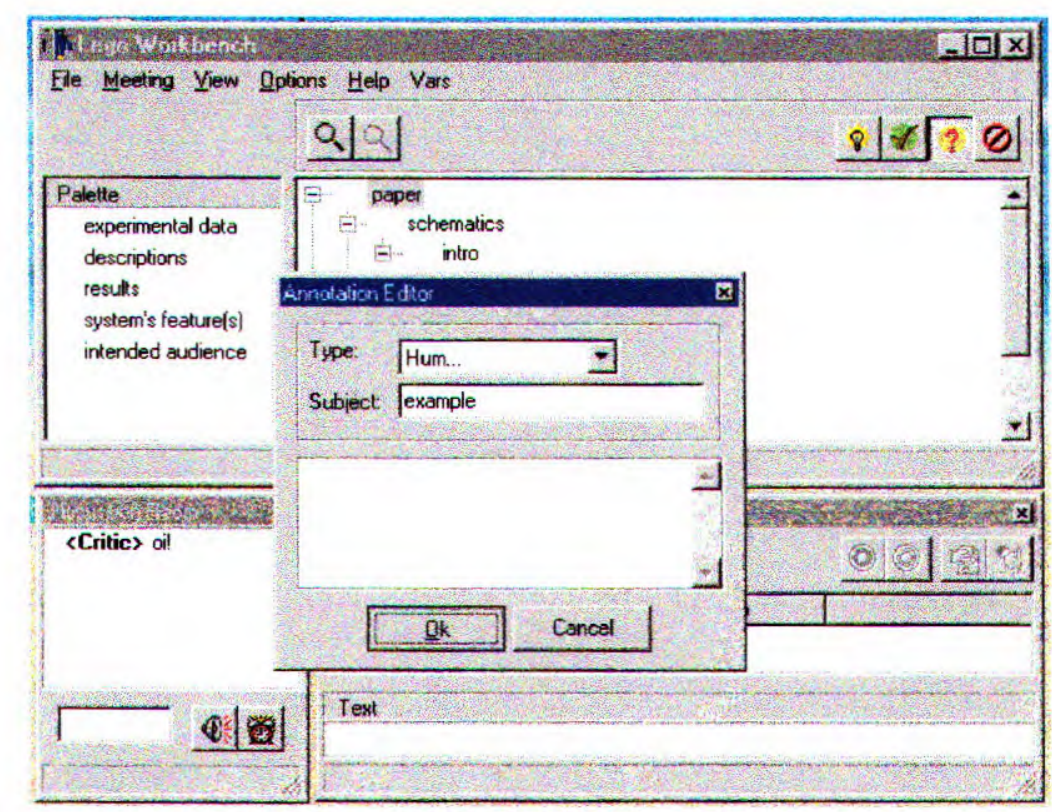

Figura B. 9: Pedido ao Protótipo para que Recupere Casos Semelhantes ao Esquematizado 


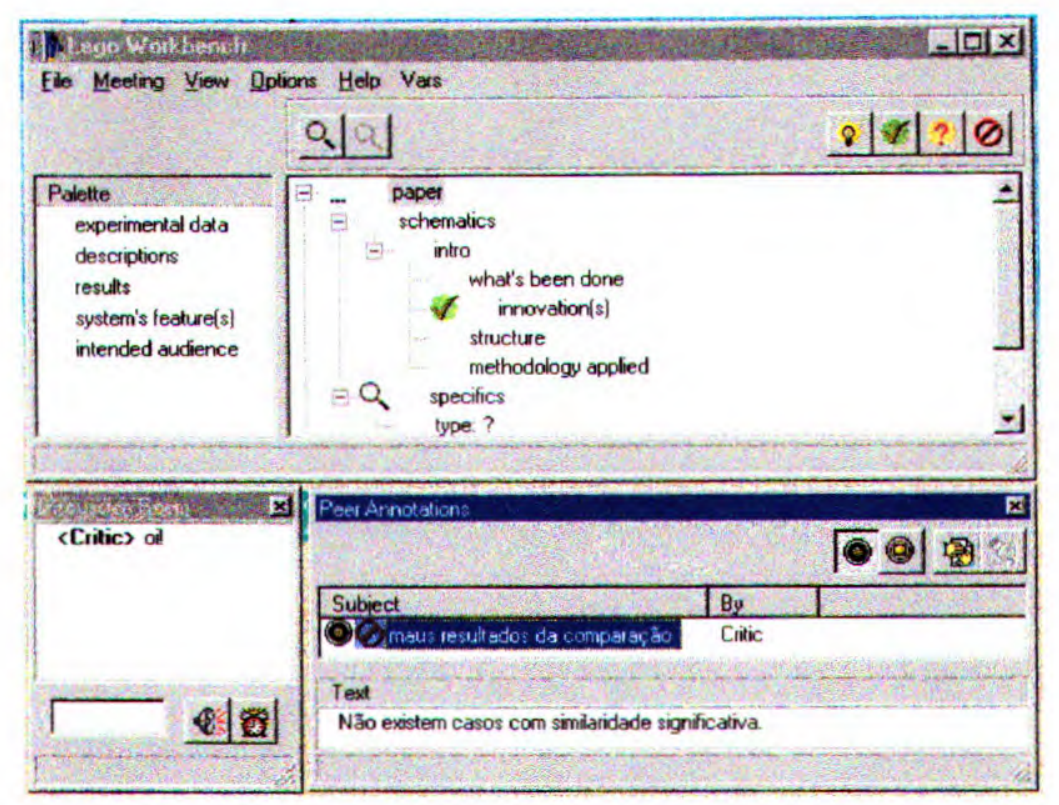

Figura B. 10: Resposta do Protótipo a um Pedido de Recuperação de Casos Semelhantes ao Esquematizado

Para prosseguir, o usuário pode focalizar o componente "Intro" e então realizar alterações na estrutura de introdução proposta. Concluídas as alterações, ele pode novamente optar pela recuperação de casos semelhantes ou por receber as críticas emitidas pelo protótipo. Digamos que a escolha tenha sido pela segunda opção (aprimorar a estrutura baseando-se nas críticas emitidas). Dessa forma, alterações foram feitas na estrutura e o foco foi mudado para "specifics", pois mudança de foco implica em emissão de críticas. Este momento da iteração pode ser visualizado na Figura B.11. Baseado nas críticas, o usuário deve realizar novas alterações na estrutura e, no momento em que achar que aquela é a estrutura final, deve solicitar ao protótipo a recuperação de casos semelhantes armazenados na base de casos. 


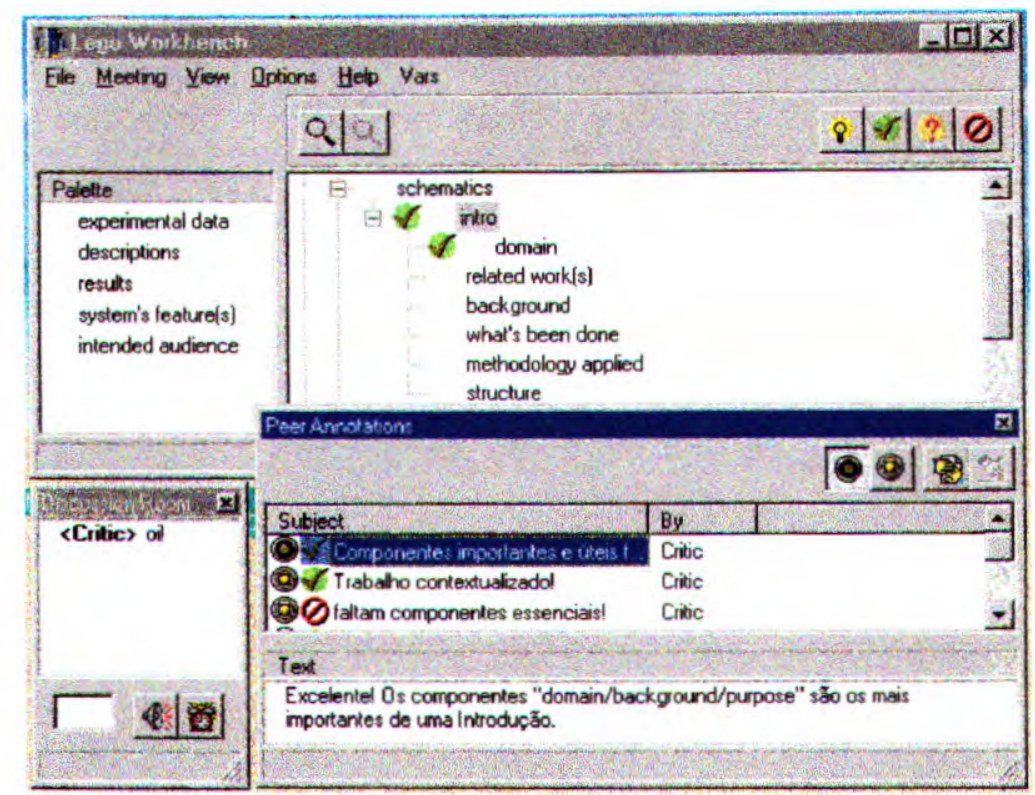

Figura B. 11: Visualização de Críticas

Após vários processos de alteração e pedido e emissão de críticas, o usuário deverá chegar à estrutura que considera ideal, como a ilustrada na Figura B.12, por exemplo. Prosseguindo, ele então pode requisitar do crítico que recupere, dos casos armazenados na base de casos, os que mais se assemelham à estrutura proposta. Como resposta obtém a crítica ilustrada na Figura B.13. Essa crítica disponibiliza estatísticas e "links" para a visualização dos casos anotados tanto quanto aos componentes esquemáticos (Figura B.14) quanto aos componentes específicos (Figura B.15).

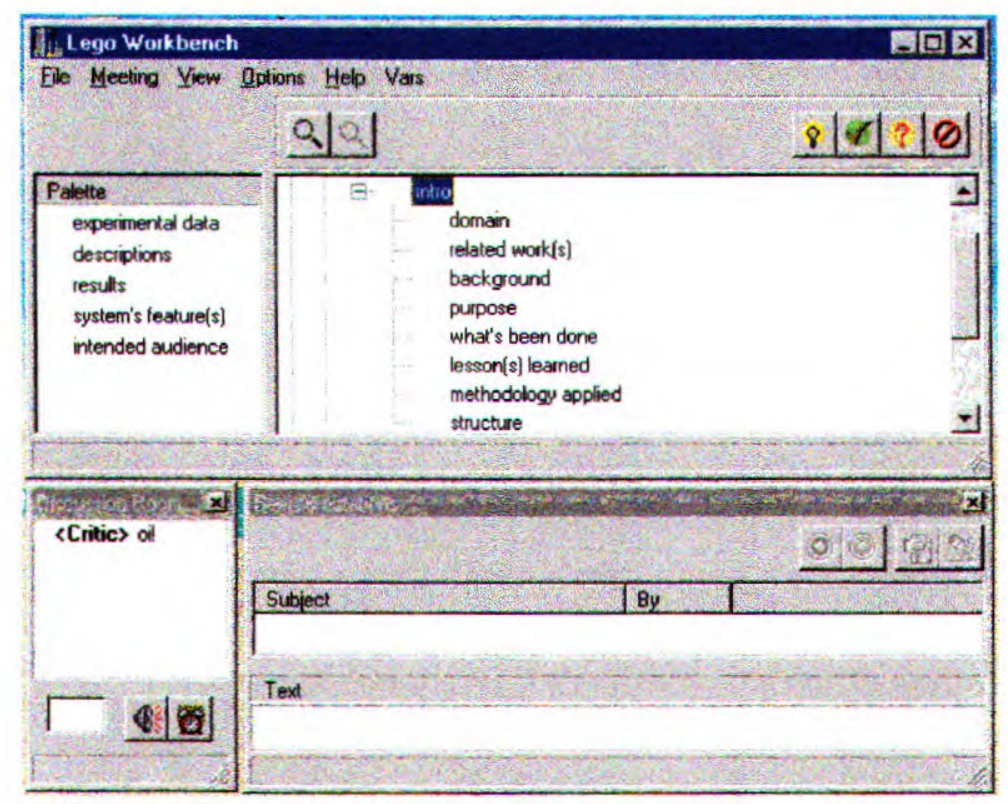

Figura B. 12: Estrutura de uma Introdução de Artigo Finalizada 


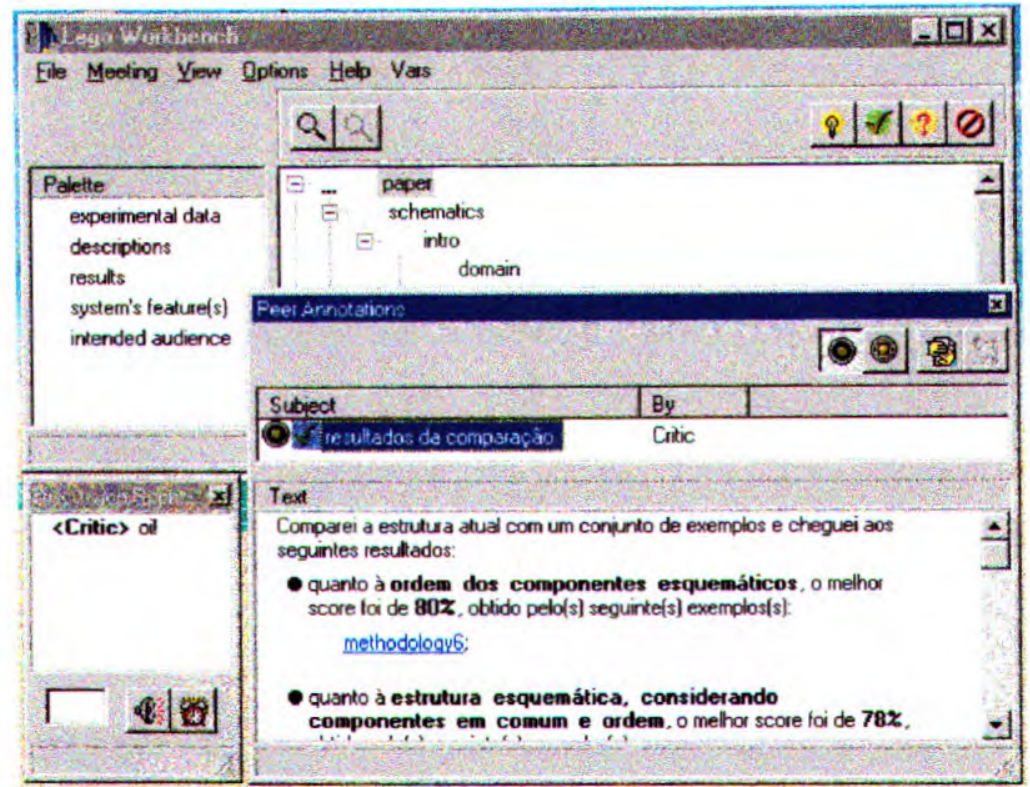

Figura B. 13: Crítica que Indica os Casos da Base mais Semelhantes ao Caso Proposto

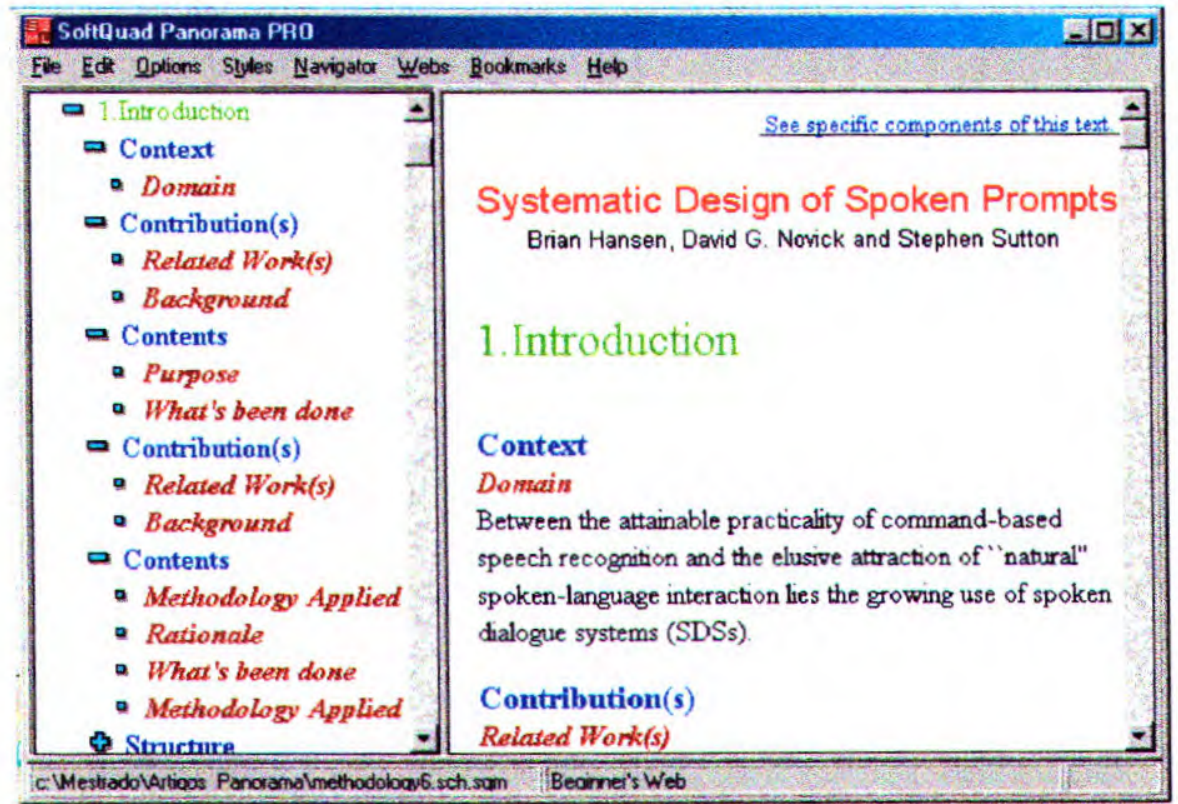

Figura B. 14: Visualização do Caso Recuperado Anotado com os Componentes Esquemáticos 


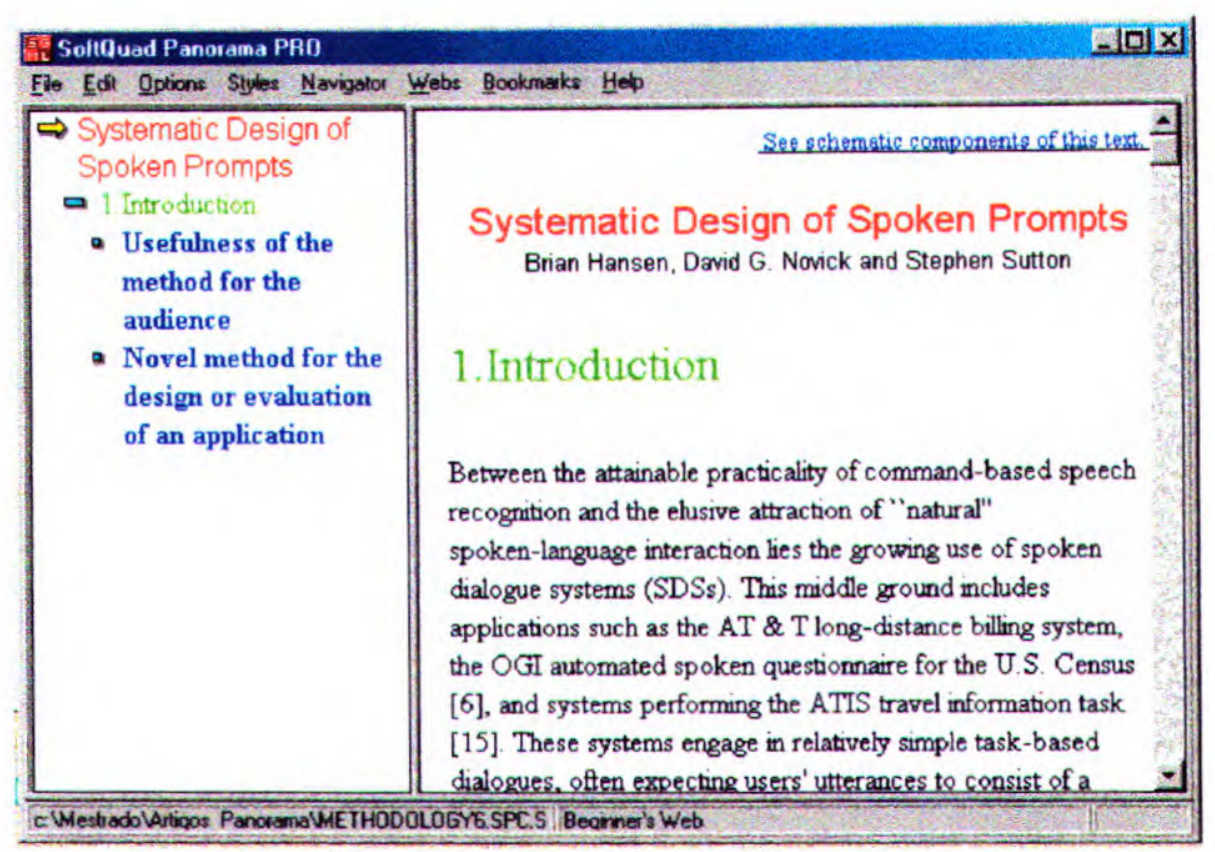

Figura B. 15: Visualização do Caso Recuperado Anotado com os Componentes Específicos

Nesse momento de interação onde o usuário visualiza exemplos de introduções de artigos, ele pode refletir sobre o seu real objetivo, e à partir dos exemplos pode melhorar o seu nível de conhecimento.

Para finalizar a sessão de utilização do protótipo da ferramenta de crítica, o usuário deve selecionar o menu Meeting (de Lego Workbench) e após a opção Quit (para encerrar o projeto). O módulo Lego Workbench deve ser fechado através do menu File, opção Exit, e os outros dois módulos - Lego Meeting Server e Lego Prolog Agent - devem ser finalizados pela utilização do botão fechar $\mathbf{x}$ de cada uma das janelas. 


\section{Referências}

Aluísio, S. M. (1995). Ferramentas para Auxiliar a Escrita de Artigos Científicos em Inglês como Lingua Estrangeira. Master's Thesis, IFSC-USP. Tese de Doutorado.

Aluísio, S. M. \& Oliveira Jr, O. N. (1995a). A Case-Based Approach for Developing Writing Tools Aimed at Non-native English Users. Lecture Notes in Artificial Intelligence 1010, pages $121-132$.

Aluísio, S. M. \& Oliveira Jr, O. N. (1995b). Developing Corpus-Based Writing Tools Aimed at Non-native Users of English. Proceedings of The Eighth Annual Conference on Writing and Computers.

Aluísio, S. M. \& Gantenbein, R. E. (1997). Towards the Application of Systemic Functional Linguistics in Writing Tools. In: Proceedings of International Conference on Computers and their Applications, pages 181-185.

Andeweg, B. A., Hoeskstra, E. R., De Jong, J. C. \& Kunst, S. (1992). Hypertext Adventures: Computer-Assisted Teaching of Technical report Writing in Deft. Instructional Science, Vol 21, N 1-3, pages 139-153.

Beeken, J., Geerts, G. \& Van Belle, W. (1992). The CONST-Project: Computer Instructed Writing. In Computers and Writing - State of the Art, P. O'Brian Holt \& N. Williams (eds), Kluwer Academic Publishers, Dordrecht, pages 337--354.

Blandford, A. E. (1994). Teaching Through Collaborative Problem Solving. Journal of Artificial Intelligence in Education 5 (1), pages $51-84$.

Bolt, P. (1991). eL: A Computer-Based System for parsing and Correcting Written English. CALL, Vol 4(3), p.173-182, 1991.

Bos, E. \& Van de Plassche, J. (1994). A Knowledge-Based, English Verb-Form Tutor. Journal of Artificial Intelligence in Education, 5 (1), pages 107-129.

Branting, L. K. \& Lester, J. C. (1996a). A Framework for Self-Explaining Legal Documents. In: Proceedings of the Ninth International Conference on Legal Knowledge-Based Systems (JURIX-96), Tilburg University, the Netherlands, December 1996.

Branting, L. K. \& Lester, J. C. (1996b). Justification Structures for Document Reuse. In: Proceedings of the Third European Workshop on Case-Based Reasoning (EWCR-96), Lausanne, Switzerland, the Netherlands, November 1996. 
Burton, M., Brna, P. \& Treasure-Jones, T. (1997). Splitting the Collaborative Atom: How to Support Learning about Collaboration. Artificial Intelligence in Education, B. du Boulay and R. Mizoguchi (Eds.), IOS Press, pages 135-142.

Chan, T. W. \& Baskin, A. B. (1990). Learning Companion Systems. In C. Frasson and G. Gauthier (eds.), Intelligent tutoring Systems: At the Crossroads of Artificial Intelligence and Education, Norwood: Ablex.

Cherry, L. (1982). Writing Tools. IEEE Transactions on Communications, 30 (1), pages 100105.

Cho, H., Yano, Y., Ha, Y. \& Kim, Y. (1997). MUGICLE: An Effective Collaborative Learning System. Artificial Intelligence in Education, B. du Boulay and R. Mizoguchi (Eds.), IOS Press, pages 574-576.

Dale, R. (1990). A Rule-Based Approach to Computer-Assisted copy-Editing, CALL Journal, Vol 12, pages 59-67.

Dillenbourg, P., Jermann, P., Schneider, D., Traum, D. \& Buiu, C. (1997). The design of MOO Agents: Implications from an Empirical CSCW Study. Artificial Intelligence in Education, B. du Boulay and R. Mizoguchi (Eds.), IOS Press, pages 15-22.

Fickas, S. \& Nagarajan, P. (1988). Critiquing Software Specifications. Expert Systems, pages 3747, November/1988.

Fischer, G., Lemke, A. C. \& Mastaglio, T. (1991). Critics: An Emerging Approach to Knowlwdge-Based Human-Computer Interaction. International J. of Man-Machine Studies 35, pages 695-721.

Fischer, G., Nakakoji, K., Ostwald, J. Stahl, G. \& Sumner, T. (1993) Embedding ComputerBased Critics in the Contexts of Design. Conference on Human Factors in Computing Systems, Amsterdam, 24-29 April/1993, pages 157-164.

Fischer, G. (1995). Rethinking and Reinventing Artificial Intelligence from the Perspective of Human-Centered Computacional Artifacts. Lecture Notes in Artificial Intelligence 991, pages $1-11$.

Fischer, G. (1996). Making Learning a Part of Life Beyond the "Gift Wrapping" Approach to Technology. In: Proceedings of NSF Symposium "Learning \& intelligent Systems", 1996. 
Fontana, N. \& Oliveira Jr, O. N. (1991). O Texto Acadêmico em Inglês como Língua Estrangeira —Dificuldades e Perspectivas. Atas do IX Simpósio Nacional de Ensino de Física. São Carlos / SP, pages 571-576.

Fontana, N., Caldeira, S. M. A., De Oliveira, M. C. F. \& Oliveira JR., O. N. (1993): Computer Assisted Writing - Aplications to English as a Foreign Language. CALL, Volume 6 (2), pages 145-161.

Goodfellow, R. (1995). A Review of the Types of Call Programs for Vocabulary Instruction, CALL, Vol 8, N.2-3, pages 205-226.

Hayes, J. R. \& Flower, L.S. (1980). Identifying the Organization of Writing Processes. In L.W. Gregg \& Steinberg (eds.), Cognitive Processes in Writing, Hillsdale, N.J. Erlbaum, pages 3-30.

Hietala, P. \& Niemirepo, T. (1997). Collaboration with Software Agents: What if the Learning Companion Agent Makes Errors? Artificial Intelligence in Education, B. du Boulay and R. Mizoguchi (Eds.), IOS Press, pages 159-166.

Kukulska-Hulme, A. (1997). Second-language Writing in on-line Courses on the Web. Proceedings of Writing and Computers 10, University of Brighton, UK, pages 115-116.

Lester, J. C., Stone, B. A., Converse, S, A., Kahler, S. E. \& Barlow, S. T. (1997). Animated Pedagogical Agents and Problem-Solving Effectiveness: A Large-Scale Empirical Evaluation. Artificial Intelligence in Education, B. du Boulay and R. Mizoguchi (Eds.), IOS Press, pages 23-30.

Liddy, E. (1991). The Discourse-Level Structure of Empirical Abstracts: An Exploratory Study. Information \& Management. Vol. 27, N 1, pages 55-81.

Miller, P. L. (1983a). ATTENDING: critiquing a Physician's Management Plan. IEEE Transactions on Pattern Analysis and Machine Intelligence, Vol PAMI-5, N.5, September 1983.

Miller, P. L. (1983b). Critiquing Anesthetic Management: The "ATTENDING" Computer System. Anesthesiology 58, pages 362-369.

Miller, P. L. \& Black, H. R. (1984). Medical Plan-Analysis by Computer: Critiquing the Pharmacologic Management of Essential Hypertension. Computers and Biomedical Research 17, pages 38-54.

Miller, P. L. (1985). Goal-Directed Critiquing by Computer: Ventilator Management. Computers and Biomedical research 18 , pages $422-438$. 
Miller, P. L., Shaw, C., Rose, J. R. \& Swett, H. A. (1986). Critiquing the Process of Radiologic Differential Diagnosis. Computer Methods and Programs in Biomedicine 22, pages 2125.

Oliveira Jr., O. N., Aluísio Calderira, S. M. \& Fontana, N. (1992). Chusaurus: A Writing Tool resource for Non-Native Users of English. In: Computer Science: Research and Application (eds.) Ricardo Baeza-Yates and Udi Manber, Plenum Press, New York, pages 63-72.

Paice, C. D. (1990). Constructing Literature Abstracts by Computer: Techniques and Prospects. Information processing \& Management, Vol. 26, N 1, pages 171-186.

Paiva, A. (1997). Learner Modelling for Collaborative Learning Environments. Artificial Intelligence in Education, B. du Boulay and R. Mizoguchi (Eds.), IOS Press, pages 215222.

Pemberton, L., Shurville, S., Broady, E., Drake, S., Hartley, T. \& Salkie, R. (1996). Motivating the Design for a Computer Assisted Environment for Writers in a Second Language. In Diaz, Arantza, Fernandez, Isabel (eds): Computer Aided Learning and Instruction in Science and Engeneering, Berlin: Spring-Verlag, pages 141-148.

Rankin, I. (1993). Natural Language Generation in Critiquing. The Knowledge Engineering Review, Vol 8:4, pages 329-347.

Reniè, D. \& Chanier, T. (1995). Collaboration and Computer-Assisted Acquisition of a Second Language. CALL Journal, Vol. 8, No.1, pages 3-29.

Rennels, G. D., Shortliffe, E. H., Stockdale, F. E. \& Miller, P. L. (1987). A Computational Model of Reasoning from the Clinical Literature. Computer Methods and Programs in Biomedicine 24, pages 139-149.

RSI 92 (1992). Reference Software International. Grammatik 5 User's Guide. Reference Software International, Washington DC, USA.

Rypa, M. \& Feuerman, K. (1995). CALLE: an Exploratory Environment for Foreign Language Learning. In: Intelligent Language Tutors - Theory Shaping Technology, (Eds.) Holland, V.M., Kaplan, J.D. and Sams, M.R., pages 55-76.

Sardinha, A. P. B. (1997). Automatic Identification of Segments in Written Texts. Master's Thesis, University of Liverpool. Tese de Doutorado.

Segalowitz, N. (1995). Automaticity and Lexical Skills in Second Language Fluency: Implications for Computer Assisted Language Learning. CALL, vol 8, N 2-3, pages 129-149. 
Silverman, B. C. (1992). Survey of Expert Critiquing Systems: Practical and Theoretical Frontiers. CACM, Vol.35, N4, pages 107-127.

Sharples, M. \& Pemberton, L. (1990). Starting from the Writer: Guideslines for the design of user-centered document processors. In: Computer Assisted Language Learning, 2, pages 37-57.

Sharples, M., Clutterbuck, A. \& Goodlet, J. A. (1994). A Comparison of Algorithms for Hypertext Notes Network Linearisation, International Journal of Human-Computer Studies, 40 (4), pages 727-752.

Shurville, S., Broady, E. \& Pemberton, L. (1997). The Composer System: a Genre-Based Writing Environment for Non-Native writers of Academic English. Proceedings of Writing and Computers 10, University of Brighton, UK, pages 122-124.

Smith, J. B. et al. (1986). WE: A Writing Environment for Professionals. TR86-025, University of North Carolina at Chapel Hill.

Suthers, D. \& Jones, D. (1997). An Architecture for Intelligent Collaborative Educational Systems. Artificial Intelligence in Education, B. du Boulay and R. Mizoguchi (Eds.), IOS Press, pages 55-62.

Swales, J. (1990). Genre Analisys - English in academic and research settings. Cambridge University Press.

Turine, M. A. S. (1994). TEGRAM: Um Sistema Tutor de Geometria Plana Baseado no TANGRAN. Master's thesis, ICMC-USP. Dissertação de Mestrado.

Weissberg, R. \& Buker, S. (1990). Writing up Research - Experimental Research Report Writing for Students of English. Prentice Hall Regents.

WTG 91 (1991). Writing Tool Group, Inc. Using Correct Grammar for Windows. Writing Tools Group, Inc. Sausalito, California, USA, 1991.

Yazdani. M. (1991). The Linger Project - An Artificial Intelligence Approach to SecondLanguage Tutoring. CALL, Vol 4 (2), pages 107-117.

Zellermayer, M., Salomon, G., Globerson, T. \& Givon, H. (1991) Enhancing Writing-elated Metacognitions Through a Computerized Writing Partner. American Educational Research Journal, Vol.28, pages 373-391. 